\title{
IX. Die DBD und die Vollkollektivierung 1958 bis 1963
}

\section{Rahmenbedingungen und Ausgangslage für die Kollektivierungspolitik}

Im Frühjahr 1960 wurde durch eine groß angelegte Kampagne die Vollkollektivierung der bis dahin verbliebenen einzelbäuerlichen Betriebe weitgehend vollzogen. Trotz hohem organisatorischen und propagandistischen Aufwand, finanziellen Vergünstigungen, sozialpolitischen Anreizen und gehörigem Druck gelangte bis Ende 1959 erst knapp die Hälfte der LNF in genossenschaftliche oder staatliche Nutzung. Nach der 33. ZK-Tagung im Herbst 1957 war die LPG-Bildung massiv verstärkt worden. Die Werbung nahm vor allem Mitglieder von Parteien und Massenorganisationen ins Visier, die als leichter für den sozialistischen Kurs zu gewinnen galten, auch weil man davon ausging, daß diese Mitglieder bereits mit politischer Schulung in Berührung gekommen waren. Auf der 2. Zentralen MTSKonferenz vom 24. bis 26. Januar 1958 in Güstrow wurde unterstrichen, daß die MTS nicht mehr als „Dienstleistungsbetriebe“ einzelbäuerliche Felder maschinell bearbeiten sollten, wie dies bisher der Fall und aufgrund der höheren Tarifbeiträge der Einzelwirtschaften auch für die Planerfüllung der maroden MTS ein lukratives Geschäft gewesen war. Vielmehr sollten die MTS nun ausschließlich die „materiell-technische Basis für die sozialistische Umgestaltung der Landwirtschaft" bilden ${ }^{1}$. Gleichwohl zeigte die Praxis, wie sehr es an der Umsetzung der Beschlüsse haperte. Die Leistung der MTS litt permanent an der völlig unausgegorenen Arbeitsorganisation, die Dienstleistungen für den sozialistischen Teil der Land wirtschaft blieben daher weit hinter dem Bedarf zurück ${ }^{2}$.

In der ersten Jahreshälfte 1958 trat eine erhebliche Zahl von Einzelbauern in LPG ein. Während der Anteil der Genossenschaftsbauern unter den bäuerlichen DBD-Mitgliedern von Mitte 1955 bis Ende 1957 unwesentlich von 15,5\% auf $18 \%$ angestiegen war, erhöhte er sich allein bis Ende März 1958 um 3\% und stieg im Jahr 1958 rasant um über 20\% auf knapp 40\% der bäuerlichen Mitglieder an ${ }^{3}$. Die Zahlen des LPG-Beitritts der DBD-Mitglieder bewegten sich im Trend der allgemeinen Mitgliederentwicklung in den LPG ${ }^{4}$. Im Vergleich zur Mitgliedsstruktur der VdgB, die traditionell mehr parteilose, mittel- und "großbäuerliche“ Mitglieder aufwies als die DBD und 1958 eine Quote von 35\% Genossenschafts-

\footnotetext{
Prokop, Übergang, S. 168-176, Zitat S. 170. Euphemistisch Graffunder, Dialektik, S. 129. BStU MfS AP 14985/92, Rietz, Bl. 33-35, Bericht Babies, HA V/3, 5. 3. 1958.

Siehe Tabelle 19.

4 Vgl. BA DE-1/20312, Bl. $71 \mathrm{f}$., Entwicklung der LPG, 31. 3.-20. 6. 1958. Bis 20.6. waren insgesamt 72398 Einzelbauern in LPG eingetreten, 5985 davon von März bis Juni.
} 
bauern zählte ${ }^{5}$ lag dieser Anteil in der DBD erstaunlicher Weise nur geringfügig höher. Die eher klein- bis mittelbäuerlich geprägte DBD-Basis verhielt sich im ganzen trotz ihrer Parteibindung nahezu ebenso distanziert gegenüber den Kooperativen wie die in der VdgB organisierten Bauern, wobei etwa $60 \%$ der DBDMitglieder zugleich der VdgB angehörten ${ }^{6}$. Die Beitrittszahlen der DBD-Mitglieder 1958 zeigen darüber hinaus vor allem, daß ungeachtet der weiteren Propagierung des sozialistischen Kurses die Zuwachsraten bei den LPG im Herbst 1958 stagnierten 7 .

Dieser Befund mußte die SED gerade deshalb befremden, weil sie auf ihrem V. Parteitag (10. bis 16. Juli 1958) als landwirtschaftspolitisches Ziel den weiteren Ausbau des sozialistischen Sektors und damit einhergehend die Umwälzung der Lebensverhältnisse in den Dörfern verkündet hatte. Zu diesem Zweck umwarb sie die gesamte Bauernschaft, einschließlich wirtschaftsstarker Mittel- und „Großbauern"; letztere waren seit 1955 zwar verhalten als LPG-Mitglieder akzeptiert worden, in der Praxis überwog jedoch deren Benachteiligung8. Angesichts der Stagnation seit September korrigierte der Sektor Landwirtschaft der Staatlichen Plankommission im Oktober 1958 den Zeitpunkt der erwarteten Vollendung der Vollkollektivierung von 1963 auf 1965; auch die bisherigen Erfahrungen bezüglich des Beitrittsverhaltens von Privatbauern in den volksdemokratischen Ländern spielten dabei eine Rolle9. Die VI. LPG-Konferenz im Frühjahr 1959 änderte nichts an den rückläufigen Beitrittszahlen. In der Folge der Konferenz stand für den SED-Landwirtschaftsapparat zunächst die betriebswirtschaftliche Sanierung der LPG im Vordergrund ${ }^{10}$. Alarmiert und ratlos angesichts des Stillstands der LPG-Zuwächse, gab das Politbüro im Juli 1959 einen umfassenden Bericht in Auftrag, der den Ursachen vor Ort nachspüren sollte ${ }^{11}$.

$\mathrm{Zu}$ den volkswirtschaftlichen Rahmenbedingungen, unter denen die Vollkollektivierung vorangetrieben wurde, zählte die Einbettung in den Fünfjahrplan, der im Zuge der Anpassung im RGW 1959 von einem Siebenjahrplan abgelöst wurde. Auf dem V. Parteitag der SED hatte Ulbricht bekanntlich eine neue Zielmarge für die Volkswirtschaft der DDR formuliert. Er griff damit in der deutschdeutschen Variante den von Chruschtschow verkündeten Systemwettbewerb mit den USA auf. Das ehrgeizige Unterfangen bestand darin, die Bundesrepublik als westdeutschen Vergleichsstaat in der wirtschaftlichen Kraft bis 1961 zu überho-

\footnotetext{
5 Prokop, Übergang, S. 179.

6 Vgl. Tabelle 11 .

7 Tabelle 19. In der DDR-Literatur wurde diese Stagnation meist verschwiegen und eingeebnet. So etwa Graffunder, Dialektik, S. 140 f.; anders Kaiser, Zusammenarbeit, S. 635 , Anm. 24.

8 Prokop, Übergang, S. 176-180; Kaiser, Politik, S. 6.

9 BA DE-1/20313, Bl. 94 f., Aktenvermerk Sektor Landwirtschaft, Fachgebiet LPG, über Besprechung zu Problemen der LPG-Bildung, 15. 10. 1958. Ebd., Bl. 98-101, Information der ZKSK über die Bildung von LPG, 25. 10. 1958.

10 Graffunder, Dialektik, S. $133 \mathrm{f}$.

11 SAPMO DY 30 J IV 2/2/657, Protokoll PB, 7. 7. 1959, Bl. 2, unter TOP 2.
} 
len, explizit nannte Ulbricht, den Pro-Kopf-Verbrauch mit Lebensmitteln und Konsumgütern zu übertreffen ${ }^{12}$.

Wie ungeschickt es war, ein fixes Datum anzugeben, zeichnete sich bald ab. Mit dem Abbruch des Fünfjahrplanes verschob sich der erhoffte Endpunkt, zu dem das Ziel erreicht sein sollte, zunächst bis 1965 und wurde dann immer unpräziser formuliert. In der Agrarwirtschaft sollte bis 1962 eine Eigenversorgung an tierischen Produkten erreicht werden. Der SED-Parteitag leitete daraus ab, daß nur durch einen forcierten sozialistischen Umbau der Agrarwirtschaft dieses Ziel realisiert werden könne. Besonders durch die Aufhebung der letzten, immerhin bis Mai 1958 geltenden Lebensmittelrationierungen, fiel der Agrarproduktion für die Deckung des Konsumbedarfs eine entscheidende Bedeutung $\mathrm{zu}^{13}$, zumal der Verbrauch infolge von Lohnerhöhungen 1958 angestiegen war ${ }^{14}$. Die DBD übernahm von den Beschlüssen des V. SED-Parteitages den "Aufbau des Sozialismus“ in der Landwirtschaft als ihre „Hauptaufgabe ${ }^{\star 15}$.

Die SED schlug im Kontakt mit den Blockparteien 1958 insofern neue Pfade ein, als sie diese zur Vorbereitung des Parteitages erstmals aufforderte, ihrerseits Vorschläge einzubringen. Ulbricht informierte die Vorsitzenden der anderen Blockparteien in internen Sitzungen schon im Vorfeld über den Parteitag ${ }^{16}$. Damit griff die SED-Zentrale auch eine Praxis aus den Bezirken auf, wie sie im Bezirk Dresden schon nach dem IV. Parteitag anzutreffen war. Die dortige Bezirksleitung rief die Blockparteivorsitzenden regelmäßig zusammen, um sie zu ihrer jeweiligen Linie zu instruieren und ihnen anstehende Entscheidungen im vorhinein zu eröffnen ${ }^{17}$.

Die 1956 von der sowjetischen Botschaft angeregte Belebung der Blockpolitik führte also nicht zur Aktivierung des Blockes oder zum Einflußgewinn der anderen Parteien im Staat, sondern lediglich dazu, daß diese ihre Anregungen in den SED-Apparat einbrachten. Die nominelle Einbindung in die Vorbereitung eines SED-Parteitags erstickte jegliche abweichenden Vorschläge im Keim; eine effektive Mitarbeit der Blockparteien gereichte nur der SED zum Vorteil. Der Einheitspartei eröffnete sich die Möglichkeit, Ideenpotential abzuschöpfen und als eigene Innovation zu präsentieren. Andererseits lief die DBD Gefahr, infolge der eigenen programmatischen Profillosigkeit seit 1957 jegliche Ausstrahlung auf jene privatbäuerlichen und im dörflichen Milieu verankerten Bevölkerungsschichten zu verlieren, die sie bislang besser als die SED erreichen konnte. Dieser Tendenz leistete die Praxis Vorschub, gemeinsam mit der SED Versammlungen abzuhalten, denn

12 Protokoll der Verhandlungen des V. PT der SED, Bd. 1, S. 221. Siehe Staritz, Geschichte, S. 173-178.

13 Der Konsum sollte auf kostengünstiger herzustellende Produkte gelenkt werden, etwa auf Margarine statt Butter. SAPMO DY 30 J IV 2/2/661, Protokoll PB, 28. 7. 1959.

14 Poutrus, Lebensmittelkonsum, S. 397 f.; Krebs, Weg, S. 354 f.; Kaiser, Politik, S. 85.

15 So z. B. ACDP VI-052-1355, Protokoll Sekretariat BV Schwerin, 4. 8. 1958.

16 So Kaiser, gestützt allerdings nur auf eine mündliche Aussage von Siegfried Wetzig, damals stellv. Leiter der AG BO. Kaiser, Politik, S. 12; dies., Zusammenarbeit, S. $628 \mathrm{f}$.

17 SAPMO DY 30 IV 2/15/3, Bericht BL Dresden zu Zusammenarbeit mit Blockparteien, 9. 5. 1958 . 
dies nährte erneut Gerüchte über eine baldige Verschmelzung der Parteien, etwa im Bezirk Schwerin ${ }^{18}$.

Eine besondere Symbiose zwischen DBD und SED entwickelte der Rostocker Bezirksverband ab 1958. Der damalige Leiter der Organisationsabteilung, Ernst Mecklenburg, verstand die DBD zeitweise als eine Art politischen Vorbereitungskurs auf die SED ${ }^{19}$. Mehrere prominente DBD-Funktionäre wechselten seit 1957 zur SED, häufig mit der Begründung, ihren „Parteiauftrag“ erfüllt zu haben, worunter sie die Gründung der DBD verstanden. So kehrte Franz Pilarski, eine Schlüsselfigur der Mecklenburger Gründungszeit, zur SED zurück, tief enttäuscht darüber, daß ihm eine Karriere in der DBD nicht gelungen war. In anderen Fällen, wie beim Wechsel Dietrich Beslers, immerhin einstiger Abteilungsleiter für Organisation beim Parteivorstand, verbreitete das DBD-Sekretariat die Version, die SED suche erfahrene Agrarfunktionäre. Besler nannte gegenüber dem MfS die mangelnde Unterstützung der DBD als Grund für sein Ersuchen, in die SED aufgenommen zu werden ${ }^{20}$. Der Prozeß der tiefgehenden Gleichschaltung in den Bezirkssekretariaten hielt 1958 an; selbst nur hinter vorgehaltener Hand geäußerte Meinungen wichen kaum von der Parteilinie ab. Um so erstaunlicher ist es, daß im Bezirkssekretariat Suhl 1958 noch „zwei Linien“ anzutreffen waren, worunter sich angesichts der Zusammensetzung der Grundeinheiten höchstwahrscheinlich Forderungen verbargen, die Belange der Einzelbauern nicht völlig außer Acht zu lassen ${ }^{21}$.

Im Vergleich zu CDU und LDPD stellte die Arbeitsgruppe BO 1958 fest, daß die DBD trotz Ausnahmen wie in Suhl die verläßlichere Partei für den Aufbau des Sozialismus sei22. Hingegen sei die Mehrheit der Mitglieder der CDU und LDPD mit diesem Ziel nicht einverstanden. Außerdem gebe es Bestrebungen, „fortschrittliche Kräfte" wie den Vorsitzenden der LDPD, Hans Loch, aus den Füh-

18 MLHA BPA Schwerin IV 2/15/1687, BV der DBD an SED-BL, 12.6. 1958.

19 ACDP VI-052-0538, Protokolle Sekretariatssitzungen, 17.11., 29.11., 6. 12. 1958, 19. 1. 1959.

$20 \mathrm{Ab}$ diesem Zeitpunkt wurde Besler als IM vorerst abgelegt. BStU MfS AIM 3562/59, Bd. 2 Personalakte Besler, Bl. 41, Beschluß über Abbruch der Verbindung, 5. 8. 1959. Andeutungen zum Vorgang in ACDP VI-052-0538, Protokoll Sekretariat, 6. 10. 1958; die Version des DBD-Sekretariates in ACDP VI-052-0322, Protokoll Präsidium, 19.12. 1958. SAPMO DY 30/vorl. SED 4071, Köhler an Matern, 2. 8. 1958; vermutlich wurde auch Hans Heinrich Müller, Mitarbeiter des Bezirkssekretariats Neubrandenburg abgeworben, (ACDP VI-052-0545, Protokoll Sekretariat, 11.9. 1961), ebenso Wilhelm Jendrass im Bezirk Rostock zusammen mit einer Reihe weiterer LPG-Vorsitzender der DBD, wobei Kaderleiter Rietz 1955 selbst eingeräumt hatte, daß eine solche Abwerbung in Ordnung gehe, sofern dies zur Gründung einer Parteiorganisation der SED führe. SAPMO DY $30 /$ vorl. SED 4072. Die Abwerbung von Jendrass war durch ein Zerwürfnis mit der DBD begünstigt. Vgl. Reichelt, Blockflöte, S. 204, ohne Namensnennungen. Bauer, Gründung, S. 303.

21 Den bewußt uneindeutigen Formulierungen in Sekretariatsprotokollen ist dies nicht immer klar zu entnehmen. ACDP VI-052-0963, Protokoll Sekretariat BV Suhl, 12. 2. 1958. "Schlechte Linien“ wurden 1956 auch dem Bezirkssekretariat Erfurt attestiert, ACDP VI-052-0319, Protokoll Präsidium, 30. 10. 1956.

22 SAPMO DY 30 IV 2/15/2, Bericht AG BO zur „Entwicklung der kleinbgl.-demokratischen Parteien zwischen dem IV. und V. Parteitag“, an Ulbricht am 31. 5. 1958 versandt. 
rungsorganen zu entfernen. „[O]bwohl die Masse der Mitglieder [der DBD] ebenfalls noch nicht davon überzeugt war, daß der Sozialismus gesellschaftlich notwendig und unabwendbar ist", gebe es solche Verdrängungsversuche in der DBD und NDPD nur vereinzelt. Parteiübergreifend konstatierte die Arbeitsgruppe „stark verbreitete Spekulationen in allen Parteien“, daß mit der „Herstellung der Einheit, die auf Kosten der DDR gehen würde“, sich die gesellschaftlichen Verhältnisse in der DDR wieder ändern würden. Das gesamtdeutsche Argument war also weiterhin ein wichtiger Faktor für die mangelnde Bereitschaft der ländlichen Bevölkerung, den LPG beizutreten.

Bis Dezember 1959 überwog bei den maßgeblichen Agrarpolitikern des ZK, voran bei Erich Mückenberger, jene Konzeption, die in paternalistischer Manier auf die politische „Überzeugung" der Einzelbauern setzte und diese noch durch die Schaffung von „Beispielen“ für die LPG gewinnen wollte. Bei dieser Vorstellung fielen makroökonomische Überlegungen ins Gewicht, die sich daran ausrichteten, wieviel an Kollektivierung sich die Volkswirtschaft DDR leisten konnte, ohne den Staatshaushalt ungebührlich hoch zu belasten und ohne die inländisch erwirtschaftete Versorgung mit Lebensmitteln noch mehr zu gefährden.

Die Stagnation in der Kollektivierung seit Herbst 1958 wurde von der SEDFührung nicht hingenommen. Anläßlich einer Sitzung in Berlin, die die Agrarfunktionäre der Bezirke zur Vorbereitung der VI. Konferenz der Vorsitzenden und Aktivisten der LPG versammelte, ließ Mückenberger auch den anwesenden Paul Scholz unmißverständlich wissen, daß bis zum Jahresende 1959 in jedem Dorf eine LPG bestehen müsse und man keine "Inseln" ohne LPG dulde ${ }^{23}$. Wie im Vorfeld des Kollektivierungsschubs 1952 von sowjetischen Stellen empfohlen, sollten auch 1959 „Musterdörfer“ geschaffen werden. Als Schwäche in der Tätigkeit der SED prangerte Mückenberger die unzureichende Kontrolle neu gebildeter LPG an. Weiter drängte er darauf, DBD und VdgB für die Vorbereitung der VI. LPG-Konferenz stärker in die Pflicht zu nehmen ${ }^{24}$. Insgesamt ist zu berücksichtigen, daß der auf oberster Ebene ohnehin arg begrenzte Handlungsspielraum der Blockparteien bis 1959 völlig zusammengeschnürt worden war. Hier wurden nur willfährige Instrumente der SED noch enger in die politischen Vorgänge ein-

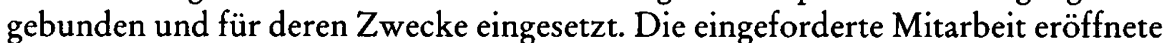
daher kein Angebot zu Mitgestaltung, sondern diente der Disziplinierung im Sinne der SED.

Für eine erfolgreiche Kollektivierung mußte in der Sicht der SED auch das Landwirtschaftsministerium als Teil des Staatsapparates, das weiterhin von einem DBD-Minister, seit 1955 wieder von Hans Reichelt, geführt wurde, auf Linie gebracht werden. Das „Gesetz über die Vervollkommnung und Vereinfachung der

23 BA DK-1/5657, Bl. 1 ff., Protokoll der Tagung am 3. 1. 1959 im ZK. Zu „Musterdörfern“ siehe Vorlage des Ministeriums für Bauwesen in BA DK-1/10474, Bl. $1 \mathrm{ff}$., Protokoll gemeinsame Sitzung des Kollegiums des MLF mit Min. für Bauwesen, 6. 1. 1959, zur Auswertung des V. PT und Vorbereitung der VI. LPG-Konferenz.

${ }^{24}$ Dieses bündnispolitische Vorgehen ist nicht als Zeichen zu sehen, „die kleinbürgerlichdemokratischen Parteien noch umfassender an der Vorbereitung und Durchführung wichtiger gesellschaftlicher Entscheidungen zu beteiligen“, so etwa Kaiser, Politik, S. 12; vgl. auch dies., Machtwechsel, S. 39. 
Arbeit des Staatsapparates" der DDR vom 11. Februar 1958 umschrieb in $\ 8$ erstmals die Aufgaben des Ministeriums. Der erste Absatz verpflichtete es zum Fortschreiben der „sozialistischen Umgestaltung “ und zu einer auf Produktionssteigerung ausgerichteten Politik ${ }^{25}$. An Häufigkeit und Schärfe erreichte die SED-Kritik am Ministerium ab 1957 und vor allem 1959 neue Dimensionen ${ }^{26}$. Immer wieder gehegte und verworfene Pläne zum Umbau des MLF und zur Eingliederung des Staatssekretariats für Erfassung und Aufkauf gewannen an Kontur; die Eingliederung erfolgte dann parallel zum offiziellen Abschluß der Kollektivierung am 15. April $1960^{27}$.

Für die Durchsetzung der Vollkollektivierung standen der SED ab 1958 weitere Machtinstrumente zur Verfügung. Seitdem sie 1957 die weitgehende Verfügung über das MfS zu ihrem Nutzen erlangt hatte, konnte sie sich in zweifacher Weise rückversichern. Zum einen hatte das MfS inzwischen Strukturen herausgebildet, die einen besseren, wenngleich nicht perfektionierten wirtschaftspolitischen Einsatz ermöglichten; zum zweiten nahm die Kontrolle der Kaderpolitik der DBD auf allen Ebenen seit 1958 infolge der Bespitzelung durch das MfS ungeahnte Ausmaße an. Aufgrund seines hervorragenden Informationsstandes über die Personalverhältnisse und den inneren Zustand der DBD war das MfS in der Lage, wichtige, eventuell für die SED nachteilige Vorgänge von Belanglosigkeiten zu unterscheiden und entsprechend an die ZK-Abteilung LOPM weiterzumelden. Dadurch gelang es dem Anleitungsapparat der SED, Gegner und Zauderer bei der Kollektivierung bis in die Kreisverbände hinein zu identifizieren und die Bauernpartei zu zwingen, diese politisch auszuschalten, sofern das dort nicht ohnehin geschah.

\section{Die Entscheidung zur Vollkollektivierung}

Zu den ungelösten Fragen in der Entscheidungsfindung zur Vollkollektivierung zählt jene nach dem sowjetischen Part. Hat die sowjetische Führung einen maßgeblichen unmittelbaren Einfluß auf die Kollektivierungspolitik insgesamt bzw. auf Teile davon, insbesondere auf ihren abrupten Abschluß ausgeübt? Für die Zeit zwischen 1959 bis 1964 konnten bislang kaum verbindliche Weisungen der KPdSU-Führung an die Adresse der SED oder der DDR aufgefunden werden ${ }^{28}$; dies heißt nicht, daß es solche nicht gibt. Über die Praxis direkter Anweisung hinaus sind auch andere Einflußformen zu bedenken, zumal mit der Kollektivierung die Einpassung eines ideologisch bedeutsamen Teils der Privatwirtschaft in die sozialistische Staatswirtschaft vollzogen wurde. Daher ist die ideologische Orientierungskraft, die von sowjetischen Modellvorstellungen im Hinblick auf die Kol-

25 GBl. DDR 1958, 1, S. 117. Vgl. die ergebnislosen Debatten und Pläne für ein Statut des MLF in: BA DK-1/1475, 8606, 9436, 249.

26 So stieß im Januar 1959 besonders die Art der „Leitung und Vorbereitung“ der VI. LPGKonferenz im MLF auf heftige Kritik der ZK-Abt. LW; SAPMO DY 30 IV 2/7/79, Protokoll ZK-Abt. LW, 10. 1. 1959, Bl. 232, 243.

27 Lapp, Ministerrat, S. 184-188.

${ }^{28}$ Kaiser, Machtwechsel, S. 37; Kaiser, Einfluß, S. 111, 126. 
lektivierung ausging, nicht zu unterschätzen. Dies zeigte sich im organisatorischen Ablauf in der Phase der Vollkollektivierung und in unmittelbaren Kontakten mit der KPdSU29.

Ereignisse und Vorgänge der sowjetischen Agrargeschichte und die damit in Zusammenhang stehende Politik wurden darüber hinaus als Vergleichsgegenstände, denen ein Vorbildcharakter beigemessen werden konnte, herangezogen. Ulbrichts Mitarbeiter und Redenschreiber für Agrarwesen seit Anfang der fünfziger Jahre, Karl Gutjahr, stützte sich auf sowjetische agrarwissenschaftliche Publikationen ${ }^{30}$. Selbstverständlich berief sich das Politbüro während der Hochphase der Vollkollektivierung im Februar 1960 ausdrücklich auf „sowjetische Erfahrungen " und legte diese dem 8. ZK-Plenum im März/April 1960 zugrunde; dieses formulierte als Aufgabe, die Belange sozialistischer Landwirtschaft in höherem Maße zu berücksichtigen ${ }^{31}$.

\section{Entscheidungen auf oberster Ebene 1959/60 - Die Feinsteuerung der Kollektivierung}

Eine Grundsatzentscheidung der SED, den Vollzug der seit Jahren betriebenen Kollektivierung zu einem raschen Ende zu bringen, ist - wenn es sie als solche gegeben hat - bislang nicht aufgefunden geworden. Dennoch wird im folgenden versucht, die Entscheidungsvorgänge auf unterschiedlichen Ebenen zu rekonstruieren. Bestimmte Indizien erlauben es, zumindest den Zeitraum einer solchen Entscheidungsfindung näher einzugrenzen.

Daß der Aufbau des Sozialismus in ideologischer Hinsicht gravierende Anforderungen an die Landwirtschaft sowie an Staat und Partei stellte, ist schon im Zusammenhang mit der Verkündung des "Aufbaus der Grundlagen des Sozialismus“ auf der 2. Parteikonferenz der SED 1952 deutlich geworden. Angesichts der ehrgeizigen ökonomischen Ziele, die Ulbricht auf dem V. Parteitag verkündet hatte, mußten die 1958 noch weit überwiegend privatwirtschaftlich produzierenden Bauern zusätzlich als Stachel im Fleisch der sich sozialistisch gebenden DDR schmerzen.

Der Sozialismus in der Landwirtschaft wurde 1959 auf unterschiedlichen politischen Ebenen und mit verschiedensten Mitteln forciert. Das allgemeine Ziel des "Aufbaus des Sozialismus“ war zwar als Konzeption seit 1952 eingeführt, allerdings nicht immer in gleichem Ausmaß auf der Durchsetzungsebene maßgeblich. Bis Mitte Januar $1960^{32}$ war keine unmittelbar handlungsanleitende Direktive des

29 Vgl. dazu die engen Absprachen über die Botschaft und die Konsulate für die Jahre 19531957 im Findbuch: Otdel ZK KPSS po swjasam s inostrannymi Kompartijami 1953-1957.

30 Siehe die Übersetzungen im Nachlaß Ulbrichts, SAPMO NY 4182/1081.

31 Siehe dazu SAPMO DY 30 J IV 2/2/688, Protokoll PB, 16. 2. 1960, Bl. 2-4, TOP 2 Einberufung des 8. Plenums des ZK, TOP 5 Bericht Grünebergs über neue Erfahrungen aus sowjetischer Landwirtschaft. Mückenberger wurde lt. Beschluß der Sitzung für ein Jahr an die Parteihochschule des ZK der KPdSU nach Moskau geschickt, Bl. 8.

32 In dieser Datierung stimme ich mit Kaiser, Politik, S. $99 \mathrm{ff}$. überein, nicht in der Interpretation. Ohne eigentlichen Beleg mit einer Zäsur Anfang 1960 argumentiert Schulz, „Kapitalistische Länder überflügeln“, S. $33 \mathrm{ff}$. 
Politbüros oder eines anderen hohen Gremiums ergangen, kurzfristig und radikal den Beitritt aller Einzelbauern in LPG herbeizuführen. Zwar kommt der häufig für den Übergang zur Vollkollektivierung angeführten ${ }^{33}$ 7. ZK-Tagung im Dezember 1959 eine gewisse Bedeutung als Zäsur zu, doch auch in ihrem Umfeld fällte die SED keine Grundsatzentscheidung zur kurzfristigen Vollkollektivierung.

Den Auftakt der Kollektivierungspolitik 1959 bildete die schon erwähnte VI. LPG-Konferenz im Februar 1959. Obgleich Mückenberger dem Personal in den Landwirtschaftsapparaten der SED in den Bezirken sowie der VdgB und DBD intern vorgegeben hatte, daß sich letztere intensiver an der politischen Vorbereitung der Konferenz beteiligen müßten, sollte diese Mitarbeit in der allgemeinen Öffentlichkeit verborgen werden ${ }^{34}$. Eine Ausarbeitung der DBD-Abteilung Agrarpolitik durfte nur an Paul Scholz als Leiter des Beirats für LPG und stellvertretenden Vorsitzenden des Ministerrates, und an Minister Reichelt weitergeleitet und sollte ausdrücklich nicht in der DBD-Parteipresse veröffentlicht werden. Das $\mathrm{Pa}$ pier faßte die von Genossenschaftsbauern in den Bezirken geführte Diskussion über die von der ZK-Landwirtschaftsabteilung im Vorfeld der LPG-Konferenz publizierten "Thesen“ zusammen ${ }^{35}$.

Die Vorschläge und Kommentare aus DBD-Mitgliedskreisen - sie stammten ausschließlich von Funktionären und LPG-Bauern, Einzelbauern kamen nicht zu Wort - stimmten den Thesen prinzipiell zu. Ergänzungen betrafen überwiegend die praktische Umsetzung, wiesen außerdem auf Versäumnisse hin. Das DBD-Papier plädierte dafür, LPG des Typs I stärker zu fördern und trat für mehr Anreize ein, um die LPG für Jugendliche attraktiver zu machen; man empfahl eine intensivere Fachberatung und Hilfe für die LPG, besonders eine gezielte agrarwissenschaftliche Betreuung für LPG des Typs I, etwa beim Übergang zu Typ III. Die DBD hielt im Unterschied zu den aufkeimenden Ressentiments im ZK-Apparat am Prinzip der Förderung individueller Hauswirtschaften der LPG-Bauern fest und plädierte daher für den Bau von Ein- und Mehrfamilienhäusern, die eine individuelle Viehwirtschaft begünstigen sollten. Eine grundsätzliche Kritik stand der DBD nicht zu.

Auf der VI. LPG-Konferenz erläuterte Ulbricht die Ziele des Siebenjahrplanes für die Landwirtschaft. Demnach sollte die Eigenversorgung mit bestimmten Agrarprodukten und die „Überflügelung“ der bundesdeutschen Agrarproduktivität ab 1962 erreicht werden. Weiter akklamierte die Konferenz der Neufassung der Musterstatuten für die LPG des Typs I, II und III, die unter Mitarbeit von

33 Zuletzt Schroeder, SED-Staat, S. 145.

34 Siehe Aufforderung Mückenbergers an die Sekretäre der SED-BL, BA DK-1/5657, Bl. 1 ff., Tagung der Sekretäre und Abt.-Leiter LW bei den BL der SED im ZK, 3. 1. 1959. Die Vorbereitungen liefen schon seit Mitte 1958, siehe dazu BA DK-1/5648, B1. 82-85, Mückenberger an Reichelt, 29. 7. 1958. Mit Rose besprach Mückenberger sich dazu im Januar 1959, ACDP VI-052-0538, Protokoll Sekretariat, 26. 1. 1959.

35 ACDP VI-052-0538, Protokoll Sekretariat, 2. 2. 1959, und Vorlage der Abt. Agrarpolitik der DBD zu den geplanten "Thesen“ der VI. LPG-Konferenz. Die „Thesen“ waren vorher in der Presse publiziert worden. Auch zum folgenden. 
Paul Scholz im Beirat für LPG beim Ministerrat erarbeitet worden waren ${ }^{36}$. Beachtenswert ist Ulbrichts Vorschlag, wonach die wirtschaftlich stabilen LPG Traktoren, Maschinen und Geräte der MTS vollständig auf der Basis von Leihverträgen erhalten sollten ${ }^{37}$. Dieser Punkt war weder in der vorher publizierten Fassung der Thesen zur Konferenz enthalten gewesen, noch taucht er in der überarbeiteten Fassung vom März 1959 wieder auf ${ }^{38}$. Erst im April 1959 fällte das Politbüro einen entsprechenden Beschluß. Reichelt war zumindest formell in die Erstellung von Mückenbergers Beschlußvorlage hierzu eingebunden gewesen. In Einschränkung des Empfängerkreises bezog sich die Übergabe der MTS-Ausstattung nun ausdrücklich nur auf LPG des Typs III in bereits vollgenossenschaftlichen Dörfern ${ }^{39}$.

Die Frage der Übergabe von Maschinen und Gerät an die LPG berührte einen zentralen Punkt der Kollektivierung. Sie betraf all jene Einzelbauern, die auf die Dienstleistungen der MTS angewiesen waren und fürchten mußten, daß sich ihre Arbeitsbedingungen zusätzlich erschwerten und sie dadurch in ein Abhängigkeitsverhältnis zu den LPG gerieten, welche quasi ein Monopol über schweres Ackergerät besessen hätten. Die Begrenzung der Empfänger verhinderte für die Einzelwirtschaften zunächst schlimmeres; andererseits wirkte sie als Anreiz, bei der Gründung von LPG von vornherein den Typ III zu wählen und alle Bauern des Ortes geschlossen zum Beitritt zu bewegen. Insofern erhöhte der Beschluß den innerdörflichen Druck auf Einzelbauern gerade dort, wo sie ohnehin in der Minderzahl waren. Schließlich berührte der Beschluß die ökonomische Leistungskraft der LPG insgesamt, weil geklärt werden mußte, wie die mit Kapital meist unterausgestatteten LPG die Übernahme eines solch großen Maschinenund Fuhrparks, die sie bezahlen mußten, finanziell verkraften könnten ${ }^{40}$. Ulbrichts überoptimistische Sozialismuseuphorie wurde durch ganz schlichte Probleme konterkariert, die gleichwohl zeigen, wie eng der Spielraum für eine avisierte Ausdehnung des sozialistischen Teils der Landwirtschaft war und wie unzureichend die Apparate Abhilfe leisteten. So fehlten im März 1959 schlichtweg die

36 Die juristischen Veränderungen 1959 zur Gestaltung der inneren Verfaßtheit der LPG und zum Rechtsinstitut des „Recht der LPG“, das die gesellschaftliche Stellung der Eigentums- und Betriebsform regelt, sind früh untersucht worden. Siehe Priew, Grundlagen; Tümmler, Agrarpolitik, S. 56-61, und als zeitgenössische DDR-Sicht Arlt, Grundriß. Mit dem am 3. Juni 1959 erlassenen „Gesetz über die Landwirtschaftlichen Produktionsgenossenschaften" (GB1. DDR I, 1959, S. 577) beendete man eine Phase, die lediglich auf Statuten beruhte, und begründete das „Recht der LPG“ als eigene Rechtsform. Beschluß über die Musterstatuten der landwirtschaftlichen Produktionsgenossenschaften, 9. April 1959, GBI. DDR I, 1959, S. 333; Bekanntmachung des Beschlusses über die Empfehlung für die Ausarbeitung der inneren Betriebsordnung der LPG vom 6. 8. 1959, GBl. DDR I, 1959, S. 657.

37 Vgl. in aller Kürze, Sowjetische Besatzungszone von 1959-1960, Eintrag 20. 2. 1959, S. $32 \mathrm{f}$. Die Thesen der LPG-Konferenz gekürzt in Dokumente der SED, Bd. VII, S. 421458. Vgl. Prokop, Übergang, S. 183.

38 BA DK-1/5651, Bl. 1-19, Thesen der VI. LPG-Konferenz, 13. 3. 1959.

39 SAPMO DY 30 J IV 2/2/639, Protokoll PB, 1. 4. 1959, TOP 3 Fragen der Landwirtschaft.

40 Bei der Kollektivierung in der Sowjetunion führte es zur Expropriation wohlhabenderer Bauern. Merl, Anfänge, S. 230, 354 ff., 369 ff., 401-414. Ulbricht dürfte dieser Zusammenhang bekannt gewesen sein. 
Treibstoffe, um die Bestellungsarbeiten der MTS in den LPG durchzuführen, wie im Ministerrat bekannt wurde ${ }^{41}$.

Insgesamt schob die VI. LPG-Konferenz den Aspekt der betriebswirtschaftlichen Tragfähigkeit und damit das Problem der inneren Stabilisierung schon bestehender LPG in den folgenden Monaten in den Vordergrund, die Frage zügiger Neugründungen rangierte dahinter. Die Besinnung auf die mikroökonomische Basis ist auch im Zusammenhang damit zu sehen, daß auf diesem Wege das Ziel einer Eigenversorgung an tierischen Produkten bis 1962 eher erreichbar schien, wofür man weiterhin erfolgreiche Privatbetriebe brauchte.

Die Nachbereitung der VI. LPG-Konferenz im ZK-Apparat belegt, daß das Verhältnis zwischen Ulbricht und dem Sekretär für Landwirtschaft des Politbüros, Erich Mückenberger, schon seit Frühjahr 1959 aufgrund der Frage des Kollektivierungstempos nachhaltig gestört war. Eine Abteilungsversammlung kurz nach der Konferenz nahm die Arbeit der Abteilung kritisch ins Visier ${ }^{42}$. Daneben brachte die Versammlung einen Konflikt in der Abteilung selbst zu Tage, der sich darum drehte, welche politische Auffassung in der Situation einer Radikalisierung der Kollektivierung angemessen sei. Weiter wurde das Problem behandelt, wie weit die Kompetenz der Abteilung in Landwirtschaftsfragen reichte. Diese hatte sich erlaubt, Ulbrichts Wünsche zunächst zu übergehen; später ordnete er die Ausarbeitung entsprechender Vorlagen durch die Abteilung für das Politbüro an, etwa im Falle der Übergabe der MTS-Technik an die LPG. Ulbricht konnte oder wollte zu diesem Zeitpunkt den eigenen Apparat nicht zwingen, die von ihm zweifellos favorisierte härtere Gangart durchzusetzen. Seine Kritik änderte nichts am grundlegenden Kurs der Abteilung. Diese trieb die Kollektivierung zwar voran, wollte sie jedoch angesichts der Widerstände auf dem Land und der wirtschaftlichen Gegenargumente noch nicht mit allen Mitteln zu einem abrupten Ende führen. Es blieb vorerst noch offen, ob der Apparat eine ideologische Verengung, die ausschließlich auf die Durchsetzung der Vollkollektivierung gerichtet war, vorzunehmen hatte. Natürlich war letztere das Ziel der Abteilung, doch zeitweise schreckten die wenigen, noch mit der Praxis vertrauten Pragmatiker der Abteilung die unübersehbaren Widerstände der Bevölkerung und die volkswirtschaftlichen Opportunitätskosten von einer radikalen Vollkollektivierungspolitik ab.

Es ist kein Zufall der SED-Personalpolitik, daß man Mückenberger mit Bruno Kiesler im April 1959 einen schlagkräftigen Parteigänger Ulbrichts als Leiter der ZK-Abteilung Landwirtschaft an die Seite stellte ${ }^{43}$, während Mückenberger per Politbürobeschluß auf Kur geschickt wurde und eine gewisse Zeit abwesend war. Kiesler wurde in der folgenden Zeit ein vehementer Kritiker der Tätigkeit des MLF. Auf Anregung der ZK-Abteilung verdrängte der SED-Genosse Gotthard

41 BA DC-20/375, Aktennotiz Plenikowski für Grotewohl, 13. 3. 1959.

42 SAPMO DY 30 IV 2/7/75, Protokoll ZK-Abt. LW, 26. 2. 1959, auch zum folgenden.

43 SAPMO DY 30 J IV 2/2/641, Protokoll PB, 13. 4. 1959, und DY 30 J IV 2/2/644, Protokoll PB, 28. 4. 1959. 
Heinrich den altgedienten DBD-Funktionär Fritz Weißhaupt aus der Position eines Stellvertreters des Ministers im Sommer $1959^{44}$.

Vor dem Hintergrund der Stagnation der Beitrittszahlen zu den LPG, mit denen sich das Politbüro im Juli 1959 erneut beschäftigte, preschte die Abteilung Ende Juli/Anfang August 1959 unter Kieslers Leitung in ihrem Drängen auf die weitere Kollektivierung so weit vor, daß sie von Mückenberger, der die Rückendeckung des Politbüros besaß, zurückgerufen wurde. Den Anlaß bildete eine zu weit in Richtung Vollkollektivierung drängende Vorlage, die die anstehenden Delegiertenwahlen in der VdgB regeln sollte; sie hätte Einzelbauern in ihren Wahlchancen für die Ortsgruppenvorstände diskriminiert und aus Sicht der SED mißliebige VdgB-Vorstandsmitglieder als „Doppelzüngler“ beschimpft. Als Reaktion darauf verdeutlichte Mückenberger seine Position zur „Bündnispolitik“ gegenüber den Einzelbauern vor der Abteilung. Er sprach sich zugleich gegen einen aus einseitig politischen Gründen forcierten Weg zur Vollkollektivierung aus: „Wenn wir sagen, daß unser Fehler nach der VI. LPG-Konferenz die einseitige ökonomische Orientierung war, dann sind wir damit jetzt in das andere Extrem gefallen. Hier erscheint mir die Arbeit der Abteilung nicht in Ordnung zu sein und [hier] liegt ein weiterer prinzipieller Fehler, daß nach Aussprachen über die Veränderung und Verbesserung der Arbeit der Abteilung im Politbüro usw. die Gefahr besteht, von einem Extrem in das andere zu fallen [...]. Es gab in der Partei die Auffassung, wegen Opportunismus ist schon mancher gestraft, aber nicht für Sektierertum. Das ist doch falsch.“

Gegen die vorgelegte Fassung der Direktive für alle Bezirks- und Kreisstellen der VdgB zum VI. Deutschen Bauerntag wandte er ein, sie vernachlässige, daß man noch 397000 Einzelbauern habe, die rund 58\% der LNF bewirtschafteten: „Und denen knallen wir jetzt vor den Schädel: Du bist kein guter Bauer! So geht das nicht." Er fuhr fort: „Im Dokument heißt es, daß das Tempo des sozialistischen Aufbaus zu langsam geht. Man muß doch davon ausgehen, welche Wirkung lösen die Worte der Parteiführung unten aus [...]. Oder verträgt sich das mit der Bündnispolitik, wenn man schreibt, daß die Einzelbauern sofort in die LPG eintreten müssen, um den Verpflichtungen des Bündnisses nachzukommen [...]. Hattet ihr den Auftrag, den Marxismus zu revidieren [...]. Oder, daß in der VdgB um die Sauberkeit gekämpft werden muss ist doch klar. Die Formulierung ist aber so, daß Manipulationen unbedingt beseitigt werden müssen. Das heißt, wir verbinden die Wahlen in der VdgB mit dem Staatsanwalt [...]. Herausgekommen wäre, daß wir große Teile der werktätigen Einzelbauern abgetrieben hätten von der DDR. ${ }^{45}$

Insgesamt beleuchtet die Stellungnahme das Hin-und-her-Lavieren und die Suche nach dem für die SED optimalen Weg in der Kollektivierungspolitik 1959. Zwar basierte die Konzeption auf dem allgemein akzeptierten Ziel der Vollkollek-

44 SAPMO DY 30 IV 2/7/75, Protokoll ZK-Abt. LW, 27. 7. 1959. Heinrichs Bestätigung durch das PB: SAPMO DY 30 J IV 2/2/662, Protokoll PB, 4. 8. 1959. Schon im Juni beschloß das Sekretariat der DBD, Weißhaupt auf Schulung zu schicken, ACDP VI-0520539, Protokoll Sekretariat, 25. 5. 1959.

45 SAPMO DY 30 IV 2/7/75, Protokoll ZK-Abt. LW, 27. 8. 1959. Erst im Herbst 1960 fand dann unter neuer Bezeichnung der VI. Deutsche Bauernkongreß statt. 
tivierung, für deren schnelle Herbeiführung gab es jedoch noch keine Grundsatzentscheidung.

\section{Die DBD und die Kollektivierungspolitik 1959: Anleitung und Kontrolle durch die SED}

Offiziell hielt die DBD während des gesamten Jahres 1959 an der Programmatik fest, sowohl die Interessen der Genossenschaftsbauern als auch der Einzelbauern $\mathrm{zu}$ vertreten. Aufgrund der Ausrichtung auf den Sozialismus in der Landwirtschaft hatte sich ein Großteil der einzelbäuerlichen Mitglieder aus der aktiven Parteiarbeit bzw. -mitgliedschaft zurückgezogen ${ }^{46}$. Offensichtlich fielen Programmatik und politische Praxis gegenüber den Privatwirtschaften Anfang 1959 in der DBD weit auseinander. Die Arbeitsgruppe $B O$ warf ihr nun vor, sich zu wenig um die Belange der Einzelbauern zu kümmern, obwohl dies zu ihrem Auftrag zähle ${ }^{47}$.

Die SED-Kritik aus dem Jahr 1958 vor Augen, derzufolge sie erst sehr spät auf den Kurs der Errichtung des Sozialismus eingeschwenkt sei, konzentrierte sich das DBD-Sekretariat zum Jahresanfang 1959 auf drei Punkte: 1. die Entwicklung von vollgenossenschaftlichen Dörfern, 2. die ökonomische Stabilisierung von LPG und 3. die Werbung von Einzelbauern für den LPG-Beitritt. Die Bedeutung der Einzelbauern in der Partei wurde degradiert, diese galten nur noch als Objekte zur Anwerbung für einen LPG-Eintritt. Das war auch das eigentliche Anliegen eines Sekretariatsbeschlusses vom Dezember 1958 gewesen, der forderte, nun wieder unter Einzelbauern, Jugendlichen und Bäuerinnen Parteimitglieder zu werben ${ }^{48}$.

In der Beeinflussung von Mittelbauern für den LPG-Eintritt zeichnete sich jedoch erst ab Juli/August 1959 eine Zäsur ab. Mitte Juli 1959 gab ein interner Bericht über die desolate Mitgliederentwicklung im Sekretariat Anlaß festzustellen, „daß es jetzt darauf ankommt, mehr mit den werktätigen Einzelbauern zu arbeiten“. Außerdem befaßte sich das Sekretariat erstaunlicherweise mit der „Klärung folgender Fragen: Soll der Anteil der Einzelbauern in den verschiedenen Körperschaften erhöht werden, evt. durch Erweiterung der Vorstände [...]? Wie kann eine erhöhte Beteiligung der Bäuerinnen in den Leitungen erreicht werden?"49 Während die Mitarbeiter der ZK-Abteilung Landwirtschaft zumindest versucht hatten, im Falle der VdgB eine härtere Gangart gegen die Beteiligung von Einzelbauern in den Gremien einzuschlagen, hoffte die DBD, mit diesem Vorstoß die weitgehend erlahmte Mitarbeit einzelbäuerlicher Mitglieder für die Partei wiederzugewinnen. Da die Anleitung der DBD in agrarischen Grundsatzfragen 1959 hauptsächlich über Mückenberger lief ${ }^{50}$, verfolgte die DBD-Spitze offenbar nicht

46 Vgl. ACDP VI-052-0538, Protokoll Sekretariat, 20. 10.1958.

47 SAPMO DY 30 IV 2/15/52, Notizzettel zu Einschätzung der 10. PV-Sitzung der DBD (26./27. 2. 1959).

48 Siehe Beschlüsse zur Vorbereitung der VI. LPG-Konferenz und Protokoll des Sitzungsverlaufes, ACDP VI-052-0538, Protokoll Sekretariat, 6. 12. 1958.

49 ACDP VI-052-0539, Protokoll Sekretariat, 13. 7. 1959; BStU MfS AP 14985/92, Rietz, Bl. 31 f., Bericht Babies, HA V/3, über Gespräch mit Rietz, 30. 10. 1957.

$50 \mathrm{Vgl}$. ACDP VI-052-0539, Protokoll Sekretariat, 3. 8. 1959, ACDP VI-052-0538, Protokoll Sekretariat, 26. 1. 1959. 
durchweg den aggressiven Kurs gegenüber Einzelbauern, wie er von Teilen der $\mathrm{ZK}$-Abteilung gegenüber der VdgB vorübergehend vertreten wurde.

Höchstwahrscheinlich ausgelöst durch die im Politbüro diskutierte Stagnation der LPG-Beitrittszahlen, setzte die SED und ihre Helfer im MfS Mitte August eine Aussprache mit der DBD an. In der Agitierung der Einzelbauern sollte wieder einmal eine „Wende“ eingeleitet werden. Dabei kaschierte die SED die Tatsache, daß ihre eigene Politik der Herrschaftssicherung eine Reihe von Problemen, die sie der DBD vorhielt, letztlich verursacht hatte. An der Besprechung am 11. August $1959 \mathrm{im}$ ZK nahmen neben Goldenbaum, Rose und dem Hauptabteilungsleiter für Agrarpolitik Hoffmann, für die SED Matern, Mückenberger und von der Arbeitsgruppe BO Siegfried Wetzig teil51.

Matern folgte der Analyse der Arbeitsgruppe ${ }^{52}$ und hielt der DBD vor, sich ungenügend mit ideologischen Fragen unter ihren Mitgliedern auseinanderzusetzen und vor diesen „zurückzuweichen“. Sie habe die "politische Hauptaufgabe“ verfehlt, nämlich die erfolgreichen Mittelbauern zum LPG-Eintritt zu bewegen, und müsse dies bis zu ihrem VI. Parteitag Anfang 1960 grundlegend ändern. Matern kritisierte vor den Kontrahenten Rose und Goldenbaum die Zustände im Sekretariat, wo eine "Clique" herrsche. Er konfrontierte die DBD-Funktionäre mit dem Vorwurf - der im Grunde mehr die SED traf - bzw. der Direktive, daß „sie in Zukunft nicht alle Beschlüsse und Hinweise des ZK formal auf ihre Partei übertragen [...], sondern mehr auf die Eigenheit ihrer Partei achten" sollten ${ }^{53}$. Matern forderte von der DBD als deren besondere "taktische Methode“, die Einzelbauern via Mitgliedschaft in der DBD allmählich in die LPG zu führen. Er kritisierte eine „falsche Orientierung“, die ihr Augenmerk zu stark auf kleinschrötige Fragen der wirtschaftlichen Verbesserung der Zustände in den LPG richte, vom „Schweinehüttenbau" über den „Wettbewerb um das schöne sozialistische Dorf" bis zum „innerparteilichen Wettbewerb“. Dagegen habe sie „vielmehr für die sozialistische Umgestaltung der Landwirtschaft beizutragen. Die DBD hat somit in der Vergangenheit ihre politische Hauptaufgabe verfehlt. " 54

Wie eng der „eigenständig“ auszufüllende Handlungsspielraum der DBD jedoch war, zeigen die mit dem MfS abgestimmten Planungen der ZK-Arbeitsgruppe für den VI. Parteitag. Die Arbeitsgruppenleiterin Irene Köhler ließ das MfS wissen, daß man noch an einer "neuen Konzeption“ für die DBD arbeite. "Mit der DBD wurde so verblieben, dass das ZK große Teile der Ausarbeitung der Grundsatzerklärung [zur Lenkung der Mitglieder in die LPG] selbst übernehmen

51 Obwohl die Besprechung von der AG BO angestoßen wurde, ist sie nur in den Akten des MfS greifbar. Das folgende nach BStU MfS AP 661/92, Goldenbaum, B1. 74-77, Bericht der HA V/3, 29. 8. 1959. In Vor- und Nachbereitung dieses Treffens stand die AG dabei in engem Kontakt mit den für die hohen Parteifunktionäre der DBD zuständigen Mitarbeitern des MfS, Babies und Wieland.

52 SAPMO DY 30 IV 2/15/2, AG BO an Matern, 3. 8. 1959, zur Arbeitsweise des Sekretariats der DBD, Bericht über DBD in SAPMO DY 30 IV 2/15/53 überliefert.

53 BStU MfS AP 661/92, Goldenbaum, Bl. 74-77, Bericht der HA V/3, 29. 8. 1959, Zitat Bl. 75.

54 Ebd., Zitat Bl. 74. 
wird, “55 da der eingereichte - offensichtlich nicht überlieferte - Entwurf „unmöglich“" gewesen sei und vom „ZK nicht akzeptiert werden“ konnte ${ }^{56}$. Um den aus ihrer Sicht maroden personellen Zustand im Apparat des Parteivorstandes zu beheben, sah die Arbeitsgruppe einen Kadernachwuchs vor: Nachwuchs aus den Bezirken sollte einige Funktionäre im zentralen Apparat ablösen.

Diese Episode beleuchtet den Kern des Dilemmas der DBD: Sie sollte nicht die SED-Inhalte kopieren, sondern im vorgegebenen, eng begrenzten Rahmen vermeintlich eigene hervorbringen. Das hieß auch, daß ihr 1959 ein Anteil am bescheidenen Erfolg in der wirtschaftlichen Konsolidierung der LPG verwehrt wurde - denn deren Innenleben blieb der SED vorbehalten. Statt dessen fiel ihr der weitaus schwierigere Part zu, Mitglieder zum LPG-Eintritt zu bewegen und parteilose Einzelbauern anzuwerben, obwohl sie seit dem Bekenntnis zum Sozialismus in der Landwirtschaft 1957 für diese Klientel unattraktiv geworden war. Da die SED über weniger Einzelbauern in ihren Reihen verfügte, war sie hier auf den Transmissionsriemen DBD angewiesen. Die strenge Kritik der SED führte dazu, daß die DBD zur Formulierung von Grundsatzaussagen die Anleitung des ZK suchte und dann autoritative Lösungen vorgesetzt bekam. Die maßgeblichen Veränderungen im Programm und in der Kaderbesetzung bis Februar 1960 gingen auf die Anleitung der Arbeitsgruppe BO zurück, die sich dazu des Wissens des MfS bediente.

Schon im Dezember 1958 hatte der Parteivorstand der DBD einen Termin Ende Januar 1960 als Zeitpunkt für den VI. Parteitag festgelegt. Zur Vorbereitung jedes Parteitages gehörte es, über Wahlordnungen die Zusammensetzung der inneren Funktionseliten zu steuern. Während man Ende 1958 noch versucht hatte, über eine Regelung zur Wahl der Ortsgruppenvorstände den Anteil der Genossenschaftsbauern, Bäuerinnen und Jugendlichen zu erhöhen ${ }^{57}$, so diskutierte man aufgrund der Vorhaltung in der SED nun über ein Verfahren zur Einbindung von Einzelbauern in die Parteiarbeit. Dazu erwog man, die bestehenden Gremien zahlenmäßig aufzublähen, um mehr Plätze für Mittelbauern zur Verfügung zu haben ${ }^{58}$.

Der Ort und vor allem der Zeitpunkt des VI. Parteitages waren für DBD und SED von erheblicher Bedeutung. An deren Bestimmung läßt sich die Herausbil-

55 Aussprache zwischen Leutnant Wieland, MfS, und Köhler am 25. 8. 1959 in: BStU MfS AP 661/92, Goldenbaum, Bl. 74-77, Bericht der HA V/3, 29. 8. 1959, Zitat Bl. 77.

56 Ebd., Zitat Bl. 77. Pikant an der Arbeitspraxis des Sekretariats war, daß sich nur Böhm (Abt.-Leiter Schulung), Rietz (Kaderleiter), Körber (Abt.-Leiter Organisation) und Helmschrott (Chefredakteur Bauern-Echo) um die Abfassung der Grundsatzerklärung kümmerten, während sich die Parteispitze mit Goldenbaum, Rose, Reichelt und Hoffmann (Abt.-Leiter Agrarpolitik!) nicht beteiligten, aber um so mehr Korrekturen und Randnotizen anbrachten. Ihnen wurde nachgesagt, „Schwächen“ darin zu haben, „eigene Gedanken schriftlich niederzulegen.“ Ebd., Bl. 76. Gaude berichtete dem MfS, daß Böhm und Körber „wegen Unfähigkeit“ aus der Kommission zur Erarbeitung des Papieres entfernt wurden. BStU ASt Lpz. AIM 3445/92, Arbeitsvorgang Gaude, Bd. 1, Bl. 33-41, Bericht vom 8. 9. 1959.

57 ACDP VI-052-0168, Protokoll und Beschlußvorlage der 9. PV-Sitzung 1958, Vorlage, 20. 12. 1958, Beschlußvorlage Wahlordnung, 20. 12. 1958.

58 ACDP VI-052-0539, Protokolle Sekretariat, 13.7., 19. 10. 1959. 
dung einer Grundsatzentscheidung zur Vollkollektivierung ablesen. Obgleich man in Leipzig schon entsprechende Verträge abgeschlossen hatte, schlug Goldenbaum am 19. Oktober vor, den Parteitag statt Anfang Februar 1960 in Leipzig zur selben Zeit in Schwerin abzuhalten; tags darauf beschloß das Politbüro diese Variante ${ }^{59}$. Immer noch waren Genossenschaftsbauern wie Einzelbauern als Delegierte vorgesehen, was die Kontinuität der bisherigen Grundausrichtung der DBD belegt: Noch lag keine Entscheidung vor, den Parteitag in Form einer Feier der Vollkollektivierung abzuhalten, auf der Einzelbauern nichts mehr zu suchen hatten.

Für Schwerin als Austragungsort sprachen folgende Gründe: Zunächst hegte Goldenbaum eine große Vorliebe für Schwerin und den dortigen Bezirksverband. Zum zweiten suchte die Parteiführung einen Veranstaltungsort, wo sie sich durch ihren Beitrag zur Kollektivierung profiliert hatte. Der Bezirk Schwerin und der dortige Verband der DBD hatten zu diesem Zeitpunkt eine bessere Bilanz bei der mit Unterstützung der DBD betriebenen Kollektivierung aufzuweisen als vergleichsweise der Leipziger ${ }^{60}$. Es bot sich an, den Parteitag in einem vollgenossenschaftlichen Kreis durchzuführen ${ }^{61}$. Den Überlegungen im DBD-Sekretariat zufolge sprachen solche „Anzeichen“ Ende Oktober 1959 für Güstrow im Bezirk Schwerin ${ }^{62}$. Ende November schickte man daher 30 Instrukteure zur Vorbereitung in den Kreis Güstrow, unter anderem um alle Einzelbauern dazu zu bringen, in eine LPG einzutreten ${ }^{63}$. In den letzten Dezembertagen liefen die Vorbereitungen für den Anfang Februar 1960 nun definitiv in Güstrow geplanten Parteitag auf Hochtouren. Zur gleichen Zeit erreichte der Streit um die Parteiführung neue Dimensionen. Offenbar wollte Goldenbaum seinen Rivalen Rietz durch eine Delegierung auf eine Parteischule vorerst kaltstellen ${ }^{64}$.

Am 18. Januar 1960 entschied das Sekretariat der DBD, den VI. Parteitag zeitlich zu verlegen; der Einsatz der 30 Funktionäre in Güstrow mit dem Ziel, die Kollektivierung voranzutreiben, sollte nicht, wie ursprünglich gedacht, am 29. Januar enden, sondern war mit aller Kraft fortzusetzen ${ }^{65}$. Einen Tag später beschloß das Politbüro den „Einsatz von Arbeitsgruppen zur Verbreitung der Massenbewegung in der Landwirtschaft zur Überbietung des Volkswirtschaftsplanes 1960“ unter der Losung „Mit Golßener und Jesewitzer Plan überbieten wir den 60er Plan“66. Eine Woche später, am 26. Januar, legte das Politbüro fest, den DBD-Par-

59 Ebd., Protokoll Sekretariat, 19. 10. 1959. SAPMO DY 30 J IV 2/2/672, Protokoll PB, 20. 10. 1959, Bl. 3, und Anlage, wonach als Termine für die PT der Blockparteien vorgesehen waren: PT der DBD vom 4.-6.2.1960, LDPD 19.-22. 5. 1960, CDU 22.-25. 6. 1960.

60 Siehe Tabelle 23.

61 Howitz, DBD, S. 1136.

62 ACDP VI-052-0539, Protokoll Sekretariat, 26.10. 1959. Überlegungen, den PT von Schwerin nach Güstrow zu verlegen, hegten Rose und Körber, nicht aber Goldenbaum.

63 ACDP VI-052-0540, Protokoll Sekretariat, 23. 11. 1959.

64 In den zwei überlieferten Varianten des Sekretariatsprotokolls vom 21. 12. 1959 enthält eine den handschriftlich hinzugefügten Beschluß, Rietz 1960 auf eine Parteischule zu delegieren. Tatsächlich besuchte er Mitte 1960 die Parteihochschule der SED.

65 ACDP VI-052-0540, Protokoll Sekretariat, 18. 1. 1960.

66 Zur Konkretisierung der Aufgabe in den Kreisen hieß es: „Zur Verallgemeinerung der Golßener und Jesewitzer Beispiele sind in den Kreisen Wismar, Staßfurt, Prenzlau und 
teitag bis Mitte Mai zu verschieben. Die Terminveränderung sei notwendig, damit die DBD ,in die Lage versetzt wird, auch auf differenzierte Einzelfragen der Bauern zu antworten. Das ist aber erst möglich, nachdem das nächste Plenum unserer Partei getagt hat ${ }^{\text {" }}$.

Im letzten Drittel des Monats Januar 1960 hatte - der DDR-Geschichtsschreibung zufolge - unvermittelt eine Massenbewegung eingesetzt, in deren Verlauf in den nächsten Monaten des sogenannten "sozialistischen Frühlings" fast 450000 Bauern sich angeblich euphorisch zum "Schritt vom Ich zum Wir" entschlossen und sich in den einst so geschmähten Kollektiven eingefunden hatten ${ }^{68}$. Innerhalb kurzer Zeit traten damit ebensoviele Einzelbauern ein, wie zuvor im Zeitraum von sieben Jahren seit 1952. Übriggeblieben waren bis zum Frühjahr 1960 jene Bauern, die trotz schwerer Nötigungen bis dahin hartnäckig am Einzelbetrieb festhielten. Die DBD sollte sich nun besonders argumentativ wappnen, um gegen deren Ablehnung der Kollektivierung vorgehen zu können. Was löste diese vorgeblich freiwillige Bewegung "von unten“ aus und was war auf der politischen Entscheidungsebene geschehen?

\section{Die 7. ZK-Tagung vom Dezember 1959 und die Rostocker Aktion im Januar 1960}

Die 7. ZK-Tagung vom 10. bis 13 . Dezember 1959 gilt häufig als Zäsur beim Übergang zur Vollkollektivierung, weil sie das letzte wichtigere Parteiereignis vor dem Durchbruch hierzu war. Diese Einschätzung wird vertreten, obwohl von der SED keinerlei offizielle Aufforderung zum LPG-Eintritt für alle Bauern verkündet worden war. Der Parteivorstand der DBD hatte zuvor auf Sitzungen Mitte September und Ende Oktober die Pateigliederungen angewiesen, alle bäuerlichen Mitglieder zum LPG-Eintritt zu bewegen ${ }^{69}$. Es ist die These aufgestellt worden, wonach die eigentliche Initialzündung zur raschen Vollkollektivierung innerhalb kürzester Zeit Mitte Januar 1960 aus der SED-Bezirksleitung Rostock kam. Dort löste der 1. Bezirkssekretär, Karl Mewis, zwar mit Rückendeckung des dortigen sowjetischen Generalkonsulats, aber angeblich unabhängig von einer zentralen Entscheidung der SED, am 14. Januar 1960 eine Massenaktion des Staatsapparates und der Nationalen Front aus, die in kurzer Zeit den Beitritt aller Einzelbauern zu LPG nach sich zog. Mewis' vermeintliches „Husarenstück“ rollte im Einverneh-

Seelow Arbeitsgruppen des zentralen Parteiapparates, welche sich zusammensetzen aus Genossen der Abteilung Landwirtschaft, Agitation-Propaganda, Organisation und Kultur und der Agitationskommission, einzusetzen. Diese Arbeitsgruppen helfen unter Berücksichtigung der Erfahrungen aus Golßen und Jesewitz den Kreisleitungen mit den Genossenschaftsbauern in einem vollgenossenschaftlichen Dorf die Ausarbeitung und Durchführung eines Planes zur Überbietung der Ziele des Volkswirtschaftsplanes 1960 zu organisieren und die Massenbewegung im Kreis zu entfalten." SAPMO DY 30 J IV 2/2/684, Protokoll PB, 19. 1. 1960, TOP 8, Zitat Bl. 5.

67 SAPMO DY 30 J IV 2/2/685, Protokoll PB, 26. 1. 1960, TOP 10, Bl. 6, Zitat Bl. 66. Der PT der LDPD wurde auf 5.-8.7.1960 verschoben.

68 Stellvertretend Prokop, Übergang, S. $199 \mathrm{ff}$., sowie, immerhin noch 1997, Reichelt, Blockflöte, S. $178 \mathrm{ff}$.

69 ACDP VI-052-0171, Protokolle PV, 16./17. 9. 1959 und 30./31. 10. 1959. 
men mit allen Blockparteileitungen des Bezirkes ab, doch ohne Rückbindung an die SED-Spitze, da Ulbricht auf Mewis' Bitten, die Aktion abzusegnen, tagelang nicht reagiert hatte. Die „Empfehlungen“ der sowjetischen Stellen in Rostock hätten auf der Einschätzung basiert, daß die anhaltenden Versorgungsengpässe nur durch eine rasche Vollkollektivierung zu beheben $\operatorname{seien}^{70}$.

Andere wiederum unterstreichen die Steuerung der Kollektivierung durch die Parteizentrale, ohne die Vorgänge der Rostocker Peripherie damit in Zusammenhang zu bringen, aber auch ohne einzugestehen, daß der Massenbeitritt seit Ende Januar 1960 auf zentral gebilligtem und angeordnetem Druck basierte und keine freiwillige spontane Entscheidung der noch einzeln wirtschaftenden Bauern war. Ein Brief der zentralen Parteiführung vom 15. Januar 1960, der sich an alle Grundorganisationen der SED in den LPG, VEG, MTS und in den Dörfern richtete, rief dazu auf, „die noch individuell wirtschaftenden Bauern für den genossenschaftlichen Weg zu gewinnen und die bestehenden LPG weiter zu festigen"71.

Die nachgeschobene zentrale Anleitung der Grundeinheiten einen Tag nach Mewis' Vorstoß dürfte jedoch als Reaktion darauf zu sehen sein. Das Schreiben ändert nichts an der Einschätzung, daß die Initialzündung zum aktionistischen Vorgehen, das in kurzer Zeit die Vollkollektivierung herbeiführen wollte, in der Peripherie passiert war. Die Ursache für diese Initiative liegt jedoch im Drängen aus Berlin, d.h. die Peripherie reagierte auf eine qualitativ neue Linie der Zentrale und kam dieser in der Umsetzung zuvor. Anläßlich einer Parteiaktivtagung in Berlin am 6. Januar 1960 unterstrich Gerhard Grüneberg, wie wichtig es sei, den „Widerspruch zwischen den fortschrittlichsten Erfahrungen und der ungenügenden Leitungstätigkeit schnellstens zu beseitigen "72. Ausgerechnet der Rostocker Bezirksleitung wollte man „helfen, Fragen der Entwicklung der tierischen Produktion, insbesondere der Entwicklung der Viehbestände sowie der Fragen der

70 So Kaiser, Machtwechsel, S. 58f., bes. Anm. 9; dies., Politik, S. 99-105. Auf einer Sitzung der Bezirksleitung der SED am 14./15. 1. 1960 in Rostock waren erstmals und ausnahmsweise auch Vertreter der anderen Blockparteien beteiligt gewesen. Am Abend des 14. Januar fuhren fast alle anwesenden Kreissekretäre in ihre Heimatkreise und überbrachten die Nachricht, daß die volle Vergenossenschaftlichung nun durchgeführt werden solle. Tags darauf beschloß die Tagung, daß das Ziel der Vollvergenossenschaftlichung bis zum Beginn der Frühjahrsbestellung erreicht werden sollte (ebd., S. 100 f.). Grundsätzlich ist anzumerken, daß die Quellenbasis für diese weitgehende These dünn ist. Als Hauptquelle stützt sich Kaiser auf ein Interview mit dem Hauptbeteiligten Karl Mewis, das sich im Besitz der Verfasserin befindet. Andere Provenienzen bezog sie für die neuere Darstellung auch nach Öffnung der Archive nicht mit ein. Tatsächlich war Mewis' Bezirk noch Ende November 1959 von Ulbricht im „Neuen Deutschland“ heftig dafür kritisiert worden, daß der Bezirk in der Planerfüllung der LPG um 10-20\% hinterherhinke und die LPG nur einen extrem niedrigen Viehbesatz aufwiesen; Krebs, Weg, S. 359.

71 So Prokop, Übergang, S. 195; dessen Argument auf dieser ungenauen Quellenangabe beruht: Zentrales Parteiarchiv IV 2/5/10. Auffällig ist, daß Prokop Kaisers Ergebnisse, die bei Erscheinen seines Buches immerhin schon 6 Jahre vorlagen, nicht berücksichtigt. Der Verdacht liegt nahe, daß es unziemlich schien, für eine so einschneidende Wendung eine Aktion der Peripherie vom vorangegangenen Tag und nicht die SED-Zentrale in Berlin verantwortlich zu machen.

72 SAPMO DY 30 IV 2/7/11, Bl. 51-84, Referat ZK-Abt. LW auf Parteiaktivtagung der PO beim ZK, 6. 1. 1960, Zitat Bl. 84 . 
Futterproduktion - besonders Mais - so zu organisieren, daß dieser ausgesprochen landwirtschaftliche Bezirk einen großen Sprung nach vorn machen kann"73. Eine Lösung für das Problem der niedrigen Viehbestände in den LPG des Bezirkes Rostock sah man darin, gerade jene noch verbliebenen Einzelbauern, die in der Regel über höhere Viehbestände verfügten, den LPG einzuverleiben.

Angeblich zog das Sekretariat des ZK erst am 27. Januar 1960 hinter den Rostocker Entscheidungen nach, indem es eine Beratung mit den 1. Bezirkssekretären und Abteilungsleitern des ZK anberaumte ${ }^{74}$. Diese Datierung einer Grundsatzentscheidung zur Vollkollektivierung ist aufgrund der dargelegten Vorgänge um die Verschiebung des DBD-Parteitages zu spät. Schon am 18. Januar wurde der Termin des Parteitages in der Absicht geändert, bis zu diesem Parteiereignis die Vollkollektivierung erreicht zu haben. Mit der Verlegung auf Mitte Mai 1960 legte sich das Politbüro darauf fest, bis dahin auch die Vollkollektivierung durchgepeitscht zu haben. Diese weitreichende Änderung in der programmatischen Ausrichtung des Parteitages setzte eine vorherige Verständigung und einen Konsens von Politbüro und ZK-Apparat voraus ${ }^{75}$.

Die Rostocker Aktion ist daher ein Sonderfall. Sie ist erstens als Reaktion auf die anhaltende Kritik der ZK-Abteilung Landwirtschaft zu sehen, welche in paternalistischer Manier die Bezirke laufend zu mehr Anstrengungen in ihren „zurückgebliebenen "Kreisen aufforderte ${ }^{76}$. Ein Schreiben von Ende Dezember nannte jeder Bezirksleitung drei Kreise, die besonders schlechte Ergebnisse in folgenden Positionen aufwiesen: Bruttoproduktion in der Industrie, Erfüllung der Bauaufgaben, Anteil und Entwicklung des sozialistischen Teils der Landwirtschaft und Wert der Arbeitseinheiten in den LPG. Im Bezirk Rostock wurden die Kreise Ribnitz-Damgarten, Rostock-Land und Neustrelitz genannt. Die schlagartige Kollektivierung der bislang noch nicht beigetretenen, aber erfolgreich wirtschaftenden Mittelbauern, die erhebliche Viehbestände in die Kooperativen einbrachten, sollte im Bezirk Rostock helfen, die betriebswirtschaftlichen Probleme in den bestehenden LPG zu mildern, auch um deren Attraktivität für Einzelbauern zu steigern. Es ist daher kein Zufall, daß Mewis für seine Aktion „De Appel is riep“ im Januar den Kreis Ribnitz-Damgarten auswählte, den die ZK-Abteilung zuvor als besonders problembeladen charakterisiert hatte. Außerdem versprach dieses Vorgehen, den dauerhaften Ruhm zu erlangen, als erster Bezirk die Vollkollektivierung avisiert zu haben. Zweitens profitierte Mewis' Aktion von einem ausgesprochen engen Anpassungskurs der DBD an die SED, der z.B. dazu führte, daß die DBD hochqualifizierte Funktionäre an die SED abgab ${ }^{77}$. Neben der offiziellen Zusammenarbeit

73 Ebd., Bl. 80 f.; auffälligerweise wurde hier ausschließlich der Bezirk Rostock genannt.

${ }^{74}$ Kaiser, Politik, S. 105; Ulbrichts Rede auf dieser Tagung, die nichts an Eindeutigkeit in Richtung Vergenossenschaftlichung vermissen ließ, auch abgedruckt in: ders., Bauernbefreiung, Bd. 2, S. $905 \mathrm{ff}$. Aktenüberlieferung der Rede in SAPMO NY 4182/608.

75 Wenn das PB die Verschiebung erst am 26. Januar beschloß, ist zu berücksichtigen, daß der Beschluß eine weitere Klärung enthielt, wofür Vorarbeiten nötig waren, etwa in der terminlichen Feinabstimmung des PT; außerdem tagte das PB nur einmal wöchentlich.

76 SAPMO DY 30 IV 2/5/35, Bl. 51 f., Entwurf Org.-Abt. an die BL, 28. 12. 1959. Siehe auch Prokop, Übergang, S. 200, Anm. 105.

77 Diese Praxis ging, wie erwähnt, auf den damaligen Organisationssekretär der DBD in - 
Ernst Mecklenburgs mit dem MfS, die sich aus seiner Position ergab, arbeitete im Rostocker Sekretariat der DBD außerdem eine Gruppe von besonders willfährigen Spitzeln der Staatssicherheit. Als Erfüllungsgehilfen der SED setzten sie in operativen Aufträgen vor allem deren Interessen auch in den folgenden Jahren um $^{78}$. Ernst Mecklenburg wurde für seinen Einsatz im Frühjahr 1960 von der SED hoch belobigt. Sein bedingungsloser Anpassungskurs war letztlich dafür verantwortlich, daß er in den achtziger Jahren zum Parteivorsitzenden avancierte. Rostocks DBD-Führung war kein Opfer der SED-Kollektivierungspolitik, sondern arbeitete in besonderem Maße an ihrem raschen Abschluß mit.

Auch wenn man die Existenz einer solchen Initialzündung aus Rostock bejaht, muß doch betont werden, daß intern schon während und vor allem in Nachbereitung der 7. ZK-Tagung in der SED und im Staatsapparat ein Prozeß eingeleitet worden war, der einen Grundkonsens für das Erreichen der Vollkollektivierung in absehbar kurzer Zeit gestiftet hatte, wenngleich keine Festlegung auf das Frühjahr 1960 stattgefunden hatte bzw. bislang nicht nachzuweisen ist. Da diese Frage erst auf der 8. ZK-Tagung ausführlich thematisiert werden sollte, dürfte das Politbüro zum Zeitpunkt der 7. ZK-Tagung noch keine Terminierung der Vollkollektivierung für das Frühjahr 1960 geplant haben ${ }^{79}$.

Ungeachtet der singulären Bedeutung, die dem Rostocker Vorpreschen am 14. Januar 1960 zukommt, fällte das Politbüro während der 7. ZK-Tagung Entscheidungen, die eine organisatorische Straffung sowie eine Radikalisierung der agrarpolitischen Konzeption bezweckten und insgesamt auf einen kurz- bis mittelfristigen Abschluß der Kollektivierung zielten. Zum Zeitpunkt dieser ZKTagung peilte man dafür nicht schon das Frühjahr 1960 an, sondern die Zeit nach der 8. ZK-Tagung. Diese Terminierung hätte eine gebührende Vorbereitung des Apparates und eine weitere Abstimmung mit der Sowjetunion ermöglicht; letztere war eventuell nötig, um die Zusage der UdSSR für Lebensmittellieferungen zu erwirken. Auf solche war die DDR im Falle einer radikalen Kollektivierung angewiesen, da diese die landwirtschaftlichen Erträge, die ohnehin unter der ungünstigen Witterung 1959 gelitten hatten, zunächst unweigerlich schmälern würde ${ }^{80}$.

Rostock, Ernst Mecklenburg, zurück; ACDP VI-052-0538, Protokolle Sekretariat, 17.11., 29.11. und 6. 12. 1958, 19. 1. 1959. ACDP VI-052-0546, Protokoll Sekretariat, 15. 1. 1962. BStU MfS AIM 3189/63, Arbeitsvorgang Zagrodnik, Bl. 110-115, Treffbericht HA V/3, 26. 11. 1960.

78 Erwin Binder etwa berichtete schonungslos über alle Vorkommnisse in der Mitgliedschaft und trug wie auch Mecklenburg zur Ablösung Walter Spierings als Bezirksvorsitzender 1963 bei. Auf Spiering folgte Mecklenburg. BStU ASt Rst. AIM 186/63, Binder, Bd. 1/I, Bl. 47. Binder, der Mitte 1960 angeworben wurde, nachdem sich Mecklenburg in einem Gespräch lobend über ihn geäußert hatte, obwohl er die landwirtschaftliche Gehilfenprüfung nur mit der Note "genügend" bestanden habe, informierte in der Folge das MfS 1960 auch über weitere Konflikte zwischen Goldenbaum und Mecklenburg. Ebd., Bd. 1/I, Bl. 67, Befragung Mecklenburg, 29.6. 1960; ebd., Bd.1/II Arbeitsvorgang Binder, Bl. 32-39, Treffbericht, 27. 8. 1960 (zu Spiering); Bl. 41, Bericht vom 4. 11. 1960, Bl. 180-185, Bl. 264.

79 So auch Kaiser, Politik, S. 89.

80 Über Engpässe in der Versorgungslage siehe etwa die PB-Protokolle: SAPMO DY 30 J IV 2/2/672, 20. 10. 1959, Bl. 6. SAPMO DY 30 J IV 2/2/673, 3. 11. 1959, Bl. 3; Reichelt, Blockflöte, S. 172; allg. bis 1961 vgl. Poutrus, Lebensmittelkonsum, S. 398-406. 
Zur Verbesserung der Versorgungslage erwog die landwirtschaftliche Führungsspitze der SED am 24. November 1959 gegenüber dem Vorsitzenden der Staatlichen Plankommission, Bruno Leuschner, Änderungen am Entschließungsentwurf der ZK-Abteilung Landwirtschaft für das 7. Plenum vorzunehmen. Um dem steigenden Verbrauch und den Prognosen gerecht zu werden, müßten die für 1965 formulierten Produktionsziele schon 1963, die für 1963 schon 1961 erfüllt wer$\operatorname{den}^{81}$.

Als Datum für das Erreichen der Vollkollektivierung hat die SED vorübergehend das Jahr 1961 angesetzt. Es ist offensichtlich, daß auf verschiedenen mit der Agrarpolitik betrauten Ebenen während und im unmittelbaren Anschluß an die 7. ZK-Tagung Entscheidungen getroffen wurden, die zentrale Rahmenbedingungen für die mittelfristige Durchsetzung der Vollkollektivierung schufen. Erst dieses veränderte, radikalisierte Klima kombiniert mit den Vorwürfen an die Bezirksleitung hat Mewis zur eigenmächtigen Profilierung angestachelt - möglicherweise war er auch aufgrund der jahrelangen nachweislich engen Abstimmung mit dem sowjetischen Konsulat sofort über die neue Ausrichtung informiert ${ }^{82}$.

Welche Entscheidungen im Umfeld der 7. ZK-Tagung waren nun dazu geeignet, solche Rahmenbedingungen für eine Vollkollektivierung zu schaffen? Diese Entscheidungen konnten nicht mehr in den öffentlich dargebotenen Inhalt der 7. ZK-Tagung einfließen, da sie ganz kurzfristig zustande kamen und sicherlich den sorgfältig inszenierten Verlauf der 7. ZK-Tagung gestört hätten. Gleichwohl belegen die schon vor der ZK-Tagung erstellten Konzeptionen des Ministeriums und der VdgB ganz klar, daß man, obwohl noch kein nahes Enddatum für die Vollkollektivierung feststand, auch dort nur noch überlegte, wie man die einzelbäuerlichen Betriebe wirtschaftlich weiter einschnüren und so zum Eintritt in eine LPG bewegen könnte ${ }^{83}$. Im vorbereiteten Teil beschäftigte sich die 7. ZK-Tagung mit der Erfüllung der Ziele des Siebenjahrplanes in der Landwirtschaft. Erstmals waren zu einer ZK-Tagung über hundert Gäste, Agrarwissenschaftler, Brigadiere und andere Experten oder Praktiker geladen; erstmals hielt ein Nicht-SED-Mitglied, Landwirtschaftsminister Hans Reichelt, ein Grundsatzreferat auf einer SED-Parteiveranstaltung, und zwar über die Bedeutung der Viehwirtschaft im Siebenjahrplan.

Während der 7. ZK-Tagung vollzog das Politbüro auf Ulbrichts Entscheidung hin einen bedeutsamen Personalwechsel an der Spitze der Agrarpolitik. Auf einer außerordentlichen Sitzung am 11. Dezember 1959 wurde beschlossen, Erich

81 BA DE-1/3189, Bl. 117-120, Heid, Abt. Land- und Forstwirtschaft der Staatlichen Plankommission, an Leuschner, 25. 11. 1959.

82 Siehe z. B. International Department, Rolle 109 (RGANI, 5-26-425, Bl. 49-51), Gespräch Konsul Rostock, I. Timofeew, mit Mewis, 13. 2. 1956. Mewis fragte an, ob er in Rostock bleiben soll.

83 SAPMO DY 30 IV 2/7/10, Bl. 368, ZV der VdgB, gez. Herold, an Mückenberger, 16. 10. 1959; ebd., Bl. 372-382, Konzeption zur 7. ZK-Tagung des MLF, gez. Reichelt, 17. 10. 1959; vgl. auch Reichelt, Blockflöte, S. 172-174, der ebenfalls erwähnt, daß die ZK-Tagung „keine detaillierten Schlußfolgerungen aus der Entwicklung [Ausbau des genossenschaftlichen Sektors] in Halle und Rostock" zog, also im veröffentlichten Ergebnis nicht auf eine kurzfristige Vollkollektivierung zusteuerte. 
Mückenberger als Sekretär für Landwirtschaft abzulösen; er gehörte allerdings weiter dem Politbüro an. Für ihn sollte der Sekretär des ZK Gerhard Grüneberg den Vorsitz der Agrarkommission übernehmen und als Kandidat in das Politbüro einrücken ${ }^{84}$. Der unmittelbare Anlaß für Mückenbergers Abberufung lag darin, daß der Kreis Eilenburg im Bezirk Leipzig als erster Kreis der DDR die Vollkollektivierung tatsächlich erreicht hatte ${ }^{85}$. Dieser Vorgang war ungeachtet massiver Agitation offenbar nicht für diesen, sondern für einen Nachbarkreis erwartet worden. Jedenfalls bestärkte die Bewegung „von unten“ Ulbricht darin - höchstwahrscheinlich lieferte sie ihm nur einen Vorwand -, Mückenberger abzusetzen. Dieser galt nicht mehr als die am besten geeignetste Person für den in der Zentrale anvisierten Vollzug der Kollektivierung, die gegen alle Reibungen im Apparat und vor allem gegen den Widerstand der noch verbliebenen knapp 400000 Einzelbauern durchzusetzen war. Dieses Revirement an der Spitze der Agrarpolitik steht für einen Politikwechsel, der einen Kurs zur Herbeiführung der Vollkollektivierung in absehbar kurzer Zeit ins Auge faßte. Weiter sollte die Kollektivierung in einen agrarindustriellen Aufbau der DDR-Landwirtschaft eingebettet werden, wie er nach einer Konsolidierungsphase, d.h. nach Überwindung der Friktionen, die die abrupte Kollektivierung mit sich brachte, ab 1963 in der DDR mit den Namen Gerhard Grüneberg und Bruno Kiesler verbunden ist. Vielleicht behielt sich die SED vor, im Stammland der Arbeiterbewegung Sachsen den ersten vollkollektivierten Kreis zu erzielen - während die DBD im Oktober ihren Parteitagsort von Leipzig nach Güstrow, in ihr historisches Gründungszentrum nach Mecklenburg verlegte und sich dort auf die Kollektivierung konzentrierte.

Diese agrarpolitischen Ziele sollten unter Grüneberg nun auch gegen volkswirtschaftliche Rationalität verfochten werden. In Mückenbergers Ära war die volkswirtschaftlich beste Lösung der Agrarordnung immer noch so interpretiert worden, daß ein überstürzter Ausbau des genossenschaftlichen Teils der Agrarwirtschaft deren Produktivität insgesamt belaste und die DDR angesichts seit 1958 gestiegener Konsumbedürfnisse vor Aufgaben stellen würde, die sie aus eigener Kraft nicht erfüllen könnte. Außerdem schätzte man die Widerstände der Einzelbauern gegen diesen Schritt als sehr hoch ein. Insbesondere die labile Wirtschaftslage vieler LPG verhinderte in Mückenbergers Sicht, daß solide Einzelbetriebe diesen LPG beitraten und deren ökonomische Basis damit stabilisierten.

So war mit Mückenberger eine agrarpolitische Konzeption verbunden, die trotz einer seit 1957 vorhandenen grundlegenden Ausrichtung auf die gezielte Ausdehnung des sozialistischen Sektors im Prinzip stets die makroökonomischen Implikationen des Sozialisierungsprozesses berücksichtigte. Sein Vorgehen zur

84 Zur 7. ZK-Tagung (Ulbricht Berichterstatter) u. a.: „1. Der Einschätzung Ulbrichts über den bisherigen Ablauf der Diskussion zu den Landwirtschaftsfragen wird zugestimmt, 2. In der geschlossenen Sitzung des ZK ist offen zu sagen, daß die Arbeit der Agrarkommission des Politbüros nicht den hohen Anforderungen entspricht und deshalb eine Verstärkung notwendig ist." SAPMO DY 30 J IV 2/2/679, Protokoll außerordentliche PB-Sitzung, 11. 12. 1959, Bl. $1 \mathrm{f}$.

85 SAPMO DY 30 IV 2/5/60, Bl. $1 \mathrm{ff}$., Protokoll einer gemeinsamen Abteilungsversammlung der Abt. Organisation, Kaderfragen, Gewerkschaften und Sozialpolitik, Januar 1960, Bl. 28. 
Umsetzung des Sozialisierungszieles war zweigleisig angelegt: Parallel zur Werbung von wirtschaftsstarken Einzelbauern für die LPG sollte alles unternommen werden, um die LPG ihrerseits betriebswirtschaftlich voranzubringen; beide Aspekte würden ineinandergreifen und sich gegenseitig beeinflussen.

Schon im Vorfeld der 7. ZK-Tagung traf Mückenberger massive Kritik des Politbüros. Eine Reihe von Vorlagen, die unter seiner Anleitung erstellt worden waren, mußten mehrfach umgeändert werden, weil sie in Ulbrichts Sicht nicht den politischen Erfordernissen entsprachen. Ulbricht hatte bereits im November 1959 darauf gedrängt, was auf der ZK-Tagung explizit proklamiert wurde: Nicht nur im nationalen Vergleich sollte die DDR-Land wirtschaft eine bessere Produktivität erzielen, auch international sollte sie sich am "Weltniveau" messen ${ }^{86}$. Noch Anfang Dezember war das Politbüro weder mit Mückenbergers Arbeit noch mit der Redevorlage Reichelts für die ZK-Tagung einverstanden ${ }^{87}$. Auch zwischen der Staatlichen Plankommission und Mückenberger als Vertreter der Agrarwirtschaft war es im Vorfeld zu Differenzen gekommen. Es ging dabei um die Chancen der Agrarwirtschaft, die Produktionsziffern des Siebenjahrplanes zu erfüllen ${ }^{88}$. Demnach hatte Mückenberger vor Mitarbeitern der Staatlichen Plankommission am 24. November Modifikationen am Siebenjahrplan gefordert - so der Vorwurf der Plankommission -, da die Planziffern hinsichtlich der Positionen pflanzliche und tierische Erzeugung nicht mehr zuträfen ${ }^{89}$. Für die Plankommission wies Heid die Mehranforderungen an staatlichen Mitteln zurück, die gewährleisten sollten, daß man die landwirtschaftlichen Produktionsziffern erreichen könnte. Dies stieß auf heftige Kritik von Mückenberger, aber auch von Grüneberg und Reichelt. Heid mußte Mückenberger gegenüber eingestehen, daß die Plankommission zu dieser Zeit noch keine neue Konzeption über die Entwicklung des Pro-KopfVerbrauches für 1961 bis 1965 ausarbeiten könne, die der Landwirtschaftsapparat aber begleitend zur Vorgabe der Plankommission, die festlegte, bis 1962 keine Import an tierischen Erzeugnissen mehr vorzunehmen, dringend benötigt hätte.

Das Ziel, „Weltniveau“ zu erreichen, markiert die einschneidende Bedeutung der 7. ZK-Tagung. In der Sicht von Karl Gutjahr, Ulbrichts Berater in Landwirtschaftsfragen, ging die 7. ZK-Tagung durch die Ausrichtung am „Weltniveau“

${ }^{86}$ Daher müsse im Mittelpunkt der ZK-Tagung „die Erfüllung der ökonomischen Hauptaufgabe in der Landwirtschaft stehen, wobei begonnen werden muß mit der Darlegung des Standes des Weltniveaus in der Landwirtschaft und welche Maßnahmen notwendig sind, um diesen Stand zu erreichen," so die Schelte des PB an Mückenbergers Vorlagen; SAPMO DY 30 J IV 2/2/675, Protokoll PB, 17.11. 1959, Zitat Bl.3, siehe insgesamt TOP 2.

87 SAPMO DY 30 J IV 2/2/677, Protokoll PB, 1. 12. 1959, Bl. 2.

88 Die Differenzen mündeten in eine Stellungnahme der Abt. LW der Staatlichen Plankommission zur Vorlage an das PB, 29. 11. 1959, BA DE-1/3189, Bl. 124-128.

${ }^{89}$ So die Auffassung der Abt. LW der Staatlichen Plankommission, ebd., Bl. 117-120, Heid an Leuschner, 25. 11. 1959, hier Bl. 118-120. Der Bezirk Neubrandenburg fragte schon an, ob es zuträfe, daß der Siebenjahrplan geändert werde und man daher die Arbeit am „komplex-territorialen“ Plan für den Bezirk einstellen solle. Am 27. 11. 1959 wandte sich Mückenberger nach einem Gespräch am 25.11. nochmals an Leuschner um diesem zu versichern, keiner wolle auf der 7. ZK-Tagung die bisherigen Ziffern des Siebenjahrplanes „über den Haufen werfen“; ebd., Bl. 121-123. 
über die Beschlüsse des V. Parteitages hinaus ${ }^{90}$. Die Beschlüsse des Parteitages hatten, wie erwähnt, im Hinblick auf die agrarpolitischen Vorsätze unter dem Gemeinziel „Aufbau des Sozialismus“ festgelegt, innerhalb eines längeren Zeitraumes von fünf Jahren im nationalen Wettstreit die Bundesrepublik an Produktivität zu übertreffen. Auch aus den internen SED-Debatten im Vorfeld der 7. ZKTagung geht hervor, daß der Wechsel zur Zielhöhe „Weltniveau“ den entscheidenden Unterschied zu den Vorgaben des V. Parteitages bezeichnete. Die DDR bemühte sich, nicht nur im deutsch-deutschen Vergleich zu bestehen; vielmehr übernahm sie jene Aufgaben, die Chruschtschow dem gesamten Ostblock im Zusammenhang mit dem sowjetischen Siebenjahrplan zugeschrieben hatte, dessen Plankennziffern im Februar 1959 veröffentlicht worden waren ${ }^{91}$. Auch das Dezemberplenum der KPdSU, das sich mit der weiteren „Entwicklung der Landwirtschaft" befaßte, formulierte optimistisch, daß die Sowjetunion 1959 die Pro-Kopf-Fettproduktion der USA schon übertroffen habe ${ }^{92}$. Allerdings bedeutete diese veränderte Ausrichtung noch keinen radikalen Politikwechsel hin zu einer ganz kurzfristigen Durchsetzung einer Vollkollektivierung.

Obwohl die SED intern sehr wohl mit der 7. ZK-Tagung den Beginn der, so Gutjahr, "nächsten Etappe der sozialistischen Entwicklung in der Landwirtschaft ${ }^{\prime 93}$ datierte, plante das Politbüro eine intensive Auseinandersetzung mit dem Wunschziel Vollkollektivierung und dessen Herbeiführung doch erst nach einer Tagung des Nationalrates der Nationalen Front und in Zusammenhang mit der nächsten, der 8. ZK-Tagung94. In Vorbereitung auf diese Tagung betraute man die ZK-Abteilung Landwirtschaft daher mit zwei Aufgaben: zum einen mit der "Orientierung auf die politische Massenarbeit" - das bedeutete eine Anleitung der Apparate der Parteien und Massenorganisationen zum agitatorischen Vorgehen in den Dörfern - und zum anderen mit der "Organisierung und Kontrolle der Durchführung des wissenschaftlich-technischen Fortschritts in der Landwirtschaft und Orientierung auf das Weltniveau"95.

Die Ausrichtung am „Weltniveau“ implizierte, den erreichten Stand der Agrarumwälzung in der DDR innerhalb des Ostblocks zu vergleichen. Darin lag ein dynamisierendes Element für die Beschleunigung der Kollektivierung. Reichelt proklamierte im März 1960 auf einer Brigade-Versammlung in Schwerin, es sei wichtig, „unser Tempo schnell zu steigern. Außer Polen und unserer DDR sind alle sozialistischen Länder vollgenossenschaftlich" ${ }^{* 6}$. Der entscheidende Radi-

90 Siehe Materialzusammenstellung für 7. ZK-Tagung im Nachlaß Ulbricht, SAPMO NY 4182/1039, Bl. $143 \mathrm{ff}$.

91 Vgl. Meissner, Russland, S. 203-205.

92 Selenin, Agrarnaja politika, S. 112; Ploss, Conflict, S. 154-158, schätzt Chruschtschows Lage zum Zeitpunkt des Plenums als schwieriger ein.

93 Siehe Materialzusammenstellung für 7. ZK-Tagung im Nachlaß Ulbricht, SAPMO NY 4182/1039, Bl. $143 \mathrm{ff}$.

94 So Ulbricht im PB während der 7. ZK-Tagung, SAPMO DY 30 J IV 2/2/679, Protokoll außerordentliche PB-Sitzung, 11. 12. 1959, Bl. $1 \mathrm{f}$.

95 SAPMO DY 30 IV 2/7/11, Bl. 51-84, Referat der ZK-Abt. LW für die Parteiaktivtagung der PO beim ZK in Auswertung des 7. ZK-Plenums, 6. 1. 1960, hier Bl. 78.

96 ACDP VI, unverz. Best. LV Mecklenburg/BV Schwerin, Aktendeckel BV Schwerin, Abt. Agrarpolitik 1952 ff., Protokoll Brigadebesprechung am 4. 3. 1960 in Schwerin. 
kalisierungsschub, die Vollkollektivierung in aller Härte voranzutreiben, und das ehrgeizige Ziel, sich am „Weltniveau" $\mathrm{zu}$ messen, ist im internationalen Kontext sicherlich dadurch begünstigt worden, daß die sowjetische Parteiführung ihre Verbündeten für den Februar 1960 zu einer Agrarkonferenz nach Moskau eingeladen hatte97. Für die SED dürfte die Aussicht gewiß verlockend gewesen sein, dort berichten zu können, daß der Agrarsektor der DDR nun in großem Stil Produktionsmittel in genossenschaftliche Eigentumsformen einbrachte. In seiner Rede in Moskau begründete Ulbricht die Kollektivierung mit erhofften Produktionssteigerungen: Während die Erhöhung der „landwirtschaftlichen Erträge [...] unmittelbar verbunden [ist] mit der Entwicklung der landwirtschaftlichen Produktionsgenossenschaften und der Bildung vollgenossenschaftlicher Dörfer und Kreise", könne hingegen mit einer weiteren Produktionssteigerung der Einzelbauern nicht mehr gerechnet werden ${ }^{98}$. Im übrigen lag die Vollkollektivierung in der UdSSR exakt 30 Jahre zurück. Sicherlich versprach sich die DDR, deren Sozialisierungsgrad dem anderer Ostblockländer hinterher hinkte und die um internationale Anerkennung rang, mit diesem Schritt eine historisch vermittelte Legitimation als sozialistischer Staat.

Als dritter Aspekt im Zusammenhang mit der Durchführung der Vollkollektivierung steht ein qualitativ höheres Anforderungsprofil für die Apparate der SED und des Staates, das in Reaktion auf die 7. ZK-Tagung formuliert worden ist. Die Zielsetzung lautete, „den Widerspruch zwischen den fortschrittlichsten Erfahrungen und der ungenügenden Leitungstätigkeit schnellstens zu beseitigen " 99 - das hieß, die Apparate sollten adäquat damit umgehen können, daß in manchen Kreisen, wie in Eilenburg, tatsächlich ein vollkollektivierter Zustand erreicht werden konnte. Hierin unterstellte man Defizite. Wie zahlreiche Indizien belegen, wurden nach der 7. ZK-Tagung die Anforderungen zur Qualifizierung im Apparat neu bestimmt. Das betraf die untere Umsetzungsebene der Kollektivierung in den Dörfern. Die Abteilung Organisation und Propaganda sollte in Nachbereitung der 7. ZK-Tagung festlegen, „wie die Kampagne in den Fragen der Landwirtschaft weiterzuführen" sei und sie sollte künftig garantieren, daß „die Parteiführung eine schnellere und genauere Information über bestimmte Erscheinungen in der Republik erhält" ${ }^{100}$. Der Kontext legt nahe, unter „bestimmten Erscheinungen“ so wie unter "fortschrittlichsten Erfahrungen" das Erreichen des vollgenossenschaftlichen Zustandes in Eilenburg zu verstehen. Offenbar fühlte sich die Parteiführung über die Vorgänge dort unzureichend informiert. Welch neue Dimension die Agitation im Dezember 1959 auf dem Land annahm, beweisen die anschnellenden

97 SAPMO DY 30 J IV 2/2/687, Protokoll PB, 8. 2. 1960, BI. 2, Bericht Ulbrichts über die Beratungen in Moskau, 1. zur Agrarkonferenz. „Nach Rückkehr der Delegation soll ausgearbeitet werden, wie wir den Höchststand in den vollgenossenschaftlichen Dörfern erreichen, wie wir solche auf dem Weltstand stehende Kombinate für Schweine und Rindvieh in den Groß-LPG in vollgenossenschaftlichen Kreisen schaffen."

98 BA DE-1/20412, Diskussionsbeitrag Ulbrichts (18 Seiten), hier S. 2, 6.

99 So die Formel, hier im Referat der ZK-Abt. LW für die Parteiaktivtagung der PO beim ZK in Auswertung des 7. ZK-Plenums, 6. 1. 1960, SAPMO DY 30 IV 2/7/11, B1. 51-84, Zitat Bl. 84.

100 SAPMO DY 30 J IV 2/2/680, Protokoll PB, 15. 12. 1959, Bl. 2-4, TOP $9 \mathrm{c}$ und d. 
Beitrittszahlen zu den LPG, besonders auffällig in jenen Gebieten, wo der Zuwachs bis dahin rückläufig gewesen war ${ }^{101}$.

Außerdem hielt es die SED-Führung für unerläßlich, in Anlehnung an den Politbürobeschluß vom 15. Dezember 1959 die staatliche Leitungstätigkeit insgesamt den "vorauseilenden Produktionsverhältnissen"102 anzupassen, und das hieß, die mit Landwirtschaft befaßten Stellen zu reformieren. Funktionstüchtige Apparate galten als Voraussetzung für das Erreichen und die dauerhafte Beibehaltung der Vollkollektivierung. Zu diesem Zweck suchte die SED offenbar sowjetische Beratung und entsandte noch im Dezember 1959 eine Delegation des ZK zum "Studium der Parteiarbeit der KPdSU“ in die Sowjetunion. Als Ergebnis dieser Reise übernahm man die territorialen Organisationsformen des Parteiapparates der KPdSU103. Künftig sollte in der ZK-Abteilung Landwirtschaft jeweils ein Genosse für einen Bezirk verantwortlich sein; später gab es Überlegungen, einen eigenen Sektor in der Abteilung einzurichten, der nur für die territoriale Anleitung zuständig sein sollte. Außerdem drängte man auf einen Austausch mit anderen ZK-Abteilungen, um die nächste ZK-Tagung zu Landwirtschaftsfragen gemeinschaftlich, „sehr breit“, vorzubereiten.

Im Zuge des Umbaus der Abteilung Landwirtschaft Anfang 1960 fielen bei den Mitarbeitern eine Reihe politischer „Ungereimtheiten“ auf, die es auszuräumen galt ${ }^{104}$. Auch für das Ministerium zog die Umorganisation eine Reihe von Veränderungen nach sich. Wie im Politbürobeschluß vom 15. Dezember 1959 vorgezeichnet, sollte das Ministerium mehr politische Kompetenz beweisen ${ }^{105}$; zwar habe es künftig "die Grundfragen der Agrarpolitik auszuarbeiten und der Agrarkommission des ZK vor[zu]legen. Darüber hinaus muß Schluß gemacht werden damit, daß jedes Papierchen vom Ministerium oder Mitarbeitern des Ministeriums der Abteilung Landwirtschaft und dem Sekretär des ZK vorgelegt wird [...] Der

101 Für die DBD z. B. im Bezirk Leipzig, siehe Tabelle 23. Ulbricht wurde noch im Dezember vor Ort aktiv, wie Reichelt, Blockflöte, S. 174, anführt: Er empfahl lokalen SED-Apparaten auf einer Versammlung am 19. 12. 1959, "aus der Enge“ herauszutreten und mit den Massen der Bauern, in Zusammenarbeit mit der Nationalen Front und der DBD vorzugehen; dann werde man rasch sehen, „wie gut das vorwärts geht.“

102 So Kiesler in einer sehr kritischen Einschätzung zu den Reorganisationsplänen des MLF, die diesen Anforderungen nicht genügten. SAPMO DY 30 IV 2/7/39, Bl. 10-14, Stellungnahme ZK Abt. LW zur Vorlage des MLF an die Landwirtschaftskommission beim PB, 23. 1. 1960, Zitat Bl. 10.

103 SAPMO DY 30 IV 2/7/77, Bl. 141-143, Vorschläge zur Auswertung des Berichtes der Delegation des ZK der SED zum Studium der Parteiarbeit der KPdSU, 29. 12. 1959, von Karl Parske zur Vorlage an Alfred Neumann. Siehe dazu auch: SAPMO DY 30 IV $2 / 7 / 77$, Bl. 158f., Kiesler an Grüneberg, 23. 6. 1960. Ein Bezug auf „sowjetische Erfahrungen“ auch im Referat der ZK Abt. LW für die Parteiaktivtagung der PO beim ZK in Auswertung des 7. ZK-Plenums, 6. 1. 1960, SAPMO DY 30 IV 2/7/11, Bl. 51-84, hier Bl. 78.

104 Unter anderem geriet Parske, Leiter der in diesen Fragen sensiblen Sektion Agrarökonomik, in die Kritik. Er hatte die Abt. seinerseits 1956/57 über die vermeintliche „Plattform" Viewegs in der Abt. Agrarökonomik der DAL informiert (siehe SAPMO DY 30 IV 2/7/78, Bl. 386 f., Sektorenleiterbesprechung, 4. 12. 1956). SAPMO DY 30 IV 2/7/79, Protokoll Parteiaktivtagung, 12.1. 1960, Bl. $354 \mathrm{ff}$.

105 SAPMODY 30J IV 2/2/680, Protokoll außerordentliche PB-Sitzung, 15. 12. 1959, Bl. 2-4, u.a. TOP 3. 
Apparat der Partei wird sich in Zukunft nur noch mit den Grundfragen, vor allem der Mobilisierung der Werktätigen, zur Lösung der von der Partei gestellten Aufgaben beschäftigen und unten - an Ort und Stelle - gemeinsam mit den Werktätigen kontrollieren, wie die staatlichen Organe ihre Aufgaben lösen." 106 Dieser Zug, das staatliche Ministerium nur noch als unter der Oberhoheit der SED stehendes Ausführungsorgan zu begreifen und es einer vermeintlich zwischen Basis und SED abgestimmten Kontrolle zu unterwerfen, zeigt in besonderer Weise die Janusköpfigkeit der Veränderungen im Verhältnis von Staat und Partei 1960 auf, die eben nicht ausschließlich unter dem Schlagwort "moderne Reform“ zu fassen sind ${ }^{107}$. Sogar die Staatliche Plankommission geriet bis Anfang Januar 1960 in die Kritik der Zentralen Kommission für Staatliche Kontrolle, die ihr vorhielt, zum Siebenjahrplan eine „falsche Orientierung zur Entwicklung der Viehbestände“ an das MLF herausgegeben zu haben ${ }^{108}$. Die Vorwürfe wurden dort strikt zurückgewiesen.

Mehr Zuständigkeiten für die Ministerien implizierte jedoch zugleich eine wachsende Kompetenzkompetenz der Partei als "Supervisor“, die ihren Kontrollanspruch erweiterte. In bezug auf das 1960 mit dem Staatssekretariat für Erfassung und Aufkauf vereinigte Landwirtschaftsministerium bedeutete dies mittelfristig eine Ausdehnung des SED-Herrschaftsmonopols. Denn als Folge dieses Bedeutungszuwachses des Ministeriums erschien ein DBD-Minister Reichelt trotz aller Qualifikation und Verläßlichkeit nicht mehr tragbar ${ }^{109}$. Daher hatte der erste Auftritt eines DBD-Ministers auf der 7. Tagung des ZK der SED eine ambivalente Bedeutung: Die dort nur vorgetäuschte Repräsentation eines Bevölkerungsausschnitts, der über die SED-Parteimitglieder hinausreichte, stand im Vordergrund, es geschah nichts von politischer Bedeutung, das nicht der Oberkontrolle der SED unterstanden wäre. Die auftretenden Beteiligten außerhalb der SED hatten ihre Feuerprobe längst bestanden, die höhere Teilnehmerzahl bedeutete daher keinen Zugewinn an Meinungsvielfalt. So entschied die DBD, für die 8. ZK-Tagung der SED keine eigenen Vorschläge einzubringen; dies ging höchstwahrscheinlich auf die Arbeitsgruppe $\mathrm{BO}$ zurück ${ }^{110}$.

106 SAPMO DY 30 IV 2/7/11, Bl. 85-95, Thesen zu Problemen der Verbesserung der Arbeitsweise des MLF und der Lösung der Aufgaben der Landwirtschaft, wie sie sich aus dem 7. Plenum des ZK ergeben, 16. 12. 1959, Zitat Bl. 95. Vgl. die kritische, bisweilen kleinkariert argumentierende Stellungnahme der ZK, Abt. LW, SAPMO DY 30 IV 2/7/ 39, Bl. 10-14, zur Vorlage des MLF an die Landwirtschaftskommission beim PB, hier Bl. 13, verfaßt von Kiesler, 23. 1. 1960, Vorlage des MLF ebd., Bl. 16-34.

107 Letzteres legt die Gesamtinterpretation von Kaiser, Machtwechsel, S. $38 \mathrm{ff}$., $457 \mathrm{ff}$., nahe.

108 BA DE-1/27632, Stellungnahme der Leitung der Staatlichen Plankommission zum Bericht der ZKSK, 27. 1. 1960.

109 Reichelt hatte sich in der Vorbereitung der 7. ZK-Tagung als jemand präsentiert, der alles daransetzte, den Zuwachs der genossenschaftlichen Landwirtschaft voranzutreiben. SAPMO DY 30 IV 2/7/10, Bl. 372-382, Konzeption, 17. 10. 1959.

110 ACDP VI-052-0540, Protokoll Sekretariat, 8. 3. 1960. Im übrigen sah das Duo Grüneberg/Kiesler für die Vorbereitung der 8. ZK-Tagung keinerlei Beteiligung der DBD vor, siehe SAPMO DY 30 IV 2/7/14, Bl. 70, Entwurf der Thesen zur 8. Tagung des ZK, lt. Schreiben Kiesler an Grüneberg, 24. 2. 1960, zwecks Ausarbeitung der Dokumente zu 
Gerade die neuen Köpfe im Sekretariat des DBD-Parteivorstands und auf den Führungspositionen seiner Abteilungen hatten sich ebenso wie in den Bezirken seit 1959 häufig beim MfS verpflichtet ${ }^{111}$. Es erscheint naheliegend, daß sich das MfS seit dem Zeitpunkt, als offensichtlich war, daß trotz aller Anstrengungen die Zahl der LPG-Beitritte 1959 erneut stehenblieb, um mehr IM bemühte. Der 1960 auf über 70 Personen aufgeblähte DBD-Parteivorstand umfaßte ausschließlich handsortierte Personen, die von DBD- und SED-Apparaten sorgfältig auf ihre Loyalität hin überprüft worden waren. Diese Gewähr hatte das Funktionspersonal der frühen fünfziger Jahre angesichts der unterschiedlichen politischen Sozialisation, selbst wenn sie in einem sozialistisch-kommunistischen Milieu erfolgt war, und angesichts der kaderpolitischen Abstriche, die aus der Personalknappheit herrührten, noch nicht mitgebracht.

\section{Die neue Situation der DBD-Führungsebene 1960}

Reichelt übernahm es, unmittelbar nach der 7. ZK-Tagung deren Gehalt dem Sekretariat und Präsidium der DBD zu erläutern ${ }^{112}$. Eine Erklärung des Präsidiums nannte zwar ein Bündel an Aufgaben, das sich für die DBD aus dem 7. Plenum ableiten lasse ${ }^{113}$, schrieb jedoch vordringlich fest: „Die größte Reserve, um mehr und billiger $z u$ produzieren und damit die ökonomische Hauptaufgabe in der Landwirtschaft zu erfüllen, ist die sozialistische Umgestaltung. “ In Vorbereitung des VI. Parteitages gelte es daher, „durch verstärkte ideologische Überzeugungsarbeit alle noch individuell wirtschaftenden Bauern für die sozialistische Großproduktion zu gewinnen und mitzuhelfen, daß in allen landwirtschaftlichen Betrieben die Marktproduktion schnell gesteigert wird“.

Über die Brisanz der neuen Lage nach diesem Plenum war die DBD durchaus informiert; so verschob das Sekretariat sofort die „Vorbereitung der Diskussion auf dem VI. Parteitag“. Das Steuer sollte nun ganz auf die Kollektivierung ausgerichtet werden, obgleich man im Dezember noch nicht davon ausging, daß die Vollkollektivierung noch vor dem Parteitag von der SED in Gang gesetzt werde. Die neue Sicht führte dazu, daß schon am 21. Dezember 1959 kein einziger Einzelbauer für das immerhin 52köpfige Präsidium des Parteitages mehr vorgesehen war ${ }^{114}$. Vor dem offiziell proklamierten Abschluß der Kollektivierung wollte sich

8. Plenum, sei kein DBD-Mann eingeplant, wenn dann nur Genossen aus dem MLF, auch nicht Minister Reichelt.

111 Siehe etwa die Verpflichtungen von Werner Titel 15. 9. 1958, Werner Schneeweiß 17. 3. 1959 (wurde 1960 auf Kontrolle der Pressearbeit in „Bauern-Echo“ und „Pflüger“ angesetzt), Michael Koplanski 5. 5. 1959 (politischer Mitarbeiter der Abt. Organisation für besondere Aufgaben), Waltraud Mundt 30.6. 1959 (Mitarbeiterin in Abt. Agrarpolitik), Gerhard Gaude 8. 9. 1959, und die Versetzung von Stefan Zagrodnik im Februar 1960 zum Parteivorstand nach Berlin, dort führte er seine IM-Tätigkeit weiter. Soweit die ermittelten Verpflichtungen, vgl. Kap. IV.4.

112 ACDP VI-052-0540, Protokoll Sekretariat, 14. 12. 1959; ACDP VI-052-0324, Protokoll Präsidium, 17. 12. 1959.

113 Ebd., Stellungnahme Präsidium des PV zu 7. ZK-Plenum, nachfolgende Zitate ebd.

114 ACDP VI-052-0540, Protokoll Sekretariat, 21. 12. 1959. 
die DBD nur noch auf opportunes Spitzenpersonal stützen. Eine solche Marschrichtung in der Kaderpolitik für Funktionsposten erschien auch nötig, denn die soziale Zusammensetzung der Bezirkssekretariate und -vorstände belegt bis 1960, wie sehr ihre Funktionäre dort hartnäckig an ihrer einzelbäuerlichen Existenz festhielten ${ }^{115}$.

Obgleich für die SED schon vor den Rostocker Ereignissen feststand, daß die Parteiarbeit der DBD nicht mehr den Anforderungen der sozialistischen Produktionsverhältnisse in der Landwirtschaft entsprach, dynamisierte die sich abzeichnende Kollektivierung die weitere Straffung des Apparates. Das MfS und die Arbeitsgruppe BO agierten Hand in Hand. Zum einen sollten Goldenbaums Eigenmächtigkeiten im Sekretariat eingeschränkt werden, indem man striktere Regelungen für die Tätigkeit des Sekretariates traf ${ }^{116}$. Die Günstlingswirtschaft um Goldenbaum, der sogar massiv in Mißkredit geratene Personen zu halten versuchte ${ }^{117}$, beruhte auf einem Netz ausgebildeter Loyalitäten zu Schlüsselfiguren im Sekretariat. Als Anlaufstellen kamen in erster Linie Goldenbaum, Rose oder Rietz in Frage, wobei die Betonung auf "oder" liegt, denn immer wieder hatten sich getrennte Gruppierungen formiert, die im Sekretariat offen gegeneinander agierten ${ }^{118}$.

Um diese Seilschaften zu schwächen, die dem Anspruch der Arbeitsgruppe BO nach völliger Durchdringung zuwiderliefen, sollte ein Verfahren zur Relegierung wegen politisch und moralisch abweichender Verhaltensweisen durch den Umbau des Parteischiedsgerichtes entworfen werden ${ }^{119}$. Für die künftige Parteiarbeit am bedeutendsten waren jedoch die Personalveränderungen im Sekretariat der DBD im Januar 1960, die wiederum mit dem Fortgang der Kollektivierung zusammenfielen: So endete der Einfluß des Generalsekretärs Berthold Rose; er war zweifellos wegen seiner spröden persönlichen Art im Parteivorstand wenig beliebt, hatte es aber in den fünfziger Jahren als einziger verstanden, sich als eigenständiger

115 Siehe Tabelle 21.

116 ACDP VI-052-0540, Protokoll Sekretariat, 9. 11. 1959, TOP 1.

117 Einige Sympathisanten Goldenbaums dürften wegen dunkler Flecken in ihrer Biographie für eine Anwerbung interessant gewesen sein. BStU MfS AIM 3890/89, Personalakte Rothe, 6. 6. 1961 Vorschlag zur Werbung, 3. 11.1961 Verpflichtungserklärung; BStU MfS AIM 927/60, Arbeitsvorgang Böhm. SAPMO DY 30 IV 2/15/2, AG BO an Matern, 3. 8. 1959.

118 Aus der Sicht der AG BO, die sich auf MfS-Berichte stützte, sah die Konstellation im Sekretariat Mitte 1959 folgendermaßen aus: Goldenbaum und Böhm arbeiteten gegen eine Gruppe um Rose, zu der Hoffmann (Sekretär und HA-Leiter Agrarpolitik) und Rietz (Sekretär und Kaderchef) gehören würden. Körber, der Organisationsleiter, würde sich derzeit aus allem heraushalten. Goldenbaum decke Rothe, es fehle ihm an Willen, den Sozialismus voranzubringen. Rose ruhe sich aus, intrigiere gegen Goldenbaum und sei gesundheitlich geschwächt. Unter der Voraussetzung, daß Rietz eine Schule besuche, hielt man ihn für fähig, "gute“ Arbeit zu leisten. Körber sei der einzige, der die Lage in der DBD „kritischer“ einschätze, Hinweise der Genossen dankbar aufnehme und für deren Durchsetzung kämpfe. Die AG empfahl, Scholz auf dem nächsten PT ins Sekretariat zu wählen und Böhm zu entfernen. Dies und die Delegierung von Rietz auf die SED Parteihochschule 1960 belegen, wie eng die SED-Anleitung war. SAPMO DY 30 IV 2/15/2, AG BO an Matern, 3. 8. 1959.

119 ACDP VI-052-0324, Protokoll Präsidium, 17. 12. 1959, 6. 1. 1960. 
Kopf gegenüber Goldenbaum - dem er in der politischen Argumentation überlegen war -, bisweilen auch gegenüber der SED zu behaupten. Nach Absprache mit der Arbeitsgruppe BO wurde sein Rückzug als Generalsekretär auf dem VI. Parteitag, womit dieses Amt erlosch, und aus dem Sekretariat schon Mitte Januar 1960 intern beschlossen ${ }^{120}$.

Das Präsidium wählte Paul Scholz, Kurt Burkhardt und Stefan Zagrodnik am 25. Januar 1960 in das Sekretariat ${ }^{121}$. Zagrodnik gelang im Frühjahr 1960 ein rasanter Aufstieg in der DBD und in der Volkskammer, der zunächst durch seine seit 1954 erwiesene Loyalität gegenüber dem MfS, dann aber auch durch sein Vertrauensverhältnis zu Goldenbaum begründet war. Er übernahm anstelle von Georg Böhm, den man aufgrund seiner verheimlichten nationalsozialistischen Vergangenheit in das Bezirkssekretariat Berlin als Schulungsleiter abschob, die Hauptabteilung Schulung und Aufklärung; 1961 leitete er auch die wichtige Abteilung Agrarpolitik und fungierte noch stärker als maßgebliche Speerspitze des MfS und der Arbeitsgruppe BO in der DBD. Kurt Burkhardt leitete vorübergehend die Abteilung Organisation, Scholz rückte als stellvertretender Parteivorsitzender erneut ins Sekretariat ein.

Nachdem Rose entmachtet war, baute die SED in Hans Rietz ein Gegengewicht zu Goldenbaum auf und nominierte ihn im Sommer 1960 als stellvertretenden Staatsratsvorsitzenden ${ }^{122}$. Statt Rose vertrat Rietz die DBD in der Volkskammer in außenpolitischen Angelegenheiten ${ }^{123}$. Beides mußte den Parteivorsitzenden brüskieren. Vermeintlich freie Hand ließ die SED der Bauernpartei im Umgang mit jenen Funktionsträgern, denen im Laufe des Jahres braune Flecken in ihrer Vergangenheit nachgewiesen werden konnten; in der Vorbereitung des Parteitages sollte die DBD diese Personalfragen endgültig bereinigen ${ }^{124}$. Zwar „durfte“ die DBD - Grüneberg zufolge - selbst entscheiden, andererseits lenkte Materns Nomenklaturapparat längst auf das gewünschte Ergebnis hin ${ }^{125}$. Diese Vorgehensweise bewirkte, daß Funktionärskarrieren wie die Ernst Mecklenburgs, der seine SED-Treue bewiesen hatte, eben nicht über den Makel einer NSDAP-Mitgliedschaft stolperten ${ }^{126}$. Von den kleinlichen und eitlen Rivalitäten profitierte in erster

120 Im Oktober fand eine weitere Aussprache der Parteiführung mit dem ZK statt. Die SED wollte eine bessere Verbindung zwischen dem Sekretariat der DBD und dem ZK herstellen. Diese Verbindung sollte über Goldenbaum laufen. BStU MfS AIM 927/60, Arbeitsvorgang Böhm, Bl. 100 f., Bericht vom 26. 10. 1959.

121 ACDP VI-052-0324, Protokoll Präsidium, 25. 1. 1960.

122 BStU ASt Lpz. AIM 3445/92, Arbeitsvorgang Gaude, Bd. 1, Bl. 42-46, Treffen am 29. 10. 1959.

123 ACDP VI-052-0324, Protokoll Präsidium, 19. 4. 1960.

124 Ebd., Protokoll Präsidium, 25. 1. 1960. Betroffen waren davon Fritz Brix, Erich Wegner, Ewald Sieg, Georg Böhm, Bruno Curth, Werner Klütsch und Heinz Liste. Daß die DBD die Ermittlungen dazu schon im August 1959 abgeschlossen hatte, dürfte das $\mathrm{ZK}$ via MfS erfahren haben: BStU ASt Lpz. AIM 3445/92, Arbeitsvorgang Gaude, Bd. 1, Bl. 23-27, Bericht über Treffen, 13. 8. 1959.

125 BStU MfS AP 14985/92, Personalakte Rietz, Bl.66; Bericht KP „Hans“, 14. 4. 1960. ACDP VI-052-0541, Protokoll Sekretariat, 21.3. 1960.

126 BStU ASt Lpz. AIM 3445/92, Arbeitsvorgang Gaude, Bd. 1, Bl. 27-31, Bericht zu BV Rostock, 17.8.1959. 
Linie die SED; sie bot sich als helfende Hand an oder drängte sich auf, wurde als solche aber auch gesucht und konnte so ihren Einfluß sichern.

\section{Die DBD bis zum VI. Parteitag 1960}

Obwohl die DBD einen enormen Beitrag zur Herbeiführung und dann zur Verstetigung der Vollkollektivierung leistete, würdigte Ulbricht ihren Anteil daran auf dem 8. ZK-Plenum nur „halbherzig“"127. Über 17000 DBD-Mitglieder agitierten ebenso wie $15000 \mathrm{CDU}$ - und einige tausend LDP- und NDPD-Anhänger zusammen mit SED-Genossen in den gemischten Brigaden der Nationalen Front zur "sozialistischen Umgestaltung“ und strömten aufs Land. LDP und NDPD waren vergleichsweise spät von der SED darauf eingeschworen worden, diesen Auftrag als Parteilosung ernstzunehmen, obwohl beide Parteien kaum bäuerliche Mitglieder zählten ${ }^{128}$.

Das Verhältnis zwischen SED und Bauernpartei, insbesondere im Hinblick auf die veränderte Rolle letzterer in einer vollgenossenschaftlichen Landwirtschaft, wurde durch einige Schlüsselereignisse bestimmt: Am 2. März 1960 trat in Seelow der Parteivorstand der DBD, der Zentralvorstand der VdgB und die Agrarkommission des Nationalrates der Nationalen Front zusammen. Reichelt zufolge sollte die Veranstaltung die „Bandbreite der gesellschaftlichen Kräfte demonstrieren“, die „Verantwortung für die Vollendung der Umgestaltung in der Landwirtschaft trugen" ${ }^{129}$. Mit anderen Worten: All jene Organisationen und Gruppen, die sich für die Herbeiführung der Vollkollektivierung bedingungslos unter Mißachtung rechtsstaatlicher Prinzipien eingesetzt und sich dabei mitkorrumpiert hatten, sollten zur Stiftung einer Gemeinschaft der dafür Verantwortlichen aufeinander eingeschworen werden. Zwar wurde Goldenbaum als DBD-Vorsitzendem und stellvertretendem Vorsitzenden der VdgB die Ehre zuteil, das Hauptreferat bei dieser, in solcher Konstellation singulären Veranstaltung halten zu dürfen. Doch Gerhard Grüneberg, der neue starke Mann Ulbrichts in Agrarfragen, sollte der Tagung den Stempel aufdrücken. Er skizzierte nochmals die Aufgaben der Landwirtschaft im Siebenjahrplan vor dem Hintergrund der engeren Einbindung in die ehrgeizige Wirtschaftspolitik Chruschtschows: Anläßlich der agrarpolitischen Beratung der RGW-Staaten Anfang Februar in Moskau „wurde noch einmal klar herausgearbeitet, welche Aufgabe die Landwirtschaft aller sozialistischen Länder hat, nämlich, daß in kurzer Frist die landwirtschaftliche Produktion und die Steigerung der Arbeitsproduktivität so entwickelt werden müssen, daß sie den Werktätigen der sozialistischen Länder den höchsten Lebensstandard der Welt sichern. Das ist ein sehr entscheidender Beitrag für den Sieg des Sozialismus in der Deutschen Demokratischen Republik und im friedlichen Wettbewerb mit dem Kapita-

127 So Reichelt, Blockflöte, S. 185.

128 Kaiser, Zusammenarbeit, S. 638 f.; Prokop, Übergang, S. 200. Ulbricht erwähnte vage eine Zahl von über 10000 Brigademitglieder der DBD, Reichelt hält dagegen, daß nur die DBD es geschafft habe, allein 70000 Parteimitglieder zum LPG-Eintritt zu bewegen. Reichelt, Blockflöte, S. 185. Graffunder, Dialektik, S. 144.

129 Reichelt, Blockflöte, S. 175. Auch er wirft ein, daß dies reichlich spät geschah. 
lismus [...]. Die höchste Steigerung der landwirtschaftlichen Produktion und Arbeitsproduktivität sowie die Schaffung eines Überflußes an landwirtschaftlichen Produkten ist aber, liebe Freunde und Genossen, nur auf der Grundlage der sozialistischen Umgestaltung der Landwirtschaft und durch den freiwilligen Zusammenschluß der Bauern in LPG möglich. “130

Grüneberg machte in dieser Runde kein Hehl daraus - wenngleich diese Passagen nicht für die Öffentlichkeit bestimmt waren -, daß die Politik des Siebenjahrplanes zwangsläufig eine künftig niedrigere Beschäftigtenquote in der Landwirtschaft mit sich brachte ${ }^{131}$. Um so offensichtlicher hätten die Betreffenden ihre Instrumentalisierung durch die SED spüren müssen, denn sie hatte die DBD angewiesen, sich ganz den Jugendlichen und Frauen in ihrer Partei zuzuwenden, damit diese den LPG beitraten und im landwirtschaftlichen Beruf blieben ${ }^{132}$.

Gegen die euphorische ökonomische Konzeption, mit der die SED hoffte, das Problem der miserablen Arbeitsproduktivität vor allem in den überstürzt gegründeten LPG lösen zu können, hatte es sogar noch Einwände von Wissenschaftlern der DAL gegeben. Als Exponenten einer raschen Kollektivierungspolitik wiesen Karl Mewis und Bruno Leuschner diese Kritik jedoch zurück, und auch Reichelt schickte sich an, die von den Wissenschaftlern vertretenen Vorbehalte ,anhand der in der Sowjetunion gesammelten Erfahrungen" als unrichtig zu bezeichnen. So liefen auch in der DDR schon Versuche, „durch weitere Mechanisierung die Zahl der von einer Person zu betreuenden Hühner von 12 auf 15000 zu heben “ 133 .

Für das Verhältnis zwischen SED und DBD und die Rolle der DBD ist entscheidend, daß dieser Kurs hin zu einer Industrialisierung der Agrarwirtschaft gleichzeitig darauf zielte, die ideologisch-politische Tätigkeit in den LPG künftig allein der SED vorzubehalten, die DBD in ihrem politischen Handeln zu verdrängen. An der Legitimation der Bauernpartei rüttelte 1960 außerdem das offizielle Verschwinden der Einzelbauern, die ihr bisher als Klientel zugeschrieben waren und ihr Wirken wie jenes der VdgB gerechtfertigt hatten. In noch stärkerem Maße traf diese Legitimationskrise die VdgB, deren Weiterexistenz manchen als ungewiß galt ${ }^{134}$.

Erst die Folgen der Vollkollektivierung schufen einen Problemdruck, infolgedessen sich die SED notgedrungen darauf besann, der DBD wieder besondere Aufgaben zuzuweisen, die sie selbst nur schwer lösen konnte. So hatte die SED fast keinen Rückhalt in den zahlreichen LPG Typ I, die 1960 das Gros der Kollek-

130 SAPMO NY 4233/22, Bl. 1-19, Redemanuskript Grüneberg bei Tagung in Seelow am 2. 3. 1960 , Zitat Bl. 3.

131 Ebd., hier Bl. 12; die unterstrichenen Passagen sollten vermutlich nicht in seinen veröffentlichen Reden abgedruckt werden.

132 ACDP VI-052-0541, Protokoll Sekretariat, 23. 5. 1960 [schwer zu entziffern].

133 SAPMO DY 30 IV 2/7/14, Bl. 329 ff., Niederschrift der wichtigsten Diskussionspunkte der Sitzung der Redaktionskommission zum 8. Plenum des ZK der SED am 1. 4. 1960, Zitat Reichelt, Bl. 330.

134 Daher bewarb sich Herbert Eichhorn, bisher Vertreter der DBD im ZV der VdgB, um einen Sitz im PV der DBD. BStU ASt. Lpz. AIM 3445/92, Arbeitsvorgang Gaude, Bd. 1, Bl. 118-120, Treffen am 29. 6. 1960, hier Bl. 119. Berichte über Tendenzen zur „Liquidierung" der VdgB auf Kreisebene erreichten auch die ZK-Abt. LW, SAPMO DY 30 IV 2/7/ 79, Bl. 377, Sektorenleiterbesprechung, 15. 5. 1960. 
tivwirtschaften bildeten. Neben der brüchigen Legitimation litt die Position der DBD erheblich unter dem Politikstil Grünebergs. Kaum im Amt, drängte er nach Profilierung und beanspruchte für die SED nun Positionen, die vorher von Paul Scholz als staatlichem Vertreter eingenommen werden sollten ${ }^{135}$.

Auf ihrem VI. Parteitag vom 12. bis 14. Mai 1960 unterwarf sich die DBD in ihrer Tätigkeit ganz der „Führung der SED“136. Das Einwirken der Arbeitsgruppe BO auf die Vorbereitung des Parteitages durch die DBD erreichte neue Größenordnungen; dies galt auch im Hinblick auf die Ebene der Kreis- und Bezirksverbände ${ }^{137}$. So erstellte schließlich die Arbeitsgruppe BO die Grundsatzdokumente für den Parteitag; Ulbricht führte, präpariert durch Materialien des ZK, ein Vorbereitungsgespräch mit Goldenbaum und Scholz ${ }^{138}$. Bei den Besprechungen über eine neue Arbeitsordnung des DBD-Sekretariats war der Mitarbeiter der Arbeitsgruppe BO, Heinz Ackermann, anwesend ${ }^{139}$. Der Arbeitsgruppe lag daran, durch die Einführung geregelter Verfahrensweisen das Sekretariat auch in diesem Punkt völlig gleichzuschalten, das hieß, den Einfluß des bisher dominierenden Geflechts persönlicher Beziehungen einzuschränken.

Ulbrichts Mißachtung der DBD unterstreicht ein von ihm verantworteter Politbürobeschluß vom 9. Mai 1960; dieser faßte die Bedingungen für eine Mitgliederwerbung der DBD so eng, daß im Grunde alle Möglichkeiten versperrt waren ${ }^{140}$. Offenbar hielt man eine solch strikte Direktive für nötig, da Einschränkungen zur Aufnahme, die die DBD schon im Frühjahr angeordnet hatte, von den Grundeinheiten nicht befolgt worden waren. Insbesondere hatte die DBD weiterhin erfolgreich Genossenschaftsbauern angeworben, obwohl ihr dies verboten war ${ }^{141}$. Der Politbürobeschluß hatte eine existenzbedrohende Dimension, denn er verbaute der DBD Handlungsoptionen gegenüber der ohnehin schrumpfenden Mitgliederbasis, einer Basis, die infolge der Haltung der DBD zur Kollektivierung überwiegend in erdrückender Passivität verharrte.

Zusätzlich sollte sich die DBD ganz auf die Tätigkeit in den LPG Typ I beschränken, deren Fortexistenz wiederum aufgrund der forcierten Bildung von

135 So ersetzte er Paul Scholz in der Leitung eines Operativstabes zur Unterstützung und Festigung der LPG, der zunächst bei der Regierung angesiedelt sein sollte und daher Scholz als Leiter vorsah. Als die Leitung von Partei und Regierung übernommen werden sollte, setzte sich der Parteimann Grüneberg durch. Das Beispiel illustriert die zunehmende Verquickung von Partei und Staat und die Omnipräsenz der SED. Siehe dazu: BA DC-20/445, Verfügung vom 2. 4. 1960, gez. Grotewohl, sowie Korrektur vom 2. 4. 1960.

136 So auch Reichelt, Blockflöte, S. 190. Hierzu bestätigte der PT eine Änderung des Dokumentes „Charakter der DBD und Grundsätze ihrer Politik“ von 1957. Im „Bauern-Echo“ konnte man zuerst Grünebergs Redebeitrag nachlesen, bevor erst am 17.5. 1960 eine Beilage Beiträge von Paul Scholz abdruckte.

137 Siehe SAPMO DY 30 IV 2/15/53, Bericht zum Stand der PT-Vorbereitungen der DBD, 8. 2. 1960.

138 SAPMO DY 30 IV 2/15/50, AG BO an Ulbricht, 5. 5. 1960.

139 ACDP VI-052-0541, Protokoll Sekretariat, 13. 7. 1960.

140 SAPMO DY 30 J IV 2/7/702, Protokoll PB, 9. 5. 1960, Bl. 3 f., TOP 7, Informationen Ulbrichts über Besprechungen mit Vertretern der DBD. Vgl. „Bauern-Echo“, 15. 5. 1960; siehe auch Reichelt, Blockflöte, S. $191 \mathrm{f}$.

141 ACDP VI-052-0541, Protokoll Sekretariat, 14. 3. 1960. SAPMO DY 30 IV 2/15/5, Bericht Abt. LOPM über Einsatz in Leipzig, 2.-4. 6. 1960. 
LPG Typ III ebenfalls fraglich war ${ }^{142}$. Vor allem untersagte die SED der DBD, sich als Partei in den LPG zu engagieren; dort tat sich die SED selbst so überaus schwer, politisch Fuß zu fassen, und die Bauernpartei hätte folglich leicht die Oberhand gewinnen können. Die DBD-Mitglieder sollten zwar die sogenannten LPG-Aktivs stützen, dabei durften sie aber nur als Genossenschaftsbauern unter „Führung“ der SED auftreten, keinesfalls als Mitglieder der DBD.

Nachdem Ulbricht am 7. Juli eine Delegation der DBD empfangen hatte, fällte die Bauernpartei weitere Beschlüsse, die keinerlei eigenes Profil als Partei mehr erkennen ließen ${ }^{143}$. Die Einschränkung der DBD auf LPG Typ klopfte auch ein Präsidiumsbeschluß fest. Die Mitglieder sollten allerdings eine wirtschaftliche Lückenbüßerfunktion in der LPG erfüllen, um die „auftretenden Mängel in der Entwicklung der Kuh- und Schweinebestände zu überwinden“. Damit die Spitzenfunktionäre den ideologischen Anforderungen des vollgenossenschaftlichen Entwicklungsstadiums gerecht würden, verfügte die DBD-Führung, eine intensive Parteischulung durchzuführen. Sie sollte auf dem Lehrbuch „Grundlagen des Marxismus-Leninismus" beruhen. Eigens herbeigerufene Lehrer der DBD-Parteischulen unterwiesen die Führungsspitze in Berlin ${ }^{144}$. Vertreter der Blockparteien waren zwar - so wie die sowjetische Botschaft Ende 1956 nahegelegt hatte Anfang 1959 in höherem Maße in die Räte der Kreise und Bezirke aufgenommen worden ${ }^{145}$. Im Sinne der kaderpolitischen Offensive 1960 übernahm die DBD jedoch auf allen Ebenen ein Nomenklatursystem, wie es zuvor im Politbüro für sämtliche staatliche Positionen beschlossen worden war und gleichzeitig auch in der CDU eingeführt wurde ${ }^{146}$. Nicht Erweiterung und Liberalisierung verbargen sich dahinter, vielmehr strebte die SED danach, die Transmissionsfunktion der Blockparteien besser überwachen zu können. Die Hälfte der DBD-Kreisvorsitzenden waren 1964 bereits Nomenklaturkader ${ }^{147}$.

Die SED und die ihr Hörigen in der DBD-Spitze hatten mit diesem Vorgehen den Bogen an Zumutungen bis zum Zerreißen gespannt. Die SED riskierte bei konsequenter Umsetzung dieses Kurses, die DBD als politisches Instrument zu ihrem eigenen Nachteil zu demontieren. Um die von der rigorosen Kollektivierung verursachten wirtschaftlichen und politischen Probleme vor Ort aufzufangen, war es viel geschickter, der DBD einen gewissen eigenständigen, letztlich ohnehin SED-kontrollierten Handlungsspielraum einzuräumen.

142 Zwar untersagte das PB die Verwendung des Begriffs „Groß-LPG“, in der Praxis änderte sich an dieser Tendenz aber wenig. SAPMO DY $30 \mathrm{~J} \mathrm{IV} \mathrm{2/2/702,} \mathrm{Protokoll} \mathrm{PB,} \mathrm{9.} \mathrm{5.} \mathrm{1960,}$ Bl. 4.

143 Reichelt, Blockflöte, S. 221. Der Besuch erwähnt in: ACDP VI-052-0325, Protokoll Sekretariat, 7. 7. 1960.

144 ACDP VI-052-0541, Protokoll Präsidium, 11. 7. 1960.

145 Kotsch, Karrierewege, S. 175.

146 ACDP VI-052-0542, Sekretariatsvorlage als Anhang zur Richtlinie für kaderpolitische Arbeit der Partei, 14. 7. 1960. So sollte jeder Kreisvorstand je nach Größe 10-20 Personen unter Nomenklatur nehmen, jeder Bezirksverband 25-30 Nomenklaturkader, und beim PV waren für das Präsidium 45-50 haupt- und ehrenamtliche Kader vorgesehen. Zur CDU: Kotsch, Karrierewege, S. 163.

147 Reichelt, Blockflöte, S. 221. 
Die Widersetzlichkeiten bei den Mitgliedern und Funktionären an der Basis zeigten, daß eine solche Verdrängung der DBD 1960/61 weder reibungslos und schon gar nicht vollständig umzusetzen war. Der VI. Parteitag blieb den weitgehend enttäuschten, wenn nicht gar auf ihre Partei wütenden Mitgliedern eine Antwort hinsichtlich der künftigen politischen Rolle der DBD schuldig. Obwohl die Delegierten handverlesen waren und die Wahlen kontrolliert wurden, schlug sich ihr Mißmut im Abstimmungsverhalten nieder. Besonders unter den Dresdener Delegierten wurden vergleichsweise oppositionell anmutende Äußerungen laut. In Diskussionen am Rande des Parteitages kritisierten sie die Abschiebung Berthold Roses. Auf der zur Wahl gestellten Gesamtliste für den Parteivorstand strichen Delegierte aus den Bezirken Dresden, Rostock, Berlin, Suhl, Potsdam, Gera und Erfurt bestimmte Personen aus. Anläßlich eines Besuches von Scholz in Dresden beschwerte man sich darüber, daß die DBD nicht mehr selbständig, sondern nur noch im Rahmen der Nationalen Front und ganz und gar auf der sogenannten Grüneberg-Linie agiere ${ }^{148}$.

In der heiklen Frage der Mitgliederwerbung stellte die Arbeitsgruppe BO Anfang 1961 schließlich einen völlig abwegig erscheinenden Kurs der DBD-Organisationsabteilung fest. Letztere rühmte sich im Jahresbericht für 1960, der selbstverständlich auch an die SED ging, ihrer Erfolge in der Neuwerbung von Jugendlichen und Bäuerinnen ${ }^{149}$. Trotz aller Versuche, das Handeln der DBD-Leitungsebene völlig zwischen den Vorgaben und unmittelbaren Eingriffen der Arbeitsgruppe $\mathrm{BO}$ und des MfS einzuschnüren, unterstreicht dieses Umgehen des angeordneten Werbeverbotes, daß die Umsetzung des ansonsten gebilligten SEDHerrschaftszugriffs begrenzt wurde, sobald die nackte Existenz der DBD gefährdet schien.

\section{Die Kollektivierung als politischer Auftrag der DBD 1959-1961}

\section{Voraussetzungen}

Für die Durchsetzung der Vollkollektivierung im Frühjahr 1960 bedienten sich SED und DBD eines Maßnahmenbündels, das im Prinzip bereits in den vorangegangen Jahren erprobt worden war. Altbekannt war eine Kombination von finanziell und persönlich erfolgversprechenden Anreizen mit einer breiten Palette an negativ wirkenden Maßnahmen, die einzelbäuerliche Existenzen erschweren sollten. Letztere reichten von der Schaffung wirtschaftlicher Notlagen über persönliche Nötigung und Einschüchterung bis zu justitiellen Zwangsmitteln ${ }^{150}$. Neu an der ab Mitte Januar 1960 betriebenen Vollkollektivierungspolitik war die Konzen-

148 ACDP VI-052-0541, Protokolle Sekretariat, 23. und 30. 5. 1960.

149 SAPMO DY 30 IV 2/15/63, Einschätzung der organisatorischen Entwicklung unserer Partei 1960, 8. 2. 1961.

150 Siehe Tümmler, Agrarpolitik, S. 90-94, zeitgenössisch: Zwangskollektivierung, bes. S. $16 \mathrm{ff}$., Horz, Kollektivierung, S. 295. 
trierung auf den sofortigen Beitritt aller Einzelbauern und die propagandistische Vehemenz, mit der Funktionäre und Mitglieder aller Parteien in Stadt und Land für dieses Vorhaben mobilisiert werden sollten ${ }^{151}$.

Die Lenkung des Vorgehens in den Regionen übernahmen die SED-Bezirksleitungen, die ihrerseits die Verantwortlichen in den Kreisen anleiteten ${ }^{152}$. Für die Durchsetzung war es entscheidend, daß die Kollektivierung zu einer Sache des Staates und seiner Apparate deklariert wurde; der Staatsapparat wurde zum „Instrument einer ,permanenten Revolution von oben', in deren Verlauf die SED zwangsläufig zu einer ständigen Konfliktstrategie mit der Gesellschaft gezwungen wurde“ 153 . Die Innenbehörden überwachten die Vorgänge und bedienten sich staatlicher Sanktions- und Kontrollinstrumente wie Justiz und Volkspolizei. Vor allem die Abschnittsbevollmächtigten der Volkspolizei, deren Tätigkeit seit 1958 systematisiert worden war, informierten die auswärtigen Agitationstrupps eingehend ${ }^{154}$. Dies trug erheblich dazu bei, den Abschluß schnell herbeizuführen ${ }^{155}$.

Ein weiteres Spezifikum der Kollektivierung 1960 liegt darin, daß die SED aus den Fehlschlägen von 1952/53 gelernt hatte. Im Unterschied zu damals war der Vormarsch des Sozialismus nun eindeutig auf die Landwirtschaft beschränkt, also auf ein vergleichsweise kleines Bevölkerungssegment ${ }^{156}$. Er zielte nicht zugleich auf den gewerblichen Mittelstand, wenngleich auch die Produktionsgenossenschaften des Handwerkes zunahmen, und sah keine für die Arbeiterschaft negativen Auswirkungen wie 1952/53 vor. Darauf achtete man bei der Umsetzung in den Kreisen besonders und verhinderte damit einen Protest der gesamten Bevölkerung. Zwar hielt Ulbricht anläßlich einer vertraulichen Besprechung mit den Vorsitzenden der Blockparteien die bei diesen wie in der SED durchaus vorhande-

151 Kaiser, Zusammenarbeit, S. 635 ff.; dies., Politik, S. 103 ff; dies. u.a., Blockpolitik, S. $1066 \mathrm{ff}$; Graffunder, Dialektik, S. $143 \mathrm{ff}$.

152 SAPMO DY 30 IV 2/13/369, Informationsberichte der Vorsitzenden der RdB über die „Entwicklung und Festigung der sozialistischen Landwirtschaft", Bericht Nr. 11 aus Bezirk Suhl, Febr./März 1960. Zur Übermittlung an die Kreise: SStAD BPA SED BL Dresden IV/2/7/064, B1. 47-56, Niederschrift über die am 20.1.1960 stattgefundene Beratung mit den persönlichen Mitarbeitern für Landwirtschaft der KL.

153 Werkentin, Strafjustiz, S. 112.

154 Siehe dazu die in der Abt. Staat und Recht überlieferten Aktenbestände, etwa die Berichte des Operativstabes der HV der deutschen Volkspolizei über die sozialistische Umgestaltung der Landwirtschaft 1960, SAPMO DY 30 IV 2/13/367. Vgl. Lindenberger, Police Populaire, S. 151 f.; ders., ABV, S. 185.

155 Insofern haften manchen, obgleich vorsichtig formulierten Vorbehalten gegen den Begriff „Kollektivierung“, der den „Prozeß der Genossenschaftsbildung als obrigkeitsstaatlich "dominiert" fasse, apologetische Züge an. So bei Kuntsche, Umgestaltung, Zitat S. 205; polemisch Reichelt, Blockflöte, S. 180-186.

156 Vgl. Krolikowski in einer Diskussion im RdB Dresden: „Ihr wißt, daß die Partei entschieden dagegen ist, daß man ein beschleunigtes Tempo für die sozialistische Umgestaltung der Mittelschichten herstellt." SStAD BPA SED BL Dresden IV/2/7/065, Bl. 65 ff., Protokoll über Beratung mit Vorsitzenden der RdK am 28. 5. 1960, Zitat Bl. 78. Dagegen betonen die Parallelität des Vorgehens gegen die Mittelschichten: Weber, Geschichte, S. 317, Schroeder, SED-Staat, S. $145 \mathrm{f}$.: 
nen Tendenzen, auch in anderen Bereichen auf eine forcierte Sozialisierung zu drängen, für begrüßenswert, ihre Umsetzung aber für nicht sinnvoll 157 .

Die SED wußte, daß der Zustand ihrer Partei in den Dörfern die Kollektivierung behinderte. Insgesamt verfüge man auf dem Lande noch kaum über eine „Partei Neuen Typs“, monierte die SED-Bezirksleitung Dresden im Mai 1960, die kein Ausnahmefall war. Die Parteiorganisation war zwischen LPG und Ortsgruppen aufgesplittert. Auch in den SED-Ortsgruppen begegnete man häufig „zwei Linien" in der Agrarpolitik, die Genossenschaftsbauern von Einzelbauern trennten, und die die gleiche Konfliktsituation markierten, welche auch DBD-Grundeinheiten spaltete. Ein Kritikpunkt an der SED-Organisation berührte zugleich die Belange der DBD. Die ZK-Abteilung stellte im Oktober 1959 fest, daß ,von einer großen Anzahl von Parteiorganisationen der Dörfer die führende Rolle der Partei noch ungenügend verwirklicht wird"158. Angesichts dieser Einschätzung war die Kollektivierung für die nicht schlagkräftig genug arbeitenden SED-Parteiorgane im Dorf eine anspruchsvolle Herausforderung; es ging auch darum, die eigene Partei zu „erziehen“, indem man ihr aufbürdete, gegenüber der oft an bäuerlichen Mitgliedern größeren DBD-Ortsgruppe auf der "führenden Rolle“ zu beharren.

Viel weniger als die SED war die DBD eine "Partei Neuen Typs“ in den Dörfern. Dies war schon an ihrer Mitgliederstruktur abzulesen, die die Verhältnisse auf dem Land widerspiegelte: Ende 1958 wirtschafteten gut $60 \%$ ihrer bäuerlichen Mitglieder selbständig, knapp $40 \%$ in Genossenschaften ${ }^{159}$. Aufgrund dieser Struktur war die DBD viel mehr als die SED gezwungen, der unzureichenden ideologischen Durchdringung der Mitgliedschaft im Sinne eines Agrarmarxismus durch einen politischen Aktionismus zu begegnen; die Zahl der Protagonisten dieses Aktionismus war vergleichsweise gering. Die DBD versuchte, aus der Not eine Tugend zu machen, aus dem Defizit an Genossenschaftsbauern insofern politisches Kapital zu schlagen, indem sie Zustand und Sozialstruktur der Partei als Ausgangspunkt für die Kollektivierung berücksichtigte. Immerhin zeichnete die DBD aus, daß ihre Mitglieder seit 1952 eine Debatte um die LPG führten, darin eingeübter waren als die Basis jeder anderen Partei.

Wie sehr die Vermittlung ideologischer Inhalte im Parteidiskurs vernachlässigt worden war, und welcher Handlungsbedarf sich aus einem neuen politischen Auftrag für die DBD ableitete, brachte Minister Reichelt Mitte August 1959 im Präsidium der DBD zur Sprache: „Eine ganze Reihe Einzelbauern bringen jetzt in der Aussprache, die in den letzten Tagen verstärkt worden ist, solche Argumente, daß das Jahr 1959 das Jahr der Genossenschaften ist, wobei sie darunter verstehen, daß dieses Jahr so günstige klimatische Bedingungen hatte, daß die Genossenschaften höhere Erträge erreichen müssen als sie, daß sie unkrautfreie Felder haben, daß sie

157 Kaiser, Machtwechsel, S. 59.

158 So wurde die Lage in der Peripherie wie auch im ZK eingeschätzt. SStAD BPA SED BL Dresden IV/2/7/065, Bl. $8 \mathrm{f}$., Vorsitzender des RdB Dresden an MdI, z. Hd. Jendretzki, 10. 5. 1960. SAPMO DY 30 IV 2/7/10, Materialien für Mückenberger, Oktober 1959, Bl. 45-48 (Zitat).

159 Siehe Tabelle 19. 
also gut abschneiden müssen. Alle diese Dinge zeigen, daß die Einbeziehung vor allem der Einzelbauern in die genossenschaftliche Umgestaltung weit zurück ist und völlig ungenügend entwickelt war in den letzten Wochen. "160 Diese Ausführungen verdeutlichen, wie sehr die lebensweltliche und traditionale Prägung die Vermittlung des politisch radikalisierten Diskurses begrenzte. Die offizielle Lesart der Parteisprache, in der die Parole „Jahr der Genossenschaften“ bedeutete, den Bauern in großer Zahl den LPG-Eintritt nahezubringen, war bei den Mitgliedern kaum bekannt ${ }^{161}$.

Reichelt warnte davor, daß sich viele kleinere Betriebe inzwischen zu mittelbzw. "großbäuerlichen“ entwickelt hätten. Jenseits übertriebener Verdächtigungen gab es dafür nachvollziehbare Anhaltspunkte, etwa den steigenden Maschinenbesatz dieser Betriebe ${ }^{162}$. Einzelbauern würden sich systematisch in Maschinengemeinschaften zusammenschließen und Maschinen von jenen aufkaufen, die LPG beitraten. Daraus würden erneut die bekannten Forderungen von 1956/57 herrühren, schweres Gerät an Einzelbauern zu verkaufen sowie Beschäftigungsverhältnisse auf den Höfen zuzulassen. Schließlich hätten im ersten Halbjahr 1959 weit über hundert Strafprozesse gegen Mitarbeiter der Bäuerlichen Handelsgenossenschaften stattgefunden, „die also Düngemittel entgegen den gesetzlichen Bestimmungen, die ja bekanntlich sehr scharf sind, an starke Mittelbauern und Großbauern verkauft haben"163.

Es war für die DBD ungleich schwieriger, die enttäuschten und in Passivität verharrenden Mitglieder wieder mit politischen Gesprächen zu erreichen, als wirtschaftliche Hilfe für LPG zu organisieren, wovon ja auch die DBD-Genossenschaftsbauern profitierten. Der überwiegende Teil der bäuerlichen Mitglieder der DBD war Mitte 1959 inaktiv; die Mitglieder versuchten selbst, die betriebswirtschaftliche Lage ihrer Höfe zu verbessern. Die Einbindung in die Parteiarbeit sollte angekurbelt werden, indem wieder stärker darauf geachtet wurde, erfolgreiche und im Dorf anerkannte Einzelbauern für die Orts- und Kreisvorstände zu gewinnen ${ }^{164}$. Gleichzeitig sollte bei den Funktionären ein ängstliches „Zurückweichen" vor dem Parteiauftrag abgestellt werden, das etwa darin bestand, einzelbäuerliche Mitglieder mit politischer Agitation zu verschonen und sie ungestört wirtschaften zu lassen. Weiterhin blieb es Aufgabe der DBD, durch ihre Präsenz und Arbeit vor Ort den bislang erreichten Stand gesellschaftlicher Umwälzung zu verstetigen ${ }^{165}$. Die DBD sollte jene Defizite und Friktionen abdämpfen, die in-

160 ACDP VI-052-0323, Protokoll Präsidium, 18. 8. 1959, eigene Hervorhebung.

161 Zur Bedeutung von Sprache, ihrer kontext-lebensweltlich bezogenen Verwendung, wie hier am Beispiel des unterschiedlichen Verständnisses aufgezeigt, und den SinnerschlieBungsverfahren in der Analyse politischer Bewegungen siehe Childers, Sociology, S. $386 \mathrm{f}$.

162 SAPMO DY 30 IV 2/7/10, Materialien zur Vorbereitung der 7. ZK-Tagung, Bl. $402 \mathrm{f}$.

163 Dabei gab Reichelt indirekt zu, daß sich die BHG damit noch im legalen Bereich bewegt hatten; ACDP VI-052-0323, Protokoll Präsidium, 18. 8. 1959.

164 Vgl. die Diskussionen um die Zusammensetzung der Vorstände in Vorbereitung des VI. PT und die erlassenen Wahlordnungen 1959, ACDP VI-052-0539, Protokoll Sekretariat, 19. 10.1959.

165 Vgl. ACDP VI-052-0323, Protokoll Präsidium, 18. 8. 1959, auch zum folgenden. 
folge der rigoros vorangetriebenen Kollektivierung seit 1958 entstanden waren. Das Ministerium fungierte dabei als Anlaufstelle für Beschwerden der Bevölkerung. Von Mitte 1958 bis Mitte 1959 gingen dort allein 9000 Anfragen bezüglich Austritten und Ausschlüssen von Genossenschaftsbauern ein. Dieser Beratungsbedarf unterstreicht zugleich die Bedeutung, die juristisch klar geregelten Bestimmungen zur Kollektivierung zukamen. Für die DBD hatte Paul Scholz an den juristischen Ausarbeitungen maßgeblich mitgewirkt. Der Problemgehalt der Anfragen dürfte zweifellos in die Ausgestaltung des LPG-Gesetzes von Juni 1959 eingeflossen $\operatorname{sein}^{166}$.

\section{Der politische Auftrag an die $D B D$}

Die spezifischen politischen Aufgaben, die vor allem die Arbeitsgruppe BO der DBD zuwies, lassen sich chronologisch von Mitte 1959 über die Vollkollektivierung 1960 hinaus bis zur tieferen politischen und sozialen Durchdringung der Lebensverhältnisse in den LPG und Dörfern um 1963 grob in vier Punkte gliedern:

Erstens sollte die DBD ihre bislang noch einzelbäuerlichen Mitglieder zum LPG-Beitritt bewegen. Zu diesem Zweck bemühte sie sich, ihre seit dem Bekenntnis zum Sozialismus in der Landwirtschaft 1957 durch Austritte und Westfluchten geschrumpfte Mitgliederbasis durch die Neuaufnahme parteiloser Einzelbauern zu stabilisieren. 1958 verzeichnete sie rund 5000, 1959 gut 5500 Aufnahmen, unter denen aufgrund der geltenden Aufnahmebeschränkungen überwiegend Einzelbauern gewesen sein müssen ${ }^{167}$. Politische Schulung und Einbindung in das Parteileben sollten die neuen Mitglieder auf lange Sicht den LPG zuführen.

Zweitens wurde der DBD mit dem nominellen Erreichen des vollgenossenschaftlichen Zustandes im April 1960 verboten, unter den Genossenschaftsbauern, auch den parteilosen, zu werben. Zwar waren die LPG-Bauern im Prinzip schon vorher für die DBD tabu gewesen; doch sowohl aus Gründen der Zweckmäßigkeit - was tun, wenn jemand partout in die DBD und nicht in die SED wollte - als auch aufgrund mangelnder Einhaltung in den Bezirken hatte sich ein Modus flexibler Ausnahmeregelungen eingebürgert ${ }^{168}$. Wegen ihrer eklatanten Unterrepräsentation vor allem in den neugebildeten LPG des Typs I war die SED darum bemüht, dort die Konkurrenz der DBD auszuschalten oder zumindest zu beschneiden. Während sie beschloß, bis 196555000 LPG-Mitglieder aufzunehmen $^{169}$, verbot man der DBD, unter Jugendlichen und unter der zukünftigen Elite heranwachsender Hoch- und Fachschulkader zu werben. Als neue alte Aufgabe dies hatte die DBD schon in der ersten Jahreshälfte 1959 betrieben und war dafür kritisiert worden - sollte sie sich wieder um die dringend gebotene organisatori-

166 Vgl. GBl. DDR I 1959, Nr. 26, 27 und 36. Das Gesetz war vom Ministerrat am 9. 4. 1959 beschlossen worden.

167 Zahlen siehe Tabelle 5.

168 Für Dezember 1959 ist eine hohe Quote an Genossenschaftsbauern unter den Neuaufnahmen belegt (insgesamt 30,3\% GB, 48,2\% EB), in manchen Bezirken lag sie noch höher, so in Magdeburg (54,7\% GB, 38,1\% EB) und Schwerin (49\% GB, 30,2\% EB); ACDP VI-052-185/3, Einschätzung der org. Entwicklung Dezember 1959, 22. 2. 1960.

${ }^{169}$ Matschke, Entwicklung, S. 33. 
sche und wirtschaftliche Stabilisierung der LPG kümmern und die Pflicht zur Planerfüllung einhämmern.

Da weder alle DBD-Mitglieder noch alle sonstigen Einzelbauern in LPG eingetreten waren, blieb ihr nach wie vor als Aufgabe erhalten, diese zum Eintritt zu bewegen. Im April 1960 gab es immerhin noch 30000 Einzelbauern ${ }^{170}$. Die DBD zählte im September 1960 rund tausend einzeln wirtschaftende Bauern und Gärtner in ihren Reihen. Die Verdrängung aus den inneren Angelegenheiten der LPG und die Einschränkung der Werbungsoptionen bewirkte eine Bündelung der Kräfte auf die besonders schwer zu bewegende Gruppe der letzten verbliebenen Einzelbauern. In der Logik der SED kam zur Einbindung dieser a priori Verdächtigen ohnehin nur noch die DBD und nicht mehr die SED in Frage. Wieviele von den im April 1960 vorhandenen Einzelbauern keiner Partei angehörten, ist unbekannt; da sich alle Blockparteien an der Kollektivierung beteiligten und zuerst unter ihren Mitgliedern agitierten, dürften sie großteils parteilos gewesen sein.

Der VI. Parteitag nährte die vage Hoffnung auf eine angemessene Tätigkeit der Bauernpartei in den LPG, insofern man ihr einräumte, in den LPG-Aktivs mitzuarbeiten; außerdem mißverstand die DBD-Organisationsabteilung eine Äußerung Grünebergs dahingehend, daß sie - eine entsprechende Abstimmung mit der SED vor Ort vorausgesetzt - weiterhin parteilose Genossenschaftsbauern anwerben dürfe. Die Arbeitsgruppe BO registrierte diese Fehldeutung, wie erwähnt, erst im Februar 1961 und suchte sie dann auszuschalten.

Ein dritter, zentraler Wirkungsbereich der Jahre 1960 bis 1963 umfaßte die Überführung der bislang vornehmlich als abgeschlossen deklarierten Vollkollektivierung in die wirtschaftliche und soziale Praxis in den LPG und Dörfern ${ }^{171}$. Diese Aufgabe wurde um so wichtiger, je mehr sich zeigte, in welch desolatem $\mathrm{Zu}$ stand die aus dem Boden gestampften Kollektivwirtschaften waren. Vor allem nach dem Abzug der meisten Brigaden im Frühsommer 1960 lösten sich viele LPG wieder auf, andere waren latent davon gefährdet ${ }^{172}$. Da die DBD in den Dörfern verankert war, fungierte sie als Hoffnungsträger für die dauerhafte Konsolidierung der LPG und hatte dafür erhebliche Startvorteile gegenüber der SED, zumal diese in rund 10000 LPG Ende 1960 noch über keine Parteiorganisationen verfügte ${ }^{173}$.

Schließlich lag ein wesentliches Element des Sozialismus auf dem Land darin, die traditionelle kulturelle Prägung mit neuen Weltdeutungen sozialistischer Machart zu überformen. Die vormaligen Einzelbauern sollten von ihrer individu-

170 Staritz, Geschichte, S. 190.

171 So auch verbrämt in der DDR-Historiographie nachzulesen; danach erreichten die Genossenschaftsbauern erst 1964 den Zustand einer „Klasse“, Graffunder, Dialektik, S. 151 f.; Prokop, Übergang, S. $219 \mathrm{ff}$.

172 SAPMO DY 30 IV 2/5/192, Bl. 113 f., Bericht LOPM, 2. 7. 1960, über „Auflösungserscheinungen " in LPG Typ I in Neubrandenburg; SAPMO DY 30 IV $2 / 7 / 367$, Bericht Nr. 19/60 vom 22.7. 1960 zu Lage im Bezirk Dresden; „Festigungsbrigaden“ fehlten auch im Bezirk Schwerin, ACDP VI, unverz. Best. LV Mecklenburg/BV Schwerin, Aktendeckel BV Schwerin, Abt. Agrarpolitik 1952ff., Bericht zu Agrarpolitik, II. Quartal 1960.

173 BStU MfS 102109, Orientierung über die Lage in der Landwirtschaft, 3. 3. 1961. 
ellen Wirtschaftsweise abgebracht und dazu animiert werden, die Arbeitsprinzipien der LPG einzuhalten, wie sie die Statuten festlegten, d.h. ihre Flächen tatsächlich zusammenzulegen und gemeinsam zu bebauen. Sie sollten die innergenossenschaftliche Arbeitsorganisation akzeptieren, etwa das Brigadewesen oder eine Entlohnung nach vorgegebenem Leistungsprinzip ${ }^{174}$. Diese Umwälzung des agrarischen Arbeitsalltags bedeutete eine einschneidende Veränderung der gesamten Lebenspraxis. Um die LPG zu konsolidieren, aber auch um deren Akzeptanz in der dörflichen Gemeinschaft zu steigern, sollte sich die DBD besonders auf die Bäuerinnen konzentrieren. Denn ein Großteil der Ehefrauen vormaliger Einzelbauern war den LPG nicht beigetreten und kümmerte sich häufig weiterhin um die einträgliche individuelle Viehhaltung des einstigen Betriebes ${ }^{175}$. Unter dieser Praxis litten vor allem die LPG des Typs III, deren Viehbesatz völlig unzureichend war ${ }^{176}$.

Eine vierte Transmissionsaufgabe betraf das gesamte, nun „sozialistische Dorf“. Die DBD sollte an der Verwandlung des traditional geprägten ländlichen Lebensraumes der Dörfer in Richtung "sozialistischer Lebensverhältnisse“ mitwirken. Die bis 1960 viel gepriesene, aber im Grunde nicht vollzogene Angleichung der ländlichen Lebensumstände an die städtisch-industrialisierten sollte vorangebracht werden. Daraus leitete sich der neuerlich formulierte Auftrag ab, eine sozialistische Kultur in den Dörfern zu verankern und zu pflegen; daher richtete die DBD eine „Kommission zur Unterstützung der kulturellen Massenarbeit und des Sportes" beim Parteivorstand ein 177.1960 war die Kulturarbeit noch ein Stiefkind der Parteitätigkeit. Erst Ende 1963 begann man, auf diesem Feld zu agieren ${ }^{178}$.

\section{Methoden}

Seit Anfang 1959 unterstützte ein Teil der Funktionäre aus der zweiten Führungsreihe der DBD den Aufbau des Sozialismus durch demonstrative körperliche Arbeit in den LPG ${ }^{179}$. Überzeugen durch Handeln in solchen Hilfsaktionen kam in der ländlichen Klientel besser an als blasse Richtlinien ${ }^{180}$.

174 Lt. Matschke, Entwicklung, S. 4, waren im August 1960 erst die Hälfte (53\%) der LPG Typ I zur Brigadearbeit übergegangen. Selbst diese Zahl erscheint zu hoch gegriffen. Vgl. BA DE-1/1254, B1. 2-13, Information über Probleme in der LW, 30. 9. 1960.

175 Zum 31. 12. 1959 waren 588000 Frauen LPG-Mitglieder, in LPG ständig beschäftigt oder in der privaten LW tätig. Zum 31. 5. 1960 ging diese Zahl weiblicher ständig beschäftigter Arbeitskräfte in der LW um 163000 zurück: ebd., hier Bl. 6f. Andererseits traten bei Nebenerwerbsbetrieben häufig nur die Frauen ein; vgl. Humm, Weg, S. 138.

176 Vgl. Matschke, Entwicklung, S. $13 \mathrm{ff}$.

177 ACDP VI-052-0325, Protokoll Präsidium, 8. 8. 1960; ACDP VI-052-0186, Protokoll PV, 30. 8. 1963, Vorschläge für die Kulturkommission des PV.

178 Vgl. Sturm, DBD, S. 9 f. Siehe Material der Abt. Schulung und Werbung vom 1. 12. 1963 über die Beratung der Kulturkommission des PV am 21.11. 1963 in Dresden, ACDP VI052-103/1.

179 ACDP VI-052-0323, Protokoll Präsidium, 10. 2. 1959.

180 Wie etwa im Fall des handfest zupackenden Hans Schnitzler belegt ist; BStU MfS AP 6122/63, Schnitzler, Bl. 18, Einschätzung, 18. 8. 1958, Bl. 44, Bericht seines Fahrers, 5. 11. 1958. 
Die Grundeinheiten waren mit der Umsetzung des 1957 übernommenen Sozialismuskurses in der Landwirtschaft in aller Regel überfordert. Eine Brigade des Parteivorstandes, die sich aus geschulten Funktionären zusammensetzte, analysierte mit dem Blick des Außenbetrachters die Lage meist treffender. Sie informierte sich im Dorf auch bei SED-Stellen und konnte oft gegenseitigen Schuldvorwürfen, warum noch keine LPG bestehe, auf den Grund gehen. Frei von persönlichen Verflechtungen im Ort sollten die Instrukteure die wirtschaftliche Ausgangsbasis prüfen und paßgerechte Entscheidungen treffen. Sie versuchten in Gesprächen, lokale Auseinandersetzungen zwischen SED und DBD zu bereinigen. Gerade Konfliktkonstellationen im Mikrokosmos von traditioneller dörflicher Führung, alteingesessenen unterbäuerlichen Schichten, Neubauern und der neuen Gruppe aufsteigender landwirtschaftlicher Fachkräfte in abhängigen Lohnverhältnissen - in MTS, VdgB und VEG -, durchmischt mit unterschiedlichen politischen Loyalitäten, trugen erheblich dazu bei, daß die Kollektivierung nicht vorankam. Allein die Ermittlung und die Analyse dieses Geflechts war häufig der erste Schritt, um Beharrungskräfte aufzubrechen ${ }^{181}$.

Der DBD eröffnete sich im lokalen Rahmen die Möglichkeit, in der ländlichen Gesellschaft politisch zu agieren. Obwohl sie insgesamt den genossenschaftlichen Teil der Landwirtschaft klar bevorzugte, hatte sie jahrelang ebenso versucht, die einzelbäuerliche Klientel zum Nutzen der instabilen LPG unter dem Signum der "guten kameradschaftlichen Zusammenarbeit" zwischen Einzelbauern und Genossenschaftsbauern einzubinden ${ }^{182}$. Zogen SED- und DBD-Mitglieder an einem Strang, der in Richtung LPG wies, bestanden gute Voraussetzungen dafür, die Kollektivwirtschaft langfristig und vor allem stabil zu installieren.

Zur Mobilisierung und letztlich politischen Indoktrination der Mitglieder entsandte die Parteizentrale einzelne Instrukteure oder mehrere in Form einer „Brigade“; aber auch die Bezirks- und Kreisverbände verfügten über Instrukteure. Die Instrukteurbrigade des Parteivorstandes wurde während der Hochphase der Kollektivierung in jene "Krisengebiete“ geschickt, die z.B. wegen des Zustandes der Parteiorganisation oder aufgrund einer niedrigen Kollektivierungsrate aufgefallen waren. Die Instrukteure arbeiteten besonders in jenen Gegenden, die anläßlich eines herausragenden Parteiereignisses, wie etwa des VI. Parteitages "vorbereitet" werden sollten; darunter verstand man auch, auf eine angemessene Zahl von LPG hinzuwirken. Der Einsatz von Instrukteuren als schnelle Eingreiftruppe hatte eine immense Bedeutung, um die eigenen Mitglieder zu aktivieren und zugleich politisch zu disziplinieren. Dazu wurden orts- und kreisansässige Kollegen in die Agitationsgruppe eingegliedert. Fachliche Beratung wurde vor Ort durchaus

181 Weitere Regionaluntersuchungen sind nötig, um das Mischungsverhältnis unterschiedlich motivierter Konflikte genauer zu bestimmen. Für den Bezirk Cottbus vgl. Langenhan, „Halte Dich fern von den Kommunisten“, S. $144 \mathrm{ff}$.

182 So offiziell seit Ende 1954, vgl. ACDP VI-052-0528, Protokoll Arbeitssekretariat, 15. 12. 1954, Entwurf Wahlordnung der DBD für die Neuwahl der OG-Vorstände im Jahre 1955, 16. 12. 1954. 
angenommen und war oft ein Vehikel, um Gesprächsbereitschaft für politische Themen zu erzeugen ${ }^{183}$.

Die Einsätze der Instrukteurbrigaden verfolgten unterschiedliche Ziele. So arbeitete beispielsweise im Mai/Juni 1959 eine nur zweiköpfige „Brigade“ im Kreisverband Greifswald mit dem Ziel, die „Leitungstätigkeit“ des Sekretariats zu verbessern und die „Mitglieder der Partei, vor allem auch die einzelbäuerlichen Kollegen für die aktive Mitarbeit im Sinne der Parteibeschlüsse zu gewinnen"184. Die Instrukteure stellten fest, daß es zwar "nur wenige Einzelbauern“ gebe, „die heute noch sagen, wir werden nie in die LPG gehen“, den Zeitpunkt des Eintrittes verschob die Masse jedoch in eine ferne Zukunft. Es war eine bäuerliche Strategie, sich die Agitation mit der Bekundung grundsätzlichen Einverständnisses, dem keine handfesten Zusagen oder Handlungen folgten, vom Leib zu halten. Die Brigade forschte auch nach den Gründen, weshalb die Einzelbauern die LPG ablehnten, und förderte zu Tage, daß es im letzten Jahr zu „Überspitzungen“ gekommen sei, die MTS den Einzelbauern jede Dienstleistung verweigert hatte oder die LPG in Kölzin durch einen Zaun den Einzelbauern die Zufahrt auf ihre Äcker versperrte. Die Instrukteure scheiterten kläglich daran, Parteimitglieder zu werben, weil alle Angesprochenen entgegneten, sie wollten Einzelbauern bleiben, woraufhin von "unserer Seite aus immer gesagt [wurde], wie unsere Partei zu dieser Frage steht", also daß sie eindeutig für den Sozialismus in der Landwirtschaft eintrete. Desillusioniert mußten sie auch eingestehen: „Es gab keine Vorstellungen [,] mit Hilfe des Wettbewerbs eine breite Diskussion in den politisch-ideologischen Fragen zu entfalten und somit viele unklare Fragen unter den Mitgliedern richtig zu stellen."

Ein halbes Jahr später wollte auch ein Brigadeeinsatz in Frankfurt/Oder die Sozialisierung voranbringen. $Z$ war konnte in diesem Bezirk bereits ein vergleichsweise hoher Stand in der Kollektivierung erreicht werden; 48,7\% der LNF zählte im September 1959 schon der sozialistische Sektor, der, grob gesagt, VEG und LPG umfaßte. Dennoch war spätestens seit September ein Nachlassen des DBD-Engagements in der Bildung von LPG zu verzeichnen, im Oktober wurde sogar keine einzige LPG mit Hilfe der Bauernpartei gegründet; nur 13 Mitglieder traten in diesem Monat dort einer LPG bei, angesichts von 866 Beitritten in allen Bezirksverbänden im Oktober eine beschämende Bilanz. Um den Gründen dieser Lethargie nachzuspüren, entsandte das Sekretariat noch im Oktober eine Brigade in den Bezirk Frankfurt/Oder ${ }^{185}$. Laut IM-Bericht lagen die „Ursachen" bei eini-

183 Zum Thema „Agitationsbrigaden“ vgl. Reichelt, Blockflöte, S. 176-180. Er weist darauf hin, daß die Tätigkeitsmerkmale der Brigaden nicht nur unter dem Schlagwort Zwang zu fassen sind. Bislang fehlt eine eingehende Analyse des Brigadeprinzips in dieser Variante. Abwegig ist Reichelts Interpretation, wonach "Zwang" nur dort geherrscht habe, wo man fachliche Beratung vernachlässigte, ebd., S. 179.

184 ACDP VI-052-0539, Vorlage an Sekretariat des PV, 23. 5. 1959: Aufgabenstellung für die Instrukteureinsätze zur Vorbereitung der 11. PV-Sitzung; Bericht über Instrukteureinsatz im KV Greifswald vom 27. 5.-19.6. 1959, auch zum folgenden.

185 Zahlen lt. Übersicht Entwicklung LPG im Monat Oktober, Anlage zu Sekretariatsprotokoll 16. 11. 1959, ACDP VI-052-0539; Plan zu Brigadeeinsatz am 19. 10. 1959 im Sekretariat beschlossen, ebd. 
gen Funktionären des Bezirkssekretariats, genannt wurden der Bezirksvorsitzende Arthur Pech und der Organisationsleiter Hans Dorn ${ }^{186}$, bei denen es „politische Unklarheiten" gebe ${ }^{187}$. Dahinter verbarg sich in diesem Fall, daß sie den Vorständen und Mitgliedern nicht die Kraft zutrauten, auf einen LPG-Eintritt hinwirken zu können und sie sich daher ihrerseits gar nicht erst um deren Mobilisierung bemühten. Außerdem beschränkte der Bezirksvorsitzende Pech die Beziehung zur SED darauf, zu einigen wenigen Personen im persönlichen Kontakt zu stehen. Unter näherer Zusammenarbeit im Rahmen des „Bündnisses“ zur SED verstanden die Instrukteure allerdings etwas anderes. Zudem sei im Bezirkssekretariat außer einer Buchhalterin kein Personal mit bäuerlichem Hintergrund beschäftigt. Diese Personalstruktur verschaffte der DBD also wenig Rückhalt bei den bäuerlichen Mitgliedern. Von Elan zur Kollektivierung war der DBD-Bezirksverband Frankfurt/Oder in der zweiten Jahreshälfte 1959 also weit entfernt.

Zur Instruierung südlicher Kreisverbände, die im Kollektivierungserfolg bekanntlich den nördlichen Bezirken hinterherhinkten, verfügte das Sekretariat im November 1959, Instrukteureinsätze in Ilmenau, Cottbus, Zerbst und Glauchau durchzuführen ${ }^{188}$. Die Instrukteurberichte der DBD von 1959 deuten insgesamt darauf hin, daß die Kreisverbände der DBD, die früh „vollgenossenschaftlich“ waren, in denen also alle bäuerlichen DBD-Mitglieder der LPG beigetreten waren, diesen Zustand nicht infolge solch gezielter Parteieinsätze erreicht hatten. Vielmehr war dieses Ergebnis nur dann - auch durch einen Brigadeeinsatz - zu erlangen, wenn schon ein längerfristiger Trend zum LPG-Eintritt die Gegend prägte. Eine jahrelange, etwa durch die Existenz einer LPG angestoßene Debatte um die Kollektivierung im Dorf oder im Kreis erhöhte die Chancen, die kurzfristige Vollkollektivierung herbeizuführen. Ende November 1959 war der Kreisverband Quedlinburg der DBD „vollgenossenschaftlich“, Anfang Dezember folgten Nebra und Querfurt ${ }^{189}$.

Nachdem die Würfel zur Vollkollektivierung gefallen waren, beschloß das Sekretariat, den zur Vorbereitung des Parteitages im Februar eigentlich befristet geplanten Instrukteureinsatz im Kreis Güstrow weiterzuführen und die beteiligten Kreissekretäre weiterhin heranzuziehen. Da der Termin für den Parteitag aus den dargelegten Gründen verschoben worden war, konnte man sich dort der Herbeiführung des gewünschten „gesellschaftlichen Zustands“ widmen ${ }^{190}$. Die Güstro-

186 Zum folgenden BStU ASt. Lpz. AIM 3445/92, Arbeitsvorgang Gaude, Bd. 1, Bl. 54-61, Abschrift eines Brigadeberichtes über Einsatz in Frankfurt/Oder, 3.-13. 11. 1959. Dorn wird in anderen IM-Akten als IM „Hans“ bezeichnet, sofern er identisch ist mit dem 1961 im PV beschäftigten Instrukteur namens Dorn. BStU MfS AIM 9130/63, Arbeitsvorgang Titel, Bd. 2, Bl. 4-6, Treffbericht 5. 1. 1961.

187 Außerdem schrieb man Pech, einem der dienstältesten Funktionäre der DBD, einen impulsiven Diskussionsstil zu, infolgedessen er sich verzettele und nicht „auf Wesentliches“ konzentriere; BStU ASt. Lpz. AIM 3445/92, Arbeitsvorgang Gaude, Bd. 1, Bl. 54-61, Abschrift eines Brigadeberichtes über Einsatz in Frankfurt/Oder 3.-13. 11. 1959.

188 ACDP VI-052-0539, Protokoll Sekretariat, 3. 11. 1959.

189 Vgl. „Bauern-Echo“, 24. 11., 4. 12., 6. 12. 1959. Lt. „40 Jahre Demokratische Bauernpartei Deutschlands“ wurden im KV Quedlinburg erst am 28.11. 1959 alle bäuerlichen DBD-Mitglieder Genossenschaftsmitglieder.

190 ACDP VI-052-0540, Protokoll Sekretariat, 18. 1. 1960. 
wer Brigaden bestanden überwiegend aus DBD-Mitgliedern, arbeiteten jedoch eng mit SED-Stellen zusammen ${ }^{191}$, wodurch diese wiederum die Vorkehrungen für den Parteitag im Blick hatten ${ }^{192}$.

Brigadearbeit und Verhöre waren gängige diktatorische Methoden. In „persönlichen Gesprächen" wurden die Opponierenden allein oder mit einer Gruppe bisweilen täglich besucht oder zur „Aussprache“ in Amtsstuben vorgeladen, um sie vom LPG-Eintritt zu „überzeugen“. Kenntnis der sozialen Netze in den Dörfern und Einblick in familiäre Verhältnisse erlaubten es den eingesessenen Funktionären gezielt vorzugehen. Anlaufstellen waren nicht nur die Bauern; häufig versuchte man, Ehegatten gegeneinander auszuspielen oder Konflikte in der Familie oder zwischen den Generationen zu schüren und den Wunsch, die familiären Eigentumsverhältnisse zu ändern, für den Sozialismus auszunutzen ${ }^{193}$. Den überarbeiteten Bäuerinnen versprach man in der LPG ein vergleichsweise besseres Leben als das ihrer bundesdeutschen Berufskolleginnen; allerdings scheint diese Begründung, die auch die DBD-Presse suggerierte ${ }^{194}$, auf wenig fruchtbaren Boden gefallen zu sein, wie daran abzulesen ist, daß die Bäuerinnen oft nicht gemeinsam mit ihren Männern beitraten. Die Jugendlichen lockte man mit den Versprechungen der technischen Moderne in den LPG, auch mit dem zutreffenden Argument, daß familieneigene Kräfte häufig unterbezahlt seien ${ }^{195}$.

Die Brigaden hatten häufig die Aufgabe, ,auch die letzten Bauern für die LPG zu gewinnen"196. Dabei wurde durchaus eingestanden und zugleich gebilligt, daß „Überspitzungen“ an der Tagesordnung waren. So sei der Vorsitzende der DBDOrtsgruppe Reddlich „durch die Polizei zur Aussprache geholt“ worden. „Alle Kollegen der Ortsgruppe haben ihre Mitgliedsbücher auf den Tisch gelegt [...] Ein Bauer in der Gemeinde unternahm sogar einen Selbstmordversuch, allerdings im angetrunkenen Zustand [!]“, wie ein Erfahrungsbericht aus dem Bezirk Rostock während der Hochphase der Zwangskollektivierung im März 1960 vordergründig exkulpierend festhielt. Die Verfasser hoben besonders den Lerneffekt für die Funktionäre hervor; denn „beim Masseneintritt im Bezirk Rostock“ hätten sie „eine ganze Menge neuer Erfahrungen gesammelt [...], von denen wir als Mitarbeiter des Parteivorstandes nicht unmittelbar berührt wurden“. Daher rieten sie der Zentrale, jeder politische Mitarbeiter dort solle fünf bis sechs Tage in einer gemischten Brigade mitarbeiten, und zwar an Orten, wo eine "Massenbewegung“" stattfinde, "weil jeder von uns für seine Arbeit als Parteifunktionär diese Erfahrungen benötigt“. Seit 1959 hatte das MfS seinen Einblick in Instrukteurberichte

191 ACDP VI-052-246/1 [Ablage der Abt. Agrarpolitik des PV], Brigadebesprechung in Güstrow am 18. 2. 1960.

192 SAPMO DY 30 IV 2/15/53, Bericht zum Stand der PT-Vorbereitungen der DBD, 8. 2. 1960.

193 Siehe dazu ACDP VI-052-0324, Bericht über den Einsatz im Bezirk Rostock, 10.-12. 3. 1960.

194 „Bauern-Echo“, 1. 12. 1959. Vgl. Börner, Wirken, S. 61, 66, 77.

195 Vgl. „Ein Wort an meine Kollegen Einzelbauern“ des LPG-Vorsitzenden in Terpitz in "Bauern-Echo“, 17. 12. 1959.

196 ACDP VI-052-0324, Bericht über Einsatz im Bezirk Rostock, 10.-12. 3. 1960, gez. von [Hans Joachim] Friz und [Waltraud] Mundt. 
der DBD durch die Verpflichtung des Mitarbeiters in der Organisationsabteilung, Gerhard Gaude, erweitert. Es wies ab 1962 auch IM „Staude“ alias Zagrodnik an, neben einem informatorischen vor allem einen politisch-operativen Zugriff auf die Instrukteurbrigade zu gewährleisten, d.h. unmittelbar auf sie einzuwirken ${ }^{197}$.

Ein Vehikel von Agitation wie Kontrolle war die Wettbewerbsbewegung. Die ländliche Bevölkerung sollte über die Beteiligung an solchen Kampagnen, die Wettbewerbe zwischen Ortschaften, zwischen Parteiformationen oder LPG propagierten, politisch „erzogen“ werden; vor allem sollte sie jederzeit für beliebig füllbare Zwecke mobilisierbar gemacht werden. Zwar wurde die Wettbewerbsbewegung in der DBD von Beginn an zu unterschiedlichen Anlässen und Zielsetzungen betrieben. Gerade in der Kombination mit dem Einsatz von Brigaden 1959 und in der Vorbereitung des VI. Parteitages stellte sie jedoch ein besonders dynamisches Element beim Vorantreiben der Kollektivierung dar. Dies galt insbesondere ab Mitte Januar 1960, als der Parteitag in den Mai hinein verschoben wurde, und man bis dahin einen vollgenossenschaftlichen Zustand erreicht haben mußte. So informierte sich das Sekretariat in seinen Sitzungen regelmäßig über den "Stand des innerparteilichen Wettbewerbs in Vorbereitung des Parteitages" und konnte daran - verschleiert hinter belanglosen Worten, die kaum vom Diskurs vorangegangener Jahre abwichen - den Fortgang der Kollektivierung able$\operatorname{sen}^{198}$.

Immer schon gab die Initiierung von Wettbewerbsbewegungen der Parteizentrale ein Mittel an die Hand, ein definiertes politisches Ziel öffentlich zu propagieren. Die Zentrale verließ sich darauf, daß sich die Bezirke respektive ihre ehrgeizigen Funktionäre, gegenseitig anstachelten und den politischen Ertrag so in die Höhe trieben. An der Art und Weise, wie die Rangfolgen der Bezirksverbände im Parteivorstandsapparat festgestellt wurden, fällt auf, daß die Beurteilung der Wettbewerbsergebnisse - und damit die Rangliste - oft nicht den im Vorfeld ausgegebenen Bewertungskriterien folgte; vielmehr legte man offenbar intern häufig eine andere Reihenfolge fest, die auch jenen Bezirken einmal ein Erfolgserlebnis gönnte, die als ewige Träger der „Roten Laterne“ verrufen waren, oder jene Bezirke animieren wollte, deren Kollektivierungsergebnisse nachhinkten.

Am 16. November 1959 beschloß das Sekretariat zur Vorbereitung des innerparteilichen Wettbewerbs für den VI. Parteitag einen Kriterienkatalog, der die Kollektivierung erneut beschleunigte ${ }^{199}$. Der Wettbewerb war zuvor schon durch

197 BStU MfS AIM 3189/63, P-Akte Zagrodnik, Bl. 44f., Perspektivplan der HA V/3, 1. 10. 1962.

198 ACDP VI-052-0540, Protokolle Sekretariat, 14. 12. 1959, 8. 2. 1960; ACDP VI-0520541, Protokoll Sekretariat, 8. 3. 1960; ACDP VI-052-0324, Protokolle Präsidium, 15. 3., 19. 4., 3. 5. 1960; am 14. 3. 1960 fiel die Werbung von Einzelbauern als Wettbewerbskriterium heraus.

199 An erster Stelle stand, wieviele Mitglieder in gemischten Brigaden mitarbeiteten - also der Mobilisierungsgrad der DBD -, dann zählten die Eintritte in LPG; nachrangig war schon, wieviele Mitglieder Leistungsverpflichtungen übernommen hatten, als Schichtfahrer eingesetzt worden waren oder im Nationalen Aufbauwerk Arbeitsstunden abgeleistet hatten; eine dritte Kriteriengruppe fragte nach der Anzahl der geworbenen Einzelbauern für die DBD; eine vierte überprüfte die organisatorische Schlagkraft der unteren Parteieinheiten. ACDP VI-052-0540, Protokoll Sekretariat, 16. 11. 1959, TOP: Vorbereitung des VI. PT. 
die Diskussionen um den Austragungsort angestoßen worden ${ }^{200}$. Zwar liegt auf der Hand, daß dieser Parteiwettbewerb in der DBD auf der Basis dieser Kriterien beschlossen worden war, bevor eine zentrale Weisung der SED zur Vollkollektivierung vorlag, die Kampagne damit also nicht von Anfang an im Dienste der kurzfristigen Durchführung der Vollkollektivierung stand. So hatte die DBD tatsächlich Mitte November nicht berechnend einen Wettbewerb um die kurzfristige vollständige Vergenossenschaftlichung beschlossen ${ }^{201}$. Der bereits laufende Wettbewerb ließ sich jedoch problemlos dazu ausweiten, als im Januar 1960 die Würfel gefallen waren, und stellte so ganz klar einen ganz besonderen Beitrag der DBD zur Vollkollektivierung dar.

Wie die SED propagierte auch die DBD zwecks massenhafter Nachahmung bestimmte „Beispiele“, denen Vorbildfunktion zugemessen wurde. Bekannte SEDBeispiele sind etwa "Flora und Jolanthe“ oder der "Golßener und JesewitzerPlan“. Sie warben dafür, über die im Plan vorgeschriebenen Ziffern hinaus die Marktproduktion zu steigern. Ein eigens auf die DBD zugeschnittenes Beispiel rekurrierte auf das Vorgehen der DBD-Ortsgruppe in Satow, im Kreis Bad Doberan; dort war selbstredend "unter Führung" der SED-Kreisleitung vom Kreisausschuß der Nationalen Front und der DBD ein Beispiel zur „Zusammenarbeit aller politischen Kräfte" geschaffen worden. Dieses Beispiel zielte im April 1960 darauf, alle Kollegen der Ortsgruppen zur Mitarbeit in der Nationalen Front und damit für die Vollendung der Kollektivierung, bzw. für die sogenannte „Festigung“ der LPG - ihre innere Stabilisierung in betriebswirtschaftlicher, organisatorischer und politischer Hinsicht - zu gewinnen ${ }^{202}$. Die Bilanz der Aktion blieb enttäuschend. Anfang 1962 resümierte das Sekretariat, daß lediglich in einem Drittel aller Dörfer, in denen die DBD präsent war, damit begonnen wurde, sich am Beispiel Satow auszurichten ${ }^{203}$.

Die umfassende Mobilisierung der DBD für die Kollektivierung spaltete die Partei bzw. durchbrach den dünnen Firnis, der die Basis seit 1957 noch zusammenhielt. Zwar wurden auch damals schon einfache Parteimitglieder mit dem Anspruch konfrontiert, künftig in eine LPG einzutreten. Niemand verlangte jedoch von ihnen die Bereitschaft zu einschneidenden politischen Handlungen, wie dies seit Herbst 1959 üblich war, oder in gesteigerter Form von Funktionären, daß diese sich dabei rigider agitatorischer Mittel bedienten. Wenngleich 17485 Brigademitglieder der DBD - das waren über ein Fünftel aller Parteiangehörigen (22\%) - eine sehr hohe Mobilisierungsquote belegen, so verlor die DBD gleichzeitig einen erheblichen Mitgliederanteil; über ein Fünftel kündigte ihr meist jahrelang gehaltenes Abonnement des „Bauern-Echo“, weil die Zeitung zu eindeutig die Kollektivierung vertrete ${ }^{204}$.

200 ACDP VI-052-0539, Protokolle Sekretariat, 25. 5., 21. 9. 1959; ACDP VI-052-0538, Protokoll Sekretariat, 16. 2. 1959.

201 So Reichelt, Blockflöte, S. 180.

202 Siehe dazu z. B. Artikel in „Bauern-Echo“, 8. 4. 1960.

203 ACDP VI-052-0546, Protokoll Sekretariat, 17. 1. 1962.

204 ACDP VI-052-186/1, Aufstellung der Abt. Organisation vom November 1960. ACDP VI-052-0542, Protokoll Sekretariat, 29. 8. 1960. 
Als eifriger Journalist für die Sache der Kollektivierung und in dafür gut bezahlten Diensten des MfS wirkte Ernst Otto Christalle, der damals der für Presse zuständige Mitarbeiter im Bezirkssekretariat Schwerin war ${ }^{205}$. Er verfaßte einschlägige Zeitungsartikel und Broschüren für das MfS, die den sofortigen Eintritt in LPG propagierten. Auch das „Bauern-Echo“ suchte in dieser Zeit gezielt, Problemgruppen zum LPG-Beitritt zu bewegen. Dies ist etwa in einem Artikel „Die Frau des Feuerwehrhauptmanns" zu erkennen, in dem die DBD eine traditionell im Dorf anerkannte Führungsgruppe ansprach, der von seiten des MLF eine ähnlich „negative Ausstrahlung auf die sozialistische Umgestaltung“ zugesprochen wurde wie dem Einfluß der Kirchen ${ }^{206}$. Der Plot erzählt die Geschichte eines Einzelbauern, der begeisterter und im Dorf hochgeachteter Feuerwehrhauptmann war. Während er sich auf Feuerwehrlehrgängen fortbildete, erledigte seine Frau allein die Arbeit auf dem Hof und war daher überlastet. Genossenschaftsbäuerinnen hingegen könnten zur Erholung fahren, weil sie abkömmlich seien. Seine Frau redete ihm schließlich aus, er könne seinen Freunden einen LPG-Eintritt nicht antun, indem sie anmerkte, alle außer ihm würden immer häufiger an einen Wechsel in die LPG denken. Nachdem beide Genossenschaftsmitglieder geworden waren, kommentierte die „Stimme des Dorfes“, daß sie gut daran getan hätten, sonst wäre er nicht mehr lange Feuerwehrhauptmann geblieben. Die Lehre lautet also, gerade wer seinen Einfluß wahren möchte, sollte schnell einer LPG beitreten, andernfalls überrolle ihn die Entwicklung.

Die DBD hatte wie alle anderen Blockparteien im Zuge der Kollektivierung auch deutschlandpolitische Überzeugungsarbeit zu leisten. Die Verbindung dieser beiden Argumentationsstränge - Deutschlandpolitik und Kollektivierung wurde um so wichtiger, je mehr sich am Eintrittsverhalten und an der Stimmung der Mitglieder ablesen ließ, wie sehr in Zeiten internationaler Gipfelkonferenzen mit der Hoffnung auf ein geeintes Deutschland der Widerstand gegen den LPGEintritt zunahm. Es gehörte zu den gängigen Begründungsmustern, mit denen auch die DBD ihre Mitglieder bearbeitete, daß die DDR der einzig legitime deutsche Staat sei, in dem der Sozialismus den Frieden garantiere, der wiederum erst durch die Ausdehnung des sozialistischen Sektors in der Landwirtschaft gesichert werden mußte. Der DBD war seit geraumer Zeit bekannt, daß diese Verdrehung der Wahrheit an der bäuerlichen Bevölkerung abprallte ${ }^{207}$. Nach dem Startschuß zur administrativen Vollkollektivierung Mitte Januar 1960 genügte eine reservierte Distanz zur deutschlandpolitischen Agitation, um die verbliebenen Einzelbauern mit entsprechenden Strafandrohungen der "Sabotage am Frieden" zu be-

205 Christalle schrieb seit 1958 für das MfS Artikel zu Fragen des Sozialismus auf dem Land und Agitationsbroschüren, er wurde dafür regelmäßig bezahlt. BStU ASt Swn. AIM 353/ 65, Bd. 1, Personalakte Christalle (= „Werner“, „Harry“, „Paul“, „Egmont“), Bl. 159, Bericht vom 25. 11. 1958, Bl. 169, Bericht 28. 5. 1959, Bl. 187, 191, 192.

206 BA DK-1/1225, Bl. 1-10, Bericht: Probleme bei der sozialistischen Umgestaltung, bei Werbung von reichen Mittelbauern, 14. 10. 1959, Zitat Bl. 3; „Bauern-Echo“, 5. 11.1959.

207 Siehe ACDP VI-052-0539, Bericht zu Instrukteureinsatz im KV Greifswald vom 27. 5.19. 6. 1959; ACDP VI-052-0172, offener Brief an Abgeordnete ländlicher Wahlkeise der BRD, Protokoll PV, 30./31. 10. 1959. 
zichtigen ${ }^{208}$. Mit diesem politisch dehnbaren Vorwurf konnten die Behörden ein Klima der Drohung herstellen; auch war die Strafverfolgung dieser Delikte durch Polizeibehörden vergleichsweise leichter herbeizuführen, als die oft langwierige Ahndung von Wirtschaftsstrafvergehen. Die deutschlandpolitische Karte zu spielen, gehörte daher zu den Methoden der Vollkollektivierung.

Anfang Februar 1960, kurz nach der Tagung des Nationalrats der Nationalen Front vom 22./23. Januar, die sich mit der „Verstärkung der politischen Massenarbeit bei der sozialistischen Umgestaltung der Dörfer" ${ }^{209}$ befaßte, benannte die DBD dem Nationalrat auf dessen Anfrage hin eine Reihe von politischen Mitarbeitern zur "Vorbereitung der Gipfelkonferenz" und zum ausschließlichen Einsatz in Dörfern ${ }^{210}$. Wenngleich sprachlich verschleiert, wurden hier Agitatoren zur Massenkollektivierung abgeordnet; denn es drängt sich die Frage auf, was für ein Auftrag, wenn nicht für die Kollektivierung zu werben, für einen solchen Einsatz fast aller Fachkräfte des Parteivorstandes just zu dieser Zeit angemessen gewesen wäre, ohne sich politisch verdächtig zu machen ${ }^{211}$. Zweifellos bezweckte die SED mit diesem gesamtdeutschen Argument, auch jenen Blockparteien, die wenig bäuerliche Mitglieder aufwiesen, einen Grund zur Mobilisierung für die Vollkollektivierung zu präsentieren.

Insgesamt war die DBD-Führung um Ausgleich und Wiederannäherung an eine in weiten Teilen tief enttäuschte und distanzierte Mitgliedschaft bemüht. Es gab fast keinen Anlaß, außer der Flucht in den Westen, der zu einer nennenswerten Zahl an Ausschlüssen geführt hätte. Im Grunde konnten sich die DBD-Mitglieder gegenüber den Parteileitungen in dieser Zeit fast alles erlauben. Die Parteiführung hoffte auf die Vergeßlichkeit oder späte Einsicht der Basis in den vermeintlich notwendigen Gang der Entwicklung.

208 Vgl. die filmisch von der DEFA adaptierte Praxis, in Dörfern „Kriegs- und Friedensstühle" aufzustellen. Hartnäckige Einzelbauern hatten in Diskussionen dann auf dem Kriegsstuhl Platz zu nehmen. Werkentin, Strafjustiz, S. 100.

20940 Jahre Demokratische Bauernpartei Deutschlands, S. 47.

210 Gemeint war die für den 16. 5. 1960 in Paris angesetzte und dann geplatzte Gipfelkonferenz unter Beteiligung der Regierungschefs der vier Siegermächte; Staritz, Geschichte, S. 188. ACDP VI-052-0540, Protokoll Sekretariat, 1. 2. 1960.

211 Unter den Ausgesandten befanden sich auch Hans Joachim Friz und Waltraud Mundt, die in ihrem Bericht aus Rostock allen politischen Mitarbeitern einen Einsatz in Gebieten der „Massenbewegung“ empfohlen hatten. Mundt war am 30.6. 1959 vom MfS als IM „Anita" angeworben worden. Sie arbeitete zusammen mit Nixdorf in der Abt. Agrarpolitik im Sachgebiet LPG und sollte führende Köpfe der Abt., die sich für eine eigene agrarpolitische Kompetenz der DBD aussprachen, politisch kompromittieren. Dies sei ihr auch gelungen, so das MfS. BStU MfS AIM 392/83, Bd. I/1, Mundt, Bl. 6, Aktenspiegel, Bl. 42, Einschätzung der Mundt durch GI „Elfriede“, 20.4. 1959; B1. 63-66, Auskunftsbericht HA V/3, 4. 10. 1961. 


\section{Die Kollektivierung und die DBD: sozialstrukturelle und regionale Charakteristika}

Am 15. April 1960 bestätigte die Volkskammer „den vollständigen Übergang der Bauern zur genossenschaftlichen Arbeit in landwirtschaftlichen Produktionsgenossenschaften “ 212 und erklärte damit das offizielle Erreichen der „sozialistischen Umgestaltung der Landwirtschaft ${ }^{\text {". }}$. Als letzter Bezirk erreichte ausgerechnet Karl-Marx-Stadt am 14. April den vollkollektivierten Zustand und machte seinem Namen damit keine Ehre ${ }^{213}$. Im Laufe des Frühjahrs gingen die Entwicklungsstände der jeweiligen Bezirke gesondert bei den Innenbehörden ein und informierten über die enormen Schübe in nur wenigen Tagen ${ }^{214}$. 9840 LPG waren allein 1960 gebildet worden, zusammen mit den Ende Dezember 1959 vorhandenen 9473 LPG belief sich die Gesamtzahl Ende 1960 auf knapp unter 20000215. Die landwirtschaftlichen Genossenschaften bewirtschafteten 1960 etwa 84\% der LNF (5408064 ha von 6419755 ha LNF). In privater Nutzung verblieben noch knapp unter $8 \%$ oder 504898 ha, darunter 3908 Gartenbaubetriebe mit insgesamt 2156 ha LNF ${ }^{216}$. MfS-Angaben zufolge bewirtschafteten Ende 1960 noch 17000 Einzelbauern 1,2\% der LNF (74900 ha), 6,7\% der LNF umfaßten die privaten Nebenwirtschaften bis zu einem ha, $u$.a. von Genossenschaftsbauern ${ }^{217}$. Dieses Bild gibt die eigentumsrechtliche Zwitterlösung der Vollkollektivierung wieder, da die Bedeutung der individuellen Vieh- und Hauswirtschaften der LPG-Mitglieder deutlich abzulesen ist. Die Aufteilung der LNF verschob sich bis Ende

212 GBl. DDR I 1960, Nr. 26, S. 255.

213 Vgl. dazu Staritz, Geschichte, S. 189 f.

214 SAPMO DY 30 IV 2/7/369, Informationsbericht der HV Deutsche Volkspolizei, Nr. 2, 22. 3. 1960. Als neuen Berichtspunkt enthielt dieser Bericht erstmals unter 5. „Feindtätigkeit".

215 Statistisches Bundesamt, H. 8, Ausgewählte Zahlen zur Agrarwirtschaft 1949 bis 1989, S. 13-15; obgleich sich die Zahlen der Sonderreihe des Statistischen Bundesamtes im Grunde auf die Statistischen Jahrbücher der DDR stützen, weichen sie hier ohne Angabe von Gründen ab. Da die Literatur meist auf die Zahlen der Statistischen Jahrbücher rekurrierte, weichen die dort genannten von den hier zitierten ab. So etwa Prokop, Übergang, S. 202; Reichelt, Blockflöte, S. 170. Lt. einer ministeriellen Aufstellung betrug die Zahl der LPG im Dezember 1959 10465, bei einem genossenschaftlich-staatlichen Flächenanteil von 45,1\%. ACDP VI-053-247/1, ministerielle Aufstellung „Sozialistische Umgestaltung der Landwirtschaft" ${ }^{\circ}$, S. 1-13, hier S. 3.

216 Ausgewählte Zahlen zur Agrarwirtschaft 1949 bis 1989, S. 13-15. Außerdem gab es 1960 noch 2244 kirchl. Idw. Betriebe mit 15770 ha LNF, 298 Gärtnerische Genossenschaften mit 13686 ha LNF, 669 staatl. Güter mit 395663 ha LNF sowie 9478 sonstige Betriebe in öffentlicher Hand (kommunale Flächen) mit 81674 ha LNF. 1963 gab es weiter 1451 kirchl. ldw. Betriebe mit 14021 ha LNF, 369 Gärtnerische Genossenschaften mit 14874 ha LNF, 594 staatliche Güter mit 394055 ha LNF und 336 sonstige Betriebe in öffentl. Hand mit 59833 ha LNF.

217 Die MfS-Statistiken decken sich mit den oben genannten Zahlen. BStU MfS 102109, Orientierung über die Lage in der Landwirtschaft, 3. 3. 1961; die in der Literatur häufiger anzutreffende Zahl von 19000 geht zurück auf die Geschichte der Deutschen Demokratischen Republik, S. 214, so bei Wietstruk, Entwicklung, S. 147. 
1963 zwar nur geringfügig zugunsten des genossenschaftlichen Sektors, belegt jedoch die Überführung fast aller Einzelbauern in LPG bis dahin ${ }^{218}$.

Für den Kollektivierungsschub 1960 ist die Zunahme der LPG Typ I charakteristisch. Ab 1955 genehmigten die Behörden die Gründung einer LPG Typ I in Dörfern, die bislang nur über LPG anderen Typs verfügten, 1960 auch die Gründung von mehreren LPG Typ I in einem Dorf, weil sich die bis dahin hartnäckig weigernden altbäuerlichen Einzelwirtschaften wie erwähnt eher für diesen Typ erwärmen konnten als für LPG Typ III219. Von 1959 bis zum 31. März 1960 stieg die Zahl der LPG des Typs I und II - wobei der Typ II ein Schattendasein führte von 3597 auf 13022, also um mehr als das dreieinhalbfache, während die Zahl der LPG Typ III von 6323 im Vergleich zu 1959 sogar leicht rückläufig war. Ende 1960 gab es 961539 LPG-Mitglieder, darunter 380096 im Typ I und II, sowie 581443 Mitglieder im Typ III ${ }^{220}$. Knapp $80 \%$ der Genossenschaftsbauern waren parteilos, etwa $20 \%$ parteigebunden, so gehörten $10,9 \%$ der SED an, $6,4 \%$ der DBD, $1,7 \%$ der CDU, $0,9 \%$ der LDPD und $0,4 \%$ der NDPD. Nur knapp die Hälfte $(47,1 \%)$ war außerdem Mitglied in der VdgB, die bei vielen Bauern inzwischen als wirtschaftliche Organisation der SED galt ${ }^{221}$.

Der Bauernpartei fiel in den drei entscheidenden Monaten 1960 die Aufgabe zu, vor allem ihre altbäuerlichen Mitglieder zum LPG-Eintritt zu bewegen sowie diejenigen Neubauern, die einträgliche Betriebe führten, und deshalb keine Veranlassung sahen einzutreten. Hinsichtlich der altbäuerlichen Mitglieder lag die DBD damit im Trend. Seit 1958 stieg der altbäuerliche Anteil unter den LPG-Bauern von knapp 30000 bis Ende 1959 auf rund 112000 an, darunter ca. 18000 sogenannte "Großbauern". Hinter den ehemaligen Landarbeitern (knapp 130000) und den Neubauern mit ihren Familien (knapp 115000) nahmen sie nun den dritten Platz ein 222. Anfang 1960 hatte die DBD zwar aufgrund einer leicht geschönten Statistik ihr Klassenziel von 50\% Genossenschaftsbauern unter den bäuerlichen

218 Der private Anteil verminderte sich auf 6,75\% oder 426829 ha LNF (darunter 3416 Gartenbaubetriebe mit 2021 ha LNF); dabei handelte es sich sowohl um die restlichen Einzelbauern als auch um die privaten Hauswirtschaften in den LPG. Durch Zusammenlegungen sank zwar die Zahl an LPG auf 16330, diese bewirtschafteten jedoch eine größere Fläche von 5459470 ha LNF (85,72\%); Ausgewählte Zahlen zur Agrarwirtschaft 1949 bis 1989, S. 13-15.

219 Zwei Drittel der im Juni 1960 vorhandenen 12797 LPG Typ I wurden in den Monaten März bis Mai gegründet, hingegen stieg in diesem Zeitraum die Zahl der LPG Typ III nur um 3\%, BStU MfS 102109, Orientierung über die Lage in der Landwirtschaft, 3. 3. 1961. In 2906 von 9353 Gemeinden gab es 1960 daher zwei und mehr LPG Typ I, in den meisten Dörfern zusätzlich noch eine LPG Typ III. Matschke, Entwicklung, S. 7.

$220 \mathrm{Da}$ keine neueren publizierten statistischen Materialien vorliegen, wurden Zahlen des Statistischen Jahrbuchs der DDR 1962, S. 405 f., herangezogen.

221 Diese Prozentzahlen nennt Graffunder, Dialektik, S. 149; setzt man sie in Beziehung mit den absoluten Mitgliederzahlen in den LPG lt. Statistischem Jahrbuch und der erwiesenen Zahl der LPG-Mitglieder der DBD, so erscheinen die Zahlen des Statistischen Jahrbuches zu hoch; dann hätte nämlich die DBD 196061539 LPG-Mitglieder in ihren Reihen gezählt, anstelle der tatsächlichen Zahl von gut 59000. Siehe Tabelle 25.

222 Statistisches Jahrbuch der DDR 1960/61, S. 428f., Statistisches Jahrbuch der DDR 1962, S. 412; Merkel/Schuhans, Agrarwirtschaft, S. 83.1960 bricht in der staatlichen wie in der Statistik der DBD die Aufgliederung in Neu- und Altbauern ab. 
Mitgliedern erreicht ${ }^{223}$; allerdings klafften die Ergebnisse unter den Bezirken erheblich auseinander, was vornehmlich durch den je nach Bezirk unterschiedlichen Agitationsgrad und auch den variierenden Kollektivierungsdruck schon in den Jahren davor begründet war.

Während in den Verbänden in Halle - mit einem Spitzenwert von $83,2 \%$-, Rostock, Leipzig und Magdeburg im Januar 1960 sich schon über $60 \%$ der bäuerlichen Mitglieder den LPG angeschlossen hatten 224 , fielen die "Problemkinder", angeführt von Suhl (25,7\%), Cottbus, Karl-Marx-Stadt, Dresden, Berlin und Gera mit deutlich unter $40 \%$ erheblich ab. Gera, Suhl, Dresden und Karl-Marx-Stadt sprangen erst nach dem offiziellen Ende der Vollkollektivierung bis Juni 1960 von der $50 \%$-Marge über die $90 \%$. Besonders zäh schritt der Zuwachs ab einem bestimmten genossenschaftlichen Stand offenbar in Cottbus - nur ein Prozentpunkt Zuwachs von März bis Juni auf $88 \%$-, Halle und Berlin voran 225 .

Insgesamt traten allein 26513 DBD-Mitglieder von Januar bis Juni 1960 in LPG ein, in kürzester Zeit damit rund ebensoviele, wie vor Jahresfrist insgesamt in der Partei organisiert waren; 2765 bäuerliche Mitglieder gehörten im Juni 1960 noch keiner LPG an, die große Mehrheit von über $95 \%$ der bäuerlichen Mitglieder hatte ein Eintrittsformular unterzeichnet ${ }^{226}$. Bis 1963 führte die DBD rund 60000 ihrer Mitglieder den LPG zu, die Zahl der Einzelbauern schrumpfte auf 227227. In welchem Ausmaß die DBD-Mitglieder ihrer traditionellen Wirtschaftsweise nachhingen, ist daran abzulesen, daß Ende 1963 insgesamt noch über ein Drittel der bäuerlichen Mitglieder dem am geringsten kollektivwirtschaftlich organisierten Typ I angehörten. In den südlichen Bezirken Dresden, Karl-Marx-Stadt, Gera und Suhl dominierte diese Form sogar bei über 60\% der bäuerlichen DBD-Mitglieder; diese LPG bewirtschafteten meist nur eine LNF von unter 150 ha und verfügten oftmals über keine Parteiorganisation der SED 228 .

Trotz der tiefen Existenzkrise, in der die DBD nach der Vollkollektivierung und der fortschreitenden Entmündigung ab 1960 steckte, verlor sie entgegen dem herrschenden Trend kaum Mitglieder durch den Abstrom der Arbeitskräfte in die Städte. Die Generationsstruktur der DBD dürfte dabei insofern eine Rolle gespielt haben, als die Mitglieder mittleren und fortgeschritteneren Alters weniger berufliche Mobilität aufwiesen als Jugendliche, deren Anteil auf 4,6\% 1963

${ }^{223}$ Man zog die Zahlen von Ende Januar 1960 heran mit knapp über 50\% LPG-Mitglieder unter den bäuerlichen Mitgliedern, nicht die Zahlen von Ende 1959 mit einem Anteil von rund $47 \%$.

224 Ursächlich dafür das Vorgehen in Halle, Rostock und Leipzig 1959. Siehe beschönigende Ausführungen bei Reichelt, Blockflöte, S. 166-171. Die Quote von 80\% in Halle geht auf ein besonders rigides Vorgehen dort im Jahr 1958 zurück, auch die „Hochburg“ der DBD, der KV Bernburg, lag in diesem Bezirk. Siehe auch BA DE-1/20312, Bl. 77-80, Sektor LW der Staatlichen Plankommission, Entwicklung der LPG in Halle, 29. 9. 1958.

225 Siehe Tabelle 25. Inwiefern die nahe offene Grenze in Berlin eine Rolle spielte, wäre gesondert zu untersuchen.

226 Ebd.

227 ACDP VI-052-195/3, soziale Zusammensetzung der Partei, undatiert [1982].

228 SAPMO DY 30 IV A2/15/92, Die Situation in der DBD vor den Volkskammerwahlen 1963, 30. 10. 1963, gez. A, höchstwahrscheinlich für Heinz Ackermann. 
sank ${ }^{229}$. Da sich die Zahl der Westflüchtigen aus den Reihen der DBD mit rund 2000 Personen von 1959 bis 1961 in Grenzen hielt ${ }^{230}$, war die Parteibasis in dieser Hinsicht ein sehr stabiler Faktor in den LPG.

Im Hinblick auf regionale Durchsetzungsprobleme der Kollektivierung sind eine Reihe von Einflußfaktoren exemplarisch darzulegen. Sie sollen den spezifischen Handlungsspielraum der DBD besser ausleuchten. Als letzter Bezirk erreichte Karl-Marx-Stadt die Vollkollektivierung; dies war hauptsächlich durch dessen agrarische Struktur bedingt, die von klein- bis überwiegend mittelbäuerlichen Betrieben geprägt war und von einer speziellen Durchmischung zersplitterter Fluren in den Mittelgebirgslagen des Erzgebirges ${ }^{231}$. Als Hindernis für die Kollektivierung interessiert hier besonders die blockpolitische Konstellation, die seit 1955 alles andere als eine Kooperation begünstigte. Für den Bezirk ist charakteristisch, daß nur DBD und SED auf dem Land über politisches Gewicht verfügten. Als politische Konkurrenz für die SED gefahrlos eingeschätzt, überwog im Kontakt zwischen beiden Parteien 1955 noch die agrarfachlich ausgerichtete Anleitung gegenüber der DBD. Schon 1956 monierte die Arbeitsgruppe BO am Beispiel der SED-Bezirksleitung Karl-Marx-Stadt, daß dort das "Sektierertum“ gegenüber den anderen Blockparteien „bereits in den Büros der Bezirksleitungen beginnt“, weshalb es zu Beschwerden der Blockparteien gekommen sei. Im Juni 1959 gab dieser Mißstand den Anlaß für eine Analyse der Blockpolitik des Bezirkes, die sich u. a. mit der Frage befaßte, warum die Kollektivierung nicht vorankam ${ }^{232}$. Bei aller Gemeinsamkeit zwischen SED und DBD im politischen Ziel war das Verhältnis zwischen beiden in den Dörfern äußerst angespannt und von Konkurrenz bestimmt, eine politische Abstimmung vor Ort fand offenbar kaum statt.

Zwar warf die SED der DBD Mängel in der „politischen Wirksamkeit nach unten" vor, immerhin aber war die Parteibindungskraft für die Mitglieder, die oft nicht einmal in Ortsgruppen zusammengefaßt waren, so hoch, daß über $70 \%$ von ihnen regelmäßig zu den Jahreshauptversammlungen erschienen. Die Verwurzelung der DBD in den Dörfern zeigte sich darin, daß der DBD-Bezirksverband im Vergleich $\mathrm{zu}$ anderen mitgliederstärkeren überproportional viele Kreistagsabgeordnete und Mitglieder in Gemeindevertretungen stellte. Fast jedes fünfte Parteimitglied, insgesamt rund 1000, gehörte einer Gemeindevertretung an ${ }^{233}$. Die dichte Präsenz von LPG-Vorsitzenden aus den Reihen der DBD 234 belegt die Ab-

229 Siehe Tabelle 13.

230 Siehe Tabelle 27.

231 Die 5317 Mitglieder des DBD-BV setzten sich dementsprechend im September 1959 aus gut 230 Neubauern und deren Familien, rund 1170 LPG-Mitgliedern, aber noch 2150 altbäuerlichen Mitgliedern zusammen. ACDP VI-052-185/3, Organisationsbericht September 1959. Siehe Tabellen 21 und 22.

232 SAPMO DY 30 IV 2/15/18, Bürovorlage Abt. LOPM des Bezirkes Karl-Marx-Stadt: Bericht über Arbeit des demokratischen Blocks und die Lage in den anderen Parteien, 28. 2. 1955. Ebd., AG BO, Burkhardt an Kleinert, 26. 4. 1956 (Zitat); ebd., Bericht der BL KarlMarx-Stadt, 3. 6. 1959, über die Zusammenarbeit mit den Blockparteien, auch zum folgenden.

233 ACDP VI-052-185/3, Organisationsbericht Dezember 1959.

234 Die DBD konnte ihre Zahl an Genossenschaftsbauern von rund 500 auf $1000 \mathrm{im} \mathrm{Jahr}$ 
sicht der Partei, dort wo die Kollektivierung vorankam, in hohem Maße Leitungspositionen einzunehmen; dies veranlaßte die SED zu der kritischen Notiz, „daß die DBD sich als Interessenvertretung der LPG Bauern entwickelt“. Andererseits habe die Bauernpartei aber die „Tendenz des Ausweichens vor Schwierigkeiten bei der Einbeziehung werktätiger Einzelbauern und deren Gewinnung für die sozialistische Großraumwirtschaft noch nicht überwunden “. Am meisten erschwerten jedoch der Zustand der SED-Grundorganisationen und die weitgehende Wirkungslosigkeit der Ortsblöcke auf dem Land einen Durchbruch in der Kollektivierung. Daher seien „in einem großen Teil der Landgemeinden keine Voraussetzungen der Zusammenarbeit im Ortsblock gegeben“. Eine blockpolitische Schulung der gesamten SED-Bezirksleitung im Juni 1959 sollte dieses Übel an der Wurzel packen ${ }^{235}$.

Noch in der Hochphase der Kollektivierung im März 1960, während insgesamt über 14000 Agitatoren, darunter über 7000 hauptamtliche, im Bezirk unterwegs waren, war die Opposition der Einzelbauern über die Parteigrenzen hinweg evident. So bemängelte die Volkspolizei, es sei nicht gelungen, „vor allem in den Orten, wo es viele Mitglieder der CDU und der DBD unter den Einzelbauern gibt, durch einen verstärkten Einsatz der Mitglieder dieser Parteien Erfolge zu erzielen"236. Wie in Karl-Marx-Stadt stieß die Blockpolitik auch im Bezirk Dresden bei der Vollkollektivierung an Grenzen. Die potentiellen Handlungsträger in den Dörfern spalteten sich je nach Parteizugehörigkeit auf und zogen nicht gemeinsam für die Kollektivierung ins Feld ${ }^{237}$.

Einige bedeutendere Funktionäre der DBD in Karl-Marx-Stadt gerieten in Konflikt mit der SED. Voran ist Susanne Häber zu nennen, die einzige weibliche Funktionärin in einem Bezirkssekretariat und im Parteipräsidium während der fünfziger Jahre. Die SED-Kreisleitung lehnte 1958 ihre Volkskammerkandidatur, wenngleich erfolglos, ab, weil Häber intern die Meinung vertreten habe, die DBD solle in der Frage der politischen Führung von LPG nicht klein beigeben ${ }^{238}$.

Die DBD nahm im April 1960 eine Zwitterstellung zwischen LPG und altbäuerlichem Milieu, aber auch zwischen Anspruch auf politischen Einfluß in den LPG und Unterordnung unter die Vorherrschaft der SED in Zeiten der Vollkollektivierung ein ${ }^{239}$. Wie sehr letztlich die SED auf ein politisches Engagement der

1958 und zugleich die Anzahl der LPG-Vorsitzenden von 57 auf 97 fast verdoppeln; SAPMO DY 30 IV 2/15/18, Bericht der BL Karl-Marx-Stadt, 3. 6. 1959.

235 „Bei den Genossen auf dem Lande gibt es große Unklarheiten über die Rolle und Bedeutung der Blockpolitik. Das Sektierertum, eine Folge der Unkenntnis, ist ausgeprägt. Klarheit besteht vor allem darin nicht, daß es zwar in der DDR noch Widersprüche gibt, auch solche zwischen der SED und den kleinbürgerlichen Parteien, aber diese Parteien eben demokratischen Charakter tragen, sich unter der Führung unserer Partei im demokratischen Block vereinigt haben und sich nicht feindlich gegenüberstehen." Ebd.

236 SAPMO DY 30 IV 2/13/369, Informationsbericht des Operativstabes der HV Deutsche Volkspolizei, Nr. 1, 18. 3. 1960, Berichtsteil Karl-Marx-Stadt.

237 SAPMO DY 30 IV 2/7/11, Bl. $118 \mathrm{ff}$., Bericht zu sozialistischer Entwicklung auf dem Land, undatiert [Febr. 1960].

238 SAPMO/vorl. SED 4072, Bericht der KL Stollberg an BL der SED Karl-Marx-Stadt, 22. 7. 1958.

239 Dies verdeutlichte der oben in anderem Zusammenhang dargelegte Fall des Volkskam- 
DBD vor Ort angewiesen war, zeigt die ausgeprägte wirtschaftliche Verweigerungshaltung und politische Distanz zur SED-Herrschaft, wie sie unter den DBD-Genossenschaftsbauern des Typs I zwar allgemein zu beobachten, laut Bericht der Arbeitsgruppe $\mathrm{BO}$ aber in besonderem Maße im Bezirksverband KarlMarx-Stadt noch Ende 1963 anzutreffen war. An der Basis in den südlichen Bezirken gehörte es zu den weitverbreiteten „Unklarheiten“, daß ein Wettbewerb zwischen LPG und Einzelbauern an den Tag bringen würde, wer für die Bevölkerung mehr produziere; außerdem würden die LPG des Südens doppelt so viel produzieren wie die nördlichen. Die neuen MTS-Tarife würden als Hebel angesetzt, um „uns in die LPG-Typ III [zu] drücken“. Heinz Ackermann in der Arbeitsgruppe BO konzedierte einen Zusammenhang zwischen der politischen Einstellung und dem Handeln der Betroffenen: „Diese Unklarheiten finden ihren sichtbaren Ausdruck darin, daß ein großer Teil dieser DBD-Mitglieder noch nicht bereit ist, auf der Grundlage des Statuts die genossenschaftliche Arbeit durchzuführen, (besonders im Bezirk Karl-Marx-Stadt) werden ungenügende Anstrengungen gemacht, die Produktion auf dem Feld wie im Stall zu steigern, die Organisierung der genossenschaftlichen Viehhaltung verzögert und die Bildung der genossenschaftlichen Fonds nicht in Angriff genommen. Es gibt eine Reihe von DBD-Mitgliedern (besonders in Karl-Marx-Stadt), die die Zusammenlegung der Felder wieder rückgängig machten. “240

Die traditionelle Beharrungskraft vormals altbäuerlicher Milieus nahm in den LPG eigene, charakteristische Formen an. Dieses Festhalten an bisherigen Wirtschaftsweisen wie Lebensgewohnheiten und die Zurückweisung der neuen, durch die LPG verordneten Regeln überdauerte die Vollkollektivierung weit über das Jahr 1963 hinaus. Trotz aller Bemühungen der SED, die DBD-Spitze noch stärker gleichzuschalten, als diese es ohnehin bis 1960 war, und auf den Rang einer meinungslosen Erfüllungsgehilfin eigener agrarpolitischer Vorstellungen herabzudrücken, blieben die Auseinandersetzungen und Rivalitäten um politischen, gesellschaftlichen und persönlichen Einfluß in den Dörfern bestehen. Gerade in LPG des Typs I, die die Struktur und Lebensweise der ländlichen südlichen Teile der DDR prägten, konnte die SED aufgrund eigener Defizite in der Durchdringung des agrarischen Lebens auf die Mitglieder und Funktionäre der DBD, trotz aller Unzulänglichkeiten, die man jenen vorhielt, nicht verzichten.

Kontrastierend zum südlichen Bezirk Karl-Marx-Stadt sei der Bezirk Schwerin näher in den Blick genommen. Im Vergleich wies der Bezirk Schwerin Ende 1960 die höchste Zahl an Einzelbauern auf; dort lebten 3244 von ihnen, knapp ein Fünftel aller noch verbliebenen, die über ein Viertel der insgesamt noch einzelbäuerlich genutzten Fläche bewirtschafteten ${ }^{241}$. An diesem Bezirksverband interessiert be-

merabgeordneten A. aus dem Bezirk Karl-Marx-Stadt, der in der DBD seit Anfang der fünziger Jahre den Ruf einer angesehenen und „politisch verläßlichen“ Führungsfigur genoß. Vgl. S. $255 \mathrm{f}$.

240 SAPMO DY 30 IV A2/15/92, Die Situation in der DBD vor den Volkskammerwahlen 1963, 30. 10. 1963.

241 BStU MfS 102109, Orientierung über die Lage in der Landwirtschaft, 3. 3. 1961, eigene Berechnungen. 
sonders, ob die DBD in ihrem Gründungsland als Organisation eine spezifische Haltung einnahm oder unter den Mitgliedern besondere Einstellungen vertreten wurden.

Im IV. Quartal 1959 mußte die Leitung des Bezirksverbandes feststellen, daß die im vorausgegangenen Vierteljahr verzeichnete Steigerung des genossenschaftlichen Sektors erneut absackte. So wurde „die sozialistische Umgestaltung im Bezirk Schwerin“ erst „beschleunigt, nachdem die Bezirke Rostock und Neubrandenburg vollgenossenschaftlich waren" 242 . Die Abteilung Agrarpolitik hob eigens hervor, daß in Schwerin „bis auf Einzelfälle“ das „Prinzip der Freiwilligkeit“ nicht verletzt worden sei -, offenbar um sich so von den Vorreiterbezirken positiv abzugrenzen. Mit Ausnahme der Vorkehrungen, die man für den Parteitagsort und den Kreis Güstrow traf, wohin man Brigaden entsandte, u.a. um einen Kollektivierungsgrad herzustellen, der einem Parteitag angemessen schien ${ }^{243}$, fühlte sich die DBD demnach auch in ihrem Gründungsland weder dazu aufgerufen noch organisatorisch befähigt, eine besondere Initiative in Richtung Vollkollektivierung zu starten. DBD-Analysen zur Stimmung der Mitglieder hinsichtlich eines LPGBeitritts bestätigten, daß das viel grundsätzlichere Argument gegen einen Beitritt "wir wollen unsere Freiheit behalten" vor der Begründung "wir wollen noch abwarten" rangierte, die einen Eintritt prinzipiell schon in Aussicht stellte ${ }^{244}$. Auch sei das Kollektivierungstempo in den einzelnen Kreisen sehr unterschiedlich gewesen.

Der Bericht beschrieb eine für den Bezirk Schwerin weit verbreitete Haltung, die von der Praxis herrührte, mit Hilfe von Agitationsbrigaden den Dörfern eine Kollektivierung gezielt von außen aufzuzwingen. In Güstrow sei alles „so schnell“ gegangen, weil man dort mit gemischten Brigaden aufgetreten sei. Größere Probleme warfen dagegen die Kreise Hagenow - der größte Kreis des Bezirks und ein Grenzkreis - sowie Perleberg und Ludwigslust ${ }^{245}$ auf. Alle drei Kreise waren überwiegend altbäuerlich geprägt. In Hagenow wurde traditionell Viehzucht betrieben. Über die Bauern hinaus prägte diese Spezialisierung den Alltag der eingesessenen ländlichen Elite. In diesem gemäß Ideologie den „Großbauern" zugeschriebenen und also verwerflichen Einfluß erblickte die DBD die Ursache dafür, daß der Kreis noch Ende 1960 eine auffällige Häufung an Einzelbauern in der DBD aufwies ${ }^{246}$. Alle Überredungskünste waren dort bislang abgeprallt. Mitte März 1960 meldete man den „Durchbruch“ in den Viehzuchtgebieten

242 ACDP VI, unverz. Best. LV Mecklenburg, Aktendeckel BV Schwerin, Abt. Agrarpolitik 1952 ff., Bericht IV. Quartal 1959; ebd., Abschlußbericht zur sozialistischen Umgestaltung der Landwirtschaft im Bezirk Schwerin 1960 (Zitat).

243 Vgl. oben Kap. IX.2, S. 455; zu Güstrow ACDP VI-052-0540, Protokoll Sekretariat, 23. 11.1959.

244 ACDP VI, unverz. Best. LV Mecklenburg, Aktendeckel BV Schwerin, Abt. Agrarpolitik 1952 ff., Bericht IV. Quartal 1959.

245 Dort betrug 1945 der Anteil an Betrieben über 100 ha nur 11,8\%; Woderich, Zu den Anfängen, S. 43.

246 ACDP VI-052-186/1, Einschätzung der organisatorischen Entwicklung unserer Partei im Jahr 1960, 8. 2. 1961; SAPMO DY 30 IV 2/5/35, Bl. 96 f., Aktenvermerk Abt. Leitende Organe zur Lage im Kreis Hagenow, 18. 8. 1960. 
Hagenows. Nun versuchte die Bezirksleitung der Tendenz gegenzusteuern, in jedem Dorf fünf LPG Typ I zu gründen. Unmittelbar nach Abzug der Brigaden stieg in den drei Kreisen die Zahl der LPG-Austritte sofort wieder an, den absoluten Zahlen nach allerdings in harmlosem Ausmaß. Die Parteitagsdelegierten der DBD aus Hagenow trugen Gerhard Grüneberg, für sie der Exponent der Vollkollektivierung, die Zwangspolitik nach und warfen ihm dies noch im Juni 1963 vor ${ }^{247}$.

Andere Probleme plagten die DBD im Kreis Ludwigslust, der in der LPG-Bildung bis Mitte 1959 das Schlußlicht des Bezirkes war ${ }^{248}$. Bis dahin lag die Initiative zur LPG-Gründung offenbar meist bei einzelnen Personen der DBD, die, wie im Fall von Fritz Schenk, der die Bildung der LPG in Groß Schmölln, Kreis Ludwigslust, in die Wege leitete, altgediente KPD-Mitglieder waren und schon im SED-Auftrag die Parteigründung mitgetragen hatten. Im September 1959 sei zwar eine „stärkere Aktivität der Genossenschaftsbewegung zu verzeichnen, wohl deshalb weil Partei- und Staatsapparat ständig darauf gedrängt hätten diese zu verbessern“. Dann aber habe die Brigade den Fehler begangen, die Parole auszugeben, daß „um jeden Preis bis zum 7.10. 1959 in jeder Gemeinde eine LPG bestehen soll. So ist in Niendorf bei Tewswoos eine LPG gegründet worden, die sich aus dem Bürgermeister und seiner Frau (ohne Land), der Gemeindesekretärin (2 ha) und einem Bauern (15 ha), der bisher in keinem Jahr sein Soll erfüllt hat, zusammensetzt. Alle anderen Bauern haben dieses nun zum Vorwand genommen, sich dadurch von der LPG zu distanzieren und es wird schwer sein, sie in der nächsten Zeit für den Eintritt in diese LPG zu gewinnen."

An vier LPG, die allein im August im Kreis Ludwigslust gegründet wurden, beteiligte sich kein einziges DBD-Mitglied, obgleich in jenen Dörfern intakte Grundeinheiten bestanden. Daher sollte das Kreissekretariat mobilisiert werden. Eine Überprüfung ergab dann, daß weit über die Hälfte der Kreisvorstandsmitglieder als auch der Bürgermeister der DBD noch Einzelbauern waren. Den Ludwigsluster Rückstand führte man ursächlich auf die Haltung der Bürgermeister zurück, die als Ausgangspunkt von Aktionen staatlicher Organe fungieren sollten ${ }^{249}$. Schon Anfang 1959 hatte der ministerielle Apparat hinsichtlich der Vorgänge im Bezirk Neubrandenburg darauf hingewiesen, daß die jeweilige Einstellung der Bürgermeister für „Überspitzungen“ verantwortlich gewesen sei: „Es muß jedoch bereits jetzt auf eine mögliche Gefahr verwiesen werden, die sich in Potsdam abzuzeichnen begann und die darin besteht, daß durch die Übernabme von Verpflichtungen zur Bildung von LPG durch Funktionäre des Staatsapparates das Prinzip der Freiwilligkeit verletzt wird. “250 Gerade die politische Bearbeitung

247 SAPMO DY 30 IV 2/7/369, Bericht vom 18.3. 1960, Berichtsteil Schwerin. SAPMO DY 30 IV 2/5/192, Bl. 117, Aktenvermerk Abt. Leitende Organe, 20. 7. 1960. Vgl. MLHA BPA Schwerin IV 2/15/1688, Bericht SED KL Perleberg, 28.11. 1959. SAPMO NY 4233/44, Bl. 296-299, Information [über Verlauf des VII. DBD-PT], 4. 5. 1963.

$248 \mathrm{Vgl}$. Berichte seit 1954 und Beurteilungen zu Schenk in SAPMO DY 30/vorl. SED 4072.

249 ACDP VI, unverz. Best. LV Mecklenburg, Aktendeckel BV Schwerin, Abt. Agrarpolitik 1952 ff., Bericht über Mitarbeit bei der Entwicklung der sozialistischen Landwirtschaft, 2. 9. 1959, hier zu Ludwigslust.

250 BA DK-1/6554, Bl. 56 ff., Einschätzung der LPG-Bezirks-Konferenz in Neubranden- 
der Bürgermeister und damit die Versuche, über diese Personen einen Meinungsumschwung der Gesamtgemeinde in Richtung LPG zu bewirken, belegt eindringlich, daß ein solch radikales Vorgehen als Hebel gegenüber der Gemeinde nicht nur bekannt war, sondern prinzipiell gebilligt und systematisch herbeigeführt wurde.

Doch zurück zu den Vorgängen in Ludwigslust: Anfang 1960 analysierte die SED-Kreisleitung die Situation in der DBD wie folgt: „Die Hauptfrage ist die, daß ein Teil der Mitglieder sich noch nicht für die LPG entscheiden kann und nach einem dritten Weg sucht“, z. B. in der „Politik des Abwartens“251. Tatsächlich lag die DBD dort mit einem Anteil von 36,2\% LPG-Angehörigen unter den bäuerlichen Mitgliedern weit unter dem Bezirksschnitt vom Januar 1960, der sich knapp unter $60 \%$ bewegte 252 . Die Partei riskierte ständig, die Einzelbauern, die nach Aussage der SED „nur zögernd und auf Aufforderung an der Diskussion“ teilnahmen, in ihren Reihen gänzlich zu verlieren.

1961 errichtete die SED-Bezirksleitung aus gegebenem Anlaß in den LPG Typ I im Kreis Ludwigslust sogenannte „Konsultationsstützpunkte“. Sie sollten bewirken, daß die LPG-Statuten eingehalten würden, man endlich genossenschaftlich arbeite und die wieder eingebrachten Grenzsteine endgültig entferne. Der 1. Bezirkssekretär Bernhard Quandt lamentierte in diesem Zusammenhang gegen die Klein-LPG Typ I, da man mit ihnen „den Sozialismus nicht erringen“ könne. Denn die „kleinen LPG zwingen uns in den Dörfern eine Diskussion auf, die man gar nicht so einfach bewältigen kann. Den Kapitalismus muß man schlagen." 253 Eine Reihe ehemaliger Einzelbauern der DBD in Ludwigslust begegnete der neuen Organisationsform LPG auch noch Mitte 1962 distanziert und interesselos. So würde in der LPG Typ I in Bochin, die ein Kollege der DBD leitete, weder das Leistungsprinzip noch die „innergenossenschaftliche Demokratie“ beachtet, vielmehr sähen die Mitglieder überhaupt nicht ein, „warum man sich versammeln solle“ 254 .

burg 8./9. 2. 1959, Zitat Bl. 67, eigene Hervorhebung. Nur selten finden sich solch eindeutige Belege für dieses zielgerichtete Vorgehen mittels Verpflichtungen. Zu den günstigen Bedingungen in Neubrandenburg: „Die Tatsache, daß 139 Bürgermeister im Bezirk Neubrandenburg Mitglied der LPG sind, hat sich günstig auf die Entwicklung der LPG, vor allem im Hinblick auf die Unterstützung der LPG durch die Gemeinden ausgewirkt." (Bl. 56).

251 So gebe es in fünf Ortschaften, in denen DBD-Grundeinheiten existieren, noch keine LPG, in acht Orten nur LPG ohne DBD-Beteiligung. Nachfolgende Zitate in MLHA BPA Schwerin IV/2/15/1688, Bericht der SED KL Ludwigslust über KDK der DBD am 27. 11. 1959, 20.1. 1960.

252 Siehe Tabelle 25. Im August 1959 lag dieser Anteil im BV Schwerin immerhin auch schon bei 48,8\%; ACDP VI, unverz. Best. LV Mecklenburg, Aktendeckel BV Schwerin, Abt. Agrarpolitik $1952 \mathrm{ff} .$, Bericht über die Mitarbeit bei der Entwicklung der sozialistischen Landwirtschaft, 2. 9. 1959.

253 MLHA BPA Schwerin IV/2/3/196, Protokoll Bürositzung der BL der SED, 10. 8. 1961, TOP 2, Bericht über Stand der Entwicklung der LPG, Bl. 3 ff.

254 ACDP VI, unverz. Best. LV Mecklenburg, Abt. Agrarpolitik 1952 ff., Bericht Abt. Wirtschaft DBD Schwerin an PV, 24. 8. 1962. 
Neben dem Problem der traditionellen Haltung der Einzelbauern in der DBD beschäftigte sich die SED seit geraumer Zeit mit der starken Stellung der Bauernpartei im Bezirk Schwerin und speziell mit der Konkurrenz in den LPG. In vielen Dörfern im Bezirk Schwerin gaben auffälligerweise entweder die DBD-Mitglieder oder die SED, d. h. nicht beide gemeinsam, den Ton an. Im Falle der LPG Buchenhof im Kreis Bützow, der überwiegend agrarisch geprägt war, schickte die SED als Begründung vorweg, daß oft in „solchen zahlenmäßig starken DBDOrtsgruppen viele ehemalige Genossen sind, die 1948 der DBD beigetreten sind“; man habe dort nun keine politische Konzeption mehr, die Führung der LPG an sich zu reißen, "praktisch würden die DBD-Mitglieder das Geschehen im Dorf“ bestimmen: „Das ist vor allem deshalb der Fall, weil in den DBD-Ortsgruppen meist die einflußreichsten Bauern, die früher oft auch die ökonomisch stärksten Einzelbauern waren, die Leitung sowohl in der DBD als auch in den LPG in der Hand haben. Das wird von den Genossen zu wenig berücksichtigt, so daß diese einflußreichen Bauern die Politik bestimmen. Sie nehmen zwar keine feindliche Haltung ein, treten aber als konservative Elemente in Erscheinung, weil sie an alten Gewohnheiten zäh festhalten und ihre Ideologie als Einzelbauern noch nicht abgelegt haben." Deshalb werde dort auch der Übergang von Typ I zu Typ III nicht vollzogen 255 .

Umgekehrt würde eine Reihe von Funktionären Diskussionen darüber führen, wie lange die DBD noch existieren werde. Im Kreis Bützow, in dem die Parteigründung offenbar vornehmlich von ehemaligen SED-Mitgliedern getragen worden war, die dann eine Vorreiterrolle in der Kollektivierung spielten, ging manchen DBD-Mitgliedern die Entwicklung ihrer Partei zu langsam vonstatten; einige erwogen daher, in die SED überzuwechseln, wogegen sich wiederum die SED-Kreisleitung wandte. Offensichtlich ist von einem klar indoktrinierten Teil der Mitgliedschaft jener kleinere zu unterscheiden, der zwar DBD-Mitglied war, aber auch zum offiziellen Ende der Vollkollektivierung noch keiner LPG angehörte ${ }^{256}$. Die höhere Zahl an Genossenschaftsmitgliedern in den einst „rückständigeren" Kreisen ist auf vehementen politischen $Z$ wang in diesen Brennpunkten zurückzuführen, während man sich im Fall Bützow offenbar darauf verließ, daß der Sozialismus in der Landwirtschaft dort ohnehin gesichert sei.

Mit dem kollektivierungsfreundlichen Verhalten der Parteigründergeneration in Bützow kontrastiert die Einstellung der bäuerlichen Mitglieder im für die Gründung zentralen Kreis Wismar im Bezirk Rostock. Die Anzahl der bäuerlichen Mitglieder der DBD in LPG (58\%) dort lag bis März 1959 klar hinter dem ansonsten erreichten Stand an Genossenschaftsbauern (80\% ${ }^{257}$. Womöglich spiegelt sich darin ein gewisses Fortwirken der Parteigründer, die, obgleich von der

255 SAPMO DY 30 IV 2/15/5, Bericht über Einsatz in Bützow, 3.-7. 3. 1959. In diesem Kreis waren bis dahin schon $67 \%$ der EB in LPG eingetreten, im März gab es noch 1016 EB. Die SED zählte ca. 500 bäuerliche Mitglieder und lag damit gleichauf mit der DBD, die 535 Mitglieder hatte. In der LPG Buchenhof gehörten 20 von 23 Genossenschaftsbauern der DBD an.

256 Vgl. ACDP VI, unverz. Best. LV Mecklenburg/BV Schwerin, Aktendeckel BV Schwerin, Abt. Agrarpolitik $1952 \mathrm{ff}$.

257 SAPMO DY 30 IV 2/15/5, Bericht über Einsatz in Bützow, 3.-7.3.1959. 
SED erkoren, bald wegen politischer Verdächtigungen bzw. eines zu großen Grundbesitzes von den Führungspositionen entfernt wurden ${ }^{258}$. Diese These wird auch durch das opponierende Verhalten der dort erst spät kollektivierten Einzelbauern gestützt. So war einerseits zu beobachten, daß man ältere LPG des Typs I schon zu solchen des Typs III umwandeln konnte, andererseits gab es „in einer Reihe neugebildeter LPG Typ I große Unklarheiten über den sofortigen Beginn der gemeinsamen Zusammenarbeit"259. Abgeschreckt von Berichten, wonach LPG-Vorsitzende für wirtschaftlichen Mißerfolg gerichtlich belangt worden seien, würden sich Bauern auch weigern, Vorstandspositionen zu übernehmen. Das Politbüro und in dessen Fahrwasser dann die DBD-Führung wählten unter anderen den Kreis Wismar zur Demonstration der Erfüllung und Übererfüllung des Volkswirtschaftsplanes aus, um dort eine vermeintliche „Massenbewegung von unten“" zur Kollektivierung mit allen Mitteln in Gang zu setzen²60.

\section{Die Reaktion der Partei: Funktionäre, Mitglieder und die Kollektivierung}

Im folgenden sollen charakteristische Reaktionen der DBD-Mitglieder auf die Kollektivierung nach typologischen Gesichtspunkten vorgestellt werden. Da ein Großteil der speziell für DBD-Kollegen nachgewiesenen Stimmungen, Reaktionen und Verhaltensmuster auch allgemein in der ländlichen Bevölkerung festzustellen war, erlauben sie Rückschlüsse über den engeren Rahmen der Partei hinaus.

Die Parteifunktionäre der DBD in den Vorständen aller Ebenen vertraten im Prinzip eine ähnliche Bandbreite an Einstellungen zu den LPG, wie sie in der Gesamttendenz bei den DBD-Mitgliedern des jeweiligen Raumes vorfindlich war. Der ausschlaggebende Faktor lag in der politischen, sozialen und wirtschaftlichen Struktur des Heimatortes. Ein solcher Zusammenhang wurde durch die Praxis der ehrenamtlichen Tätigkeit in den Vorständen begünstigt, die eine Verankerung im Dorf voraussetzte und sich grundlegend von einer hauptamtlichen Anstellung etwa als Kreissekretär unterschied. Je höher die Position der bäuerlichen Repräsentanten war, desto mehr standen sie unter Druck, den Schritt in die Genossenschaft zu vollziehen. Ende 1959 gehörten rund $80 \%$ der bäuerlichen Bezirksvorstandsmitglieder LPG an, aber erst knapp $75 \%$ der Kreisvorstandsmitglieder ${ }^{261}$.

258 Siehe Bauer, Gründung, S. 306.

259 SAPMO DY 30 IV 2/5/292, Bl. 170 ff., Zitat Bl. 171, Informationsbericht LOPM aus den Bezirken Schwerin, Neubrandenburg, Frankfurt/Oder, Rostock, Cottbus, Magdeburg, Halle, 31. 3. 1960.

260 SAPMO DY 30 J IV 2/2/684, Protokoll PB, 19. 1. 1960, TOP 8 Einsatz von Arbeitsgruppen zur Verbreitung der Massenbewegung in der Landwirtschaft zur Überbietung des Volkswirtschaftsplanes 1960, BI. 5.

261 Siehe Tabellen 21 und 22. Dagegen waren Ende 1959 im Bezirk Halle schon 93,2\% der Kreisvorstandsmitglieder in LPG, aber erst $88 \%$ der bäuerlichen Bezirksvorstände. Dies 
Über die Beitrittsaktivität der Ortsvorstände liegen keine zusammenhängenden Daten vor. Doch sie dürften sich ebenso verhalten haben wie die einfachen Mitglieder vor Ort. Die Ergebnisse zur Neuwahl der Ortsgruppenvorstände von 1961 , laut denen rund $80 \%$ der Vorstände des Jahres 1960 wiedergewählt wurden, wiesen einen hohen Anteil von Funktionsträgern in den LPG auf: Rund ein Viertel aller Vorstände waren LPG-Vorsitzende, knapp ein Drittel gehörte LPG-Vorständen an, gut ein Zehntel arbeitete als Brigadiere. Die Distanz der Mitglieder zu den LPG-Vorsitzenden und Brigadieren aus der eigenen Partei war allerdings daran erkennbar, daß letztere 1961 in zu geringem Maße, wie die Parteiführung monierte, zu den Kreisparteikonferenzen delegiert wurden ${ }^{262}$. Die Toleranz gegenüber Einzelbauern nahm in den Parteiebenen nach unten hin zu. Gleichzeitig drängte die Parteileitung darauf, die einzeln wirtschaftenden Kollegen nicht administrativ von den Funktionsposten zu entfernen, vielmehr die Problemfälle durch freiwillige Einsicht zu bekehren. Letzteres war ein weitaus schwierigeres Unterfangen. Manche Bezirksverbände neigten allerdings seit der Parteivorstandssitzung vom 16./17. September 1959 dazu - sie hatte als „Hauptaufgabe“ die Herbeiführung von LPG-Beitritten ausgegeben -, Einzelbauern in die LPG zu zwingen, schon um die eigene Statistik aufzubessern ${ }^{263}$.

Die Volkskammerabgeordneten der DBD waren als staatliche Repräsentanten nicht zuletzt aufgrund der Kontrolle durch Materns Apparat - schon ab Mitte der fünfziger Jahre genötigt, einer LPG beizutreten und sich als aktive Vorkämpfer des sozialistischen Teils der Landwirtschaft auszuweisen, sofern sie ihr Amt nicht verlieren wollten ${ }^{264}$. Eine Reihe von Funktionären zog sich seit 1958 daher aus eigenem Entschluß aus der Parteiarbeit zurück, weil sie die ausschließliche Konzentration auf die LPG nicht mittragen wollten. So trat im Bezirksverband Schwerin ausgerechnet eine Gruppe von ohnehin knappen Schulungsleitern ab, deren Posten zunächst mangels genossenschaftsbäuerlichen Nachwuchses unbesetzt blieben ${ }^{265}$.

dürfte auf den massiven Kollektivierungsdruck im Bezirk 1958/59 zurückzuführen sein, der auf Initiative der SED unmittelbar in den Dörfern von Kampagnen ausgeübt wurde und auf eine vorherige Rückversicherung bei anderen Parteien im Bezirk verzichtete.

262 ACDP VI-052-186/2, Abschluß Neuwahlen der Ortsgruppenvorstände, 28. 4. 1961, eigene Berechnungen; ACDP VI-052-186/1, Einschätzung der organisatorischen Entwicklung unserer Partei im Jahr 1960, 8. 2. 1961.

263 Nach wie vor galt zwar, daß die Vorstände der DBD durch die SED bestätigt werden sollten. In der Praxis ist der unmittelbare SED-Einfluß nur für Volkskammerkandidaten nachzuweisen. Solange die SED-Kader ihrerseits nicht gänzlich auf die Vollkollektivierung ausgerichtet waren, legten sie offenbar keinen großen Wert darauf, daß die DBD als bäuerliche Vertreter in den Vorständen ausschließlich Genossenschaftsbauern akzeptierte.

264 Vgl. dazu eine Reihe von Einzelfällen an zurückgezogenen Kandidaturen aufgrund von unklarer bis ablehnender Einstellung zur Kollektivierung in SAPMO DY 30/vorl. SED $4071,4072$.

265 ACDP VI, unverz. Best. LV Mecklenburg, Aktendeckel Tätigkeitsberichte 1954 [enthält Berichte bis 1958] Quartalsbericht Einschätzung der Arbeit des BV Schwerin, I. Quartal 1958. 
Grundsätzlich strebte die Parteiführung danach, Funktionäre in Vorständen und Mitglieder bei allem Druck zum LPG-Eintritt in der Partei zu halten, Unwillige nicht auszuschließen und Austrittskandidaten wiederzugewinnen. Im Unterschied zur Parteispitze, die durch die kaderpolitische Überwachung der SED zunehmend geknebelt wurde, betrieb die DBD vor Ort aus existentiellen Gründen eine sehr elastische Personalpolitik.

Die Mitgliedschaft der DBD war spätestens seit der Übernahme der Sozialismuslosung in der Landwirtschaft 1957 gespalten. Da gab es zunächst die Anhänger der LPG, darunter eine ganze Reihe von besonders engagierten Aktivisten der Kollektivierung. Dazu zählte überwiegend jene Kerngruppe, die schon vor längerer Zeit einer LPG beigetreten war; immerhin machten die LPG-Angehörigen seit 1955 rund $15 \%$ der bäuerlichen Mitglieder aus ${ }^{266}$. Viele unter ihnen interpretierten die Vollkollektivierung als späte Bekräftigung ihrer eigenen Entscheidung: Der LPG-Beitritt hatte sie nämlich zuvor innerhalb des dörflichen Sozialverbandes vor allem in altbäuerlichen Gegenden häufig an den Rand gedrängt ${ }^{267}$; als Mitglieder von betriebswirtschaftlich solideren, weil länger bestehenden LPG waren sie jetzt automatisch sozial aufgewertet.

Viele stabilere LPG mit einem ausgeprägten inneren Sozialgefüge wehrten sich 1959 gegen die massenhafte Aufnahme neuer Mitglieder; dies galt insbesondere, wenn diese jahrelang politisch als „dubios“ gegolten hatten oder wenn es sich dabei um die traditionelle dörfliche Führungsschicht handelte, die die Machtverhältnisse in den LPG umzustülpen drohte ${ }^{268}$. Insofern war der angeordnete „Kampf um die Gewinnung der ökonomisch starken Bauern" auch ein Kampf gegen die Vorbehalte der LPG-Führungselite ${ }^{269}$. Diese LPG-Altvorderen der DBD drängten nach dem Vollzug der Kollektivierung darauf, die LPG wie versprochen mit der nötigen Technik auszustatten. Selbstbewußt forderten sie häufig, eine eigene Parteiorganisation der DBD in den LPG einzurichten.

Zur zweiten und umfassenderen Gruppe zählten diejenigen, die nur auf Druck und widerwillig den Weg ins Kollektiv fanden - und dort blieben. Am anderen Ende der Skala rangierten zum einen die massiven Gegner der Kollektivierung, die sich ein Leben in LPG aus weltanschaulichen Gründen nicht vorstellen konnten; diese Gruppe schmolz zusehends zusammen. Ende 1961 - dann endet die Berichterstattung hierzu - zählte die DBD noch gut 200 einzeln wirtschaftende Bauern. Zum anderen wandte sich eine weitere, kleinere Gruppe gänzlich von der DDR-Landwirtschaft $a b$, indem sie sich in den Westen absetzte oder in andere attraktiver erscheinende Berufszweige wechselte; letzteres galt vor allem für die

266 Siehe dazu Tabelle 7, Stand Juni 1955, bezogen jetzt allerdings nicht auf die Gesamtmitgliedschaft (rund 10,5\%), sondern nur auf die bäuerlichen Mitglieder.

267 Siehe „Erfahrungsberichte" von DBD-Mitgliedern wie Helmut Merke in: 40 Jahre Demokratische Bauernpartei Deutschlands, S. $228 \mathrm{ff}$., und Heinz Siebert, S. $234 \mathrm{ff}$., Hellmuth Weiß, S. $237 \mathrm{ff}$., Günter Urzynicok, S. 243 ff.; Wille, demokratische Bodenreform, S. $239 \mathrm{ff}$; vgl. Graffunder, Dialektik, S. $110 \mathrm{ff}$.

268 Z.B. im Bezirk Gera; SAPMO DY 30 J IV 2/2/662, Protokoll PB, 4. 8. 1959, TOP 9, Anlage 4, Bl. 5, $31 \mathrm{ff}$.

269 Umgekehrt verweigerten viele Einzelbauern den Beitritt gerade in jene LPG, zu deren Mitgliedern sie vordem ein distanziertes Verhältnis hatten. 
nachwachsende Generation. Hingegen war für die mittleren und älteren Jahrgänge der Gang in die LPG die einzige Chance, im angestammten Beruf zu bleiben; denn wer flüchtete, mußte davon ausgehen, im Westen keine neue Existenz als Landwirt aufbauen zu können.

Obwohl für Agrarfunktionäre wie Grüneberg die Kollektivierung und die Einführung landwirtschaftlicher Großbetriebe mit einem zahlenmäßigen Rückgang der in der Landwirtschaft Beschäftigen Hand in Hand ging, diese also akzeptiert und höchstwahrscheinlich bis zu einem gewissen Grad intendiert war, überstieg die Dynamik der Landflucht ab 1960 die vorhandenen Kompensationsmöglichkeiten. Das MfS hielt im Zusammenhang mit dem Jugendkommuniqué des Politbüros von $1961^{270}$ fest: „Wir müssen alle operativen Möglichkeiten anwenden, um den weiteren Abgang Jugendlicher aus dem Dorfe einzuschränken. Gegenwärtig ist eine solche Lage, daß der Abgang der Jugendlichen aus dem Dorfe schneller vor sich geht wie die Entwicklung oder Bereitstellung der landwirtschaftlichen Technik. Das ist eine große Gefahr." 271 Die Devise „Maschinen statt menschlicher Arbeitskraft" krankte einerseits daran, daß man sich keine hinreichende Technisierung leisten konnte, andererseits fehlte häufig das meist jüngere ausgebildete Personal, um die maschinelle Umstellung zu bewältigen. Da die Landflucht der Jugendlichen in einem nicht vorausgesehenen Ausmaß anstieg, erwuchs der DBD eine neue Aufgabe. Es galt, dieser Abwanderung entgegenzuwirken, indem sie Jugendliche, die auch die FDJ auf dem Land wegen der Ausrichtung ihrer Tätigkeit auf die Betriebe schwer erreichte ${ }^{272}$, in das dörfliche Milieu einbinden sollte.

Durch die Basis verlief 1960 ein tiefer Graben. Rund ein Drittel bis die Hälfte der Mitglieder quittierte das Engagement der DBD bei der Kollektivierung mit Abwendung von der Partei und Passivität ${ }^{273}$. Da man Ausschlüsse vermeiden wollte und die Gremien alles daransetzten, die inaktiven Mitglieder im Gespräch wieder zu erreichen, konnte der Zusammenhalt der fünfziger Jahre über die Krise bis 1963 leidlich gerettet werden. Außerdem stabilisierten jene Gruppen die Partei, die persönlich weniger von der Kollektivierung betroffen waren, wie die rund $30 \%$ Angestellten, Arbeiter und sonstigen Kleingruppen. Ihnen eröffnete die Kollektivierung zum Teil neue soziale Aufstiegschancen in der LPG. Als sich die ökonomischen Grunddaten der DDR-Agrarwirtschaft ab Mitte der sechziger Jahre verheißungsvoll besserten ${ }^{274}$, engagierten sich auch die jahrelang enttäuschten DBD-Mitglieder wieder mehr.

Diese Grobtypologie gilt es im folgenden weiter aufzugliedern ${ }^{275}$. Die Einwände der Mitglieder gegen einen LPG-Eintritt waren vielfältig, lassen sich aber

270 Vgl. Schuster, SED-Jugendkommuniqués, und Skyba, Hoffnungsträger, S. 416-418.

$271 \mathrm{BStU}$ MfS 102109, Orientierung über die Lage in der Landwirtschaft, 3. 3. 1961, Bl. 29.

272 Skyba, Hoffnungsträger, S. 410.

273 ACDP VI-052-186/1, Abt. Organisation, Einschätzung der Entwicklung im III. Quartal, 1.11. 1960.

274 Nehrig, Landwirtschaftspolitik, S. 300-302; Kuntsche, Umgestaltung; Roesler, Plan, S. 130.

$275 \mathrm{Da}$ es an lokal eindeutig zuzuordnenden Berichten aus DBD-Materialien mangelt und die Argumentationen überwiegend in der aggregierten Berichtsform des zentralen Apparates vorliegen, ist es kaum möglich, die spezifische lokale Gesprächssituation zu rekonstruie- 
in einigen Begründungssträngen zusammenfassen. Ein Argument kreiste um den schlechteren Verdienst, die unklaren juristischen Verhältnisse und Verfahren beim Beitritt. Das berührte etwa die Eigentumsverhältnisse oder die Ausbezahlung von in die LPG eingebrachten Eigentumsanteilen an Vieh und totem Inventar. Aufgrund der oftmals niedrigeren Verdienste fürchteten viele einen Einkommensund Statusverlust in der LPG, zumal wenn diese in einem desolaten Zustand war; außerdem wurde den bislang erfolglos wirtschaftenden Genossenschaftsmitgliedern unterstellt, auf Kosten der Neumitglieder höhere Verdienste und ein einfacheres Wirtschaften zu erreichen ${ }^{276}$. Die Mitglieder führten auch die vormals von den Politfunktionären selbst benutzten, Anfang 1960 aber ideologisch überholten Argumente ins Feld, denen zufolge die Einzelbauern ihrer Pflicht dadurch nachkommen sollten, daß sie die Marktleistung und Produktivität im Rahmen des Fünf- bzw. Siebenjahrplanes steigerten; als Einzelbauer könne man diese Pflicht viel besser erfüllen als in unrentablen LPG. Schon seit 1956 drehten die Gegner den Spieß um und erklärten, sie wollten mit ihrem Eintritt die aufgrund der enormen Zahlungen an LPG und MTS ohnehin strapazierte Staatskasse nicht noch mehr schädigen ${ }^{277}$. Allerdings griffen diese Argumente dann nicht mehr, als die Kampagne im Frühjahr 1960 die LPG nicht nur als einzige volkswirtschaftlich zwingende Lösung verkaufte, sondern den Beitritt zur Feuerprobe politischen Wohlverhaltens erklärte: Nur wer für die LPG sei, sei für den Frieden, gegen Krieg und damit für den Sozialismus. Ein Teil der Mitglieder ließ sich durchaus auf die Propagandamuster der SED ein, sofern sie den eigenen Zwecken nützlich erschienen. Im Eingehen auf den SED-Diskurs ist zweifellos ein gewisser Politisierungserfolg des Regimes zu sehen. So stießen die Agitationsbrigaden in Halle 1959 auf folgende Meinung eines einzelbäuerlichen Genossen, die auch in der DBD verbreitet war: "Geht lieber produktiv arbeiten und macht euch aus dem Dorf raus. In die LPG gehe ich nicht, denn da müßte ich verhungern. Als Sozialist bin ich mit Eurer Politik nicht einverstanden, weil Ihr Bolschewisten seid und den Bolschewismus wollt." 278

Eine ähnliche Zielrichtung verfolgten die mit erbrechtlichen Traditionen und generationellen Fragen verknüpften Einwände 279 : Auf die alten Tage würde man

ren. Zum bäuerlichen Verhalten in der heißen Kollektivierungsphase mit einigen DBDBeispielen, siehe auch Osmond, Kontinuität, S. 155-163. Vgl. auch Langenhan, „Halte Dich fern von den Kommunisten“, S. 150 ff., Schier, Alltagsleben, S. 150-152.

276 Niedrigere Einkünfte ergaben sich lt. Staatlicher Plankommission für Mittel- und „Großbauern" und Bauernfamilien, die mit weniger Mitgliedern eintraten, als vorher im Betrieb beschäftigt waren; BA DE-1/1254, Bl. 2-13, Information über einige Probleme in der LW, 30. 9. 1960, hier Bl. 9-11.

277 Dies teilte Scholz auch dem Sekretär der sowjetischen Botschaft, Kulikow, mit; International Department, Rolle 109 (RGANI, 5-26-427, Bl. 89-94), Protokoll über Gespräch, 26. 3. 1956, hier Bl. 92.

278 SAPMO NY 4182/1082, Bl. $66 \mathrm{ff}$, Karl Gutjahr, Information zu Fragen der Gewinnung von Bauern für die LPG, Tätigkeit einer Brigade in Halle, 26. 7. 1959, Zitat Bl. 71.

279 Vgl. dazu am Beispiel der Magdeburger Börde allgemein Griepentrog, Struktur, zu den Altenteilregelungen, S. $102 \mathrm{f}$. Bis in die siebziger Jahre hinein mußten Regelungen zum Ausgedinge oder Altenteil getroffen werden, um die ausscheidende Großelterngeneration zu versorgen, S. $105 \mathrm{f}$. 
vor so einem tiefgehenden Einschnitt mit Auswirkungen auf die Nachwachsenden zurückschrecken, die nächste Generation solle den Schritt tun und dann auch verantworten. Die Kollektivierung prallte hier mit einer tief verwurzelten mentalen Einstellung in altbäuerlichen Gegenden zusammen, derzufolge sich die Hofinhaber primär in der Rolle von zeitlich befristeten Trägern einer bestimmten Aufgabe sahen, nämlich den Hof als Lebensgrundlage an die nächste Generation weiterzugeben; man verstand sich weniger als Eigentümer, die über ihr Kapital frei verfügen konnten und denen die LPG unter Umständen ein bequemeres Leben eröffnete. Wie sehr die Kollektivierung diese generationelle Verklammerung aufbrach, illustriert die unerwartet hohe Abwanderung Jugendlicher aus der Landwirtschaft.

Eingeschüchtert durch Agitatoren und Vorladungen von staatlichen Instanzen, die für widerständiges Verhalten Strafen verhängen konnten, reagierten viele weniger mit grundsätzlichen Einsprüchen als mit pragmatischen Begründungsmustern. Nichtsdestotrotz hielt man an der Verzögerungsstrategie fest und suchte die Werber nebulös auf die "nächsten Jahre“, die Zeit nach einer selbst bestimmten Zäsur, etwa nach der nächsten Herbsternte, nach dem Heranwachsen der Kinder etc. als Eintrittsdatum zu vertrösten. Diese dilatorischen Argumente wiesen die Bedrängten nicht von vornherein als Systemgegner aus.

Eine andere Gruppe versuchte dem steigenden Kollektivierungsdruck ab Mitte 1959 mit grundsätzlich anderen, ideell bestimmten Alternativentwürfen zu begegnen, die im SED-Jargon als „Einzelbauernideologie“ verdammt wurden. Man wolle sein Eigentum und die persönliche Freiheit nicht verlieren, sondern an der unabhängigen Lebensform festhalten; man lasse sich nicht die Arbeit - und damit einen konstitutiven Teil des bäuerlichen Alltags - von irgendjemandem, gar minderqualifizierten SED-Hörigen in der LPG diktieren. Teilweise brachte man gegen einen Eintritt vor, daß die damit verbundene Akzeptanz des Sozialismus nicht mit der religiösen Haltung zu vereinbaren sei. Belegt ist dies für das katholische Eichsfeld oder katholische Siedlungsgebiete wie etwa in Teterow ${ }^{280}$. Auch die DBD wollte religiös gebundene Personen ansprechen, wie aus verschiedenen Artikeln ihrer Parteipresse hervorgeht, in denen LPG-Mitglieder über die Religionsfreiheit berichteten oder Pfarrer sich angeblich für die LPG aussprachen ${ }^{281}$.

280 Die Bedeutung dieses Faktors spiegelt sich auch im Bemühen der SED wider, durch diverse Aktionen eine vermeintliche Zustimmung beider Kirchen zu suggerieren, in der Hoffnung, dies beeinflusse das Verhalten des Kirchenvolkes. Für die katholische Kirche ließen die Bischöfe und bischöflichen Kommissare der Berliner Ordinarienkonferenz in einem Schreiben vom 6.4. 1960 an Grotewohl keinen Zweifel an den Verletzungen der Menschenrechte bei den Werbeversuchen, Lange u.a. (Hg.), Dokumente, S. 180-182, auch Besier/Wolf (Hg.), Pfarrer, S. 218 f., Raabe, SED-Staat, S. 244-249; der SED-Berichterstattung zufolge sei es tatsächlich gelungen, die Kirchenvertreter „zu differenzieren“ und teilweise für sich zu gewinnen, andererseits würden sich CDU-Anhänger infolge des Hirtenbriefes nun von ihrer Partei abwenden. Zur vermeintlich positiven Wirkung der Kirchen in Rostock: Kaiser, Politik, S. 104. In Leipzig registrierte man angeblich ein Schreiben von Pfarrern an den Bezirkstag, das die christlichen Bauern zum LPG-Eintritt aufforderte; SAPMO DY 30 IV 2/7/369, Bericht der verschiedenen Bezirke, 18. 3. 1960.

281 „Bauern-Echo“, 2. 3.1960, „Antwort an einen Eichsfeldbauern: Kann ein Christ Mitglied der LPG werden?" 
Hatten sich ehemalige Flüchtlinge und Vertriebene trotz aller Schwierigkeiten eine bäuerliche Existenz aufgebaut, wie z.B. im Kreisverband der DBD in Neuruppin oder schlesische Altbauern im sächsischen Löbau, wandten sie sich häufig geschlossen gegen die Kollektivierung 282 .

Wie erwähnt brachte das Regime verstärkt seit der Frühjahrskampagne 1960 die deutschlandpolitische Karte ins Spiel, getreu der Propagandalosung, nach der die DDR dank des Sozialismus der einzig legitime friedliche deutsche Staat sei. Seither nahmen in den Entgegnungen deutschlandpolitische Begründungsmuster und solche mit internationalem Bezug zu. Dies belegt zum einen den ständigen Informationsfluß über die westdeutsche Vergleichsgesellschaft in der DBD-Mitgliedschaft. In den Debatten mit den Brigaden bestritten die Einzelbauern, daß der angeratene LPG-Eintritt irgendeine Bedeutung für die „Sicherung“ des Friedens habe. Andere sahen jedoch den Zwang zum Eintritt durchaus mit der Deutschlandfrage verbunden ${ }^{283}$. So drehten spitzfindige Bauern im Bezirk Dresden den Spieß um. Sie brachten im Sommer 1961 vor, man werde im Herbst wieder einzelbäuerlich wirtschaften, um deutschlandpolitische Handlungsoptionen wiederzuerlangen: Denn nach einer Vollkollektivierung würden die amerikanischen Verhandlungsführer eine Wiedervereinigung ablehnen. Unter der ländlichen Bevölkerung hielt sich hartnäckig die Hoffnung, daß sich ohnehin "bald alles ändern“ werde $^{284}$. Die internationalen Verhandlungen um die Berlinfrage und um Deutschland als Ganzes seit 1958 wirkten sich äußerst kontraproduktiv auf die Beitrittsagitation für die LPG aus ${ }^{285}$. Die SED Dresdens warnte im Juli 1960, daß das politische Einwirken auf dem Land, die Agitation dort bei weitem nicht ausreiche. Die Bauern würden einwenden, Chruschtschow habe eine Gipfelkonferenz angekündigt, auf diese wolle man warten. Gescheiterte Versuche zu LPG-Gründungen tat man mit den Worten ab: „In Genf ist man sich nicht einig geworden und in Paris auch nicht, dann brauchen wir 17 Bauern das auch nicht.“ Angesichts der internationalen Lage versuchten die Bauern, „die Grenzsteine $50 \mathrm{~cm}$ tiefer zu setzen, damit sie erhalten bleiben“.

Ein Mitglied der LPG Coblenz im Kreis Bautzen diagnostizierte: „Wir haben in der DDR eine offene Diktatur. Die Partei diktiert alles. Wir sind erfahrene Bauern und wissen was richtig oder falsch ist. "286 Das Bewußtsein, in einer Diktatur zu leben, nahm zu, nachdem die Einrichtung des Staatsrates und die Übernahme

$282 \mathrm{Zu}$ Neuruppin: BStU ASt. Lpz. AIM 3445/92, Arbeitsvorgang Gaude, Bd. 1, Bl. 23-27, Bericht über Treffen am 13.08. 1959. SStAD BPA SED BL Dresden IV/2/7/084, Bl. 4346, Bericht zur Lage im Kreis Löbau, 4. 7. 1961.

283 Siehe für die DBD-Mitglieder MLHA BPA Schwerin IV/2/15/1687, Bericht über die bisher durchgeführten Neuwahlen der OG-Vorstände der DBD im Bezirk Schwerin, 19. 1. 1959.

284 SStAD BPA SED BL Dresden IV/2/7/084, Bl. 33-36, Durchsage der SED-Stadtleitung Dresden an 2. Sekretär der BL, 4. 7. 1961: Bericht über LPG-Austrittserklärungen.

285 Ende März 1960 wollten etwa die Bauern im Kreis Hagenow unbedingt die anstehende Gipfelkonferenz abwarten, SAPMO DY 30 IV 2/5/292, Bl. 157-163, Informationsbericht, 24. 3. 1960.

286 SStAD BPA SED BL Dresden IV/2/7/065, Bl. 290-372, Org. Kader, Material für das Referat der Bezirksparteiaktivtagung am 16.7. 1960, Bl. $302 \mathrm{ff}$. zur "politischen Massenarbeit" im Dorf. 
des Vorsitzes durch Ulbricht bekannt wurde. Luckenwalder DBD-Mitglieder kommentierten das Ereignis: „Die Bildung des Staatsrates ist ja wie bei Hitler. Ulbricht als Vorsitzender hat uns gerade noch gefehlt. Seine Machtposition ist dadurch noch weiter ausgebaut und gefestigt worden." "Charakteristisch ist dabei, “ so interpretierte der Berichterstatter, „daß gerade die Genossenschaftsbauern in solch einer Form diskutieren, die noch nicht von der Richtigkeit ihres Schritts in die LPG überzeugt sind und wo die Organisierung der genossenschaftlichen Arbeit noch Schwierigkeiten bereitet ${ }^{“ 287}$.

Eine Reihe von bekannten Verhaltensmustern trafen gleichermaßen auf die DBD-Mitglieder zu. Die Geheimpolizei stellte eine Zunahme von „Feindtätigkeit“, „Diversion“ und „Sabotageakten“ fest, wie sie seit 1952 vorkamen: Brandstiftungen, Viehabschlachtungen und -vergiftungen, Beschädigungen von Gebäuden und Maschinen, Prügeleien mit Repräsentanten des Regimes und verhaßten LPG-Vorsitzenden 288. Bis 1961 nahmen die in Kollektive Gepreßten auch das ihnen im Statut verbürgte Recht wahr, wieder auszutreten ${ }^{289}$. Besonders nach dem vorschnellen Rückzug der Brigaden im Frühsommer 1960, der im Glauben geschah, mit dem Beitritt sei die Lage endgültig geklärt, stiegen alle Formen von Resistenz und oppositionellem Verhalten in und außerhalb der LPG sprunghaft an. Die Kollektivierung war längst nicht vollzogen, sondern blieb der DBD als schwierige Aufgabe erhalten, bei der sie erhebliche politische Überzeugungsarbeit leisten mußte ${ }^{290}$. Die explosive Konstellation auf dem Land hatte sich nach dem vermeintlichen Eintritt aller Bauern keineswegs beruhigt. Unzufriedenheit und Opposition wandte sich nun gegen die bestehenden LPG und die aufoktroyierte Arbeitsordnung in Kolonnen und Brigaden, die die Bauern mit „Bolschewismus“ in Verbindung brachten. Darauf reagierte die Justiz 1961 mit schärferen Mitteln. Die Gerichte waren durch zentrale Anweisungen gehalten, strafrechtliche Exempel gegen vermeintliche Arbeitsbummelanten zu statuieren, häufig exemplarisch in jedem Kreis. Auch Verurteilungen zu Arbeitserziehung in Lagern waren üblich. Im Schutz der Berliner Mauer und im Zuge des Ausbaus des Grenzregimes wurden - wie schon 1952 - altbekannte politische Gegner im Laufe eines einzigen Tages, dem 3. Oktober 1961, aus den Gebieten um die Demarkationslinie ausgesiedelt ${ }^{291}$. Das SED-Regime griff auch zum Mittel der Todesstrafe gegen widerstän-

287 SAPMO DY 30 IV 2/15/55, Situationsbericht BO Nr. 25, 26. 9. 1960. Auch Mitglieder der DBD im BV Rostock sahen in der Übernahme des Staatsratsvorsitzes durch Ulbricht ein Zeichen der „Diktatur“; BStU ASt Rst. AIM 186/63, Bd. 1/II, Binder, Bl. 25 f., Bericht an Binder, undatiert [September 1960].

288 BStU MfS 102109, Orientierung über die Lage in der Landwirtschaft, 3. 3. 1961, Bl. 2529.

289 Werkentin, Strafjustiz, S. 105 f.; ACDP VI, unverz. Best. LV Mecklenburg, Aktendeckel BV Schwerin, Abt. Agrarpolitik 1952 ff., Bericht für II. Quartal 1960; regionale Beispiele in SStAD BPA SED BL Dresden IV/2/7/084, Bl. 30-33, KL SED Dippoldiswalde an BL der SED, 4. 7. 1961, Bl. 43-46, Bericht zur Lage über den Kreis Löbau, 4. 7. 1961.

290 Vgl. den ausführlichen Bericht „über einige Probleme in der Landwirtschaft“ der Staatlichen Plankommission, 30. 9. 1960, BA DE-1/1254, Bl. 2-13, für die DBD die intensive Nachbereitung des VI. PT.

291 Bennewitz, Die beiden Zwangsaussiedlungen, S. 365 ff., betont, daß dies im Unterschied zu 1952 auf Drängen der SED geschah; Wolter, Aktion. 
dige Bauern. Zu Abschreckungszwecken hielt sie es offensichtlich für erforderlich, diese Prozesse öffentlich auszuwerten ${ }^{292}$. Nach bisherigem Wissensstand waren von den schweren Strafurteilen kaum DBD-Mitglieder betroffen, obwohl die inkriminierten Verhaltensweisen durchaus auch bei diesen anzutreffen waren ${ }^{293}$.

Die Verhaltensweisen lassen sich generell unterscheiden in eher traditionell geprägte und solche, die die neuen Verhältnisse adaptierten. $\mathrm{Zu}$ den traditionellen und in der DBD weit verbreiteten zählte es, trotz LPG-Mitgliedschaft weiterhin individuell zu wirtschaften, die Flächenauseinanderlegungen für den Herbst anzukündigen und sich ausschließlich der individuellen Vieh- oder Hauswirtschaft zuzuwenden. Zu Beginn des Jahres 1961 hatten 30\% der neugebildeten LPG mit der genossenschaftlichen Arbeit noch nicht begonnen. „Im Bezirk Karl-MarxStadt lehnt ein großer Teil der Genossenschaftsbauern es weiterhin ab, das LPGStatut zu unterzeichnen, wenn nicht der Absatz über die Freiwilligkeit des Eintritts in die LPG geändert wird“, das gleiche Verhalten sei auch in den Bezirken Leipzig, Dresden und Magdeburg anzutreffen, meldeten die bei der ZK-Abteilung für Landwirtschaft einlaufenden Berichte, die auch auf das Verhalten der DBD-Basis zutrafen. In einer LPG formulierte man das Statut regelwidrig: „Der Zusammenschluß erfolgte nicht freiwillig." Danach wurde häufig die innere Betriebsordnung und die Bildung eines fünfzehnprozentigen unteilbaren Fonds abgelehnt. Weiter forderten die widerwilligen Genossenschaftsbauern die Erfüllung früher gemachter Versprechungen ein und erwiesen sich durchaus empfänglich für die Wohlstandsverheißungen der SED seit 1958. Besonders begehrt waren Fernsehgeräte, die den Blick gen Westen eröffneten, und Kraftfahrzeuge, aber auch eine bessere technische Ausstattung für die LPG stand auf dem Wunschzettel294. Bei den politischen Forderungen knüpfte man an 1953 an und verlangte „freie Wahlen“295. Vor der Grenzabriegelung 1961 wie auch danach drohten Genossenschaftsbauern mit dem Austritt, falls sie keinen Reisepaß bekämen und behaupteten, dieser sei ihnen als Gegenleistung für den Eintritt zugesichert worden ${ }^{296}$.

Die Austrittsbewegung ist insgesamt in Zahlen schwierig zu erfassen, da sie ein Dauerphänomen war; bei Bekanntwerden wurden ad hoc Parteikräfte mobilisiert, um diese Bauern zurückzugewinnen ${ }^{297}$. Die Androhungen von Austritt und Auflösung der LPG fungierten häufig als Abschreckungsmittel gegen den verhaßten

292 Siehe dazu Werkentin, Strafjustiz, S. 106-110; Weber, Justiz, S. 498-505.

293 Sie wurden von IM aus dem Parteiapparat an das MfS weitergeleitet; MfS Ast RSt. AIM 186/63, Bd. 1/II Arbeitsvorgang, Binder, Bl. 61 f., Treffbericht, 9. 5. 1961, Bl. $125 \mathrm{f}$., Sekretariatsvorlage, 28. 8. 1961 zu Parteiverfahren in Grevesmühlen.

294 SAPMO DY 30 IV 2/7/367, Bericht Nr. 14/1960, 17.6. 1960, Berichtszeitraum 8. 6.14.6. 1960 (1. Zitat); BStU MfS 102109, Orientierung über die Lage in der Landwirtschaft, 3. 3. 1961, Bl. 4 f. (2. Zitat).

295 SAPMO DY 30 IV 2/15/5, Einsatz einer Brigade der AG BO in Halle, 10.-13. 8. 1960.

296 SAPMO DY 30 IV 2/15/53, Abt. Organisation, 29. 8. 1961, Situationsbericht Nr. 29/61; ACDP VI-052-186/1, Organisationsbericht zu III. Quartal 1960.

297 Allein im Bezirk Erfurt lagen Ende 1960640 Austrittserklärungen vor, BStU MfS 102109, Orientierung über die Lage in der Landwirtschaft, 3. 3. 1961, Bl. 5; Anfang Juli 1961 lagen von 478 Betrieben insgesamt 928 Austrittserklärungen vor; SStAD BPA SED BL Dresden IV/2/7/007, Bl. 113-121, Bericht BL an Ulbricht, 7. 7. 1961. 
Einsatz von Druschkolonnen und Brigaden, die die SED-Kreisleitungen schickten und von der DBD wesentlich mitgetragen wurden. Da sie den Ertrag der Ernte in zwangswirtschaftlicher Manier der Verfügungsgewalt der Genossenschaftsbauern entzogen, wurden sie höchst unfreundlich behandelt. So wurde der „Brigade der Kreisleitung, die in Katzenow zum Drusch eingesetzt war, [...] auf [das] Verlangen, etwas zum Trinken zu bringen, ein Eimer mit Wasser hingestellt, mit der Bemerkung, das ist gut für Euch" - die in die LPG abgeordneten Brigaden und Kolonnen galten als großes „Übel“298. Die Glewitzer Genossenschaftsbauern der DBD, die 1960 sämtlich in die LPG gezwungen worden waren, boten in ihrer Verzweiflung einem Funktionär der DBD 1000,- DM an, wenn sie ungescholten aus der LPG wieder austreten könnten. Ein Kollege erklärte, „daß die Ausbeutung in der LPG heute weit größer ist als vor 100 Jahren. Unsere Frauen sind nicht in der Lage für unsere Kinder Mittag zu kochen, da sie dringend im Produktionsprozess gebraucht werden. Auch unsere Kinder werden täglich in der Schule 6

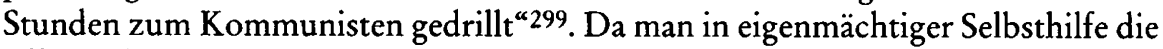
öffentliche Ordnung durchbrach und auch den Konflikt mit dem Staatsapparat nicht scheute, schien in den Augen der SED die Sicherheit auf dem Land gefähr$\operatorname{det}^{300}$.

Mit dem Beitritt zu den Genossenschaften übernahmen viele Bauern neue Verhaltensweisen, auch bislang für sie unübliche Spielregeln des gesellschaftlichen Verteilungskampfes. Bauern traten nun wie Arbeitnehmer in den Streik oder verfielen darauf, als „Bummelanten“ Dienst nach Vorschrift zu machen. Höhere Lohnforderungen - etwa 600, - DM monatlich als Entgelt für geleistete Arbeitseinheiten - waren gängig; man bestand auf einem geregelten Acht-Stunden-Tag und Freizeit, Urlaubsansprüche wurden gerne in der Hochsaison angemeldet; man nutzte die sozialversicherungsrechtliche Absicherung aus und ließ sich in Stoßzeiten krankschreiben ${ }^{301}$. Außerdem verlangte man die freie Entscheidung für die Frauen: „Unsere Frauen sollen es besser haben, so ist es uns beim Eintritt in die LPG versprochen worden. Wenn sie aber ebenso arbeiten sollen wie in der Einzelwirtschaft, dann können wir ja wieder Einzelbauern werden“, so die vormals erfolgreichen Mittelbauern der DBD im Kreis Doberan; sie akzeptierten weiterhin nicht den Führungsanspruch der SED, obwohl sie in Nachbarschaft zum „Musterdorf Satow“ lebten, dessen Beispiel ja gerade diese Frage hätte ausräumen sollen ${ }^{302}$. Eine Reihe von selbstbewußten und offensichtlich langjährigen

298 So Binder zum KV Stralsund; BStU ASt Rst. AIM 186/63, Bd. 1/II, Binder, Bl. 17 f., Bericht vom 5. 9. 1960. Ebd., Bl. 25 f., Bericht an Binder, undatiert [September 1960].

299 Ebd.

300 Z.B. widersetzte man sich in der LPG Typ I in Krakow den Kolonnen: „Ein Teil des Getreides, was sofort zum VEAB gebracht werden sollte, wurde von den Gen.Bauern abgefangen und auf ihre Böden getragen." In Wolgast gebe es "gegenwärtig harte Auseinandersetzungen, die bis zur Bedrohung von Staatsfunktionären gehen. " BStU ASt Rst. AIM 186/63, Bd. 1/II, Binder, Bl. 17f., Bericht vom 5. 9. 1960, Bl. 25 f., Bericht an Binder, undatiert [September 1960]. Vgl. hierzu Lindenberger, ABV, S. 174-191.

301 BStU MfS 102109, Orientierung über die Lage in der Landwirtschaft, 3. 3. 1961, Bl. 4-6.

302 SAPMO DY 30 IV 2/15/5, Einsatzbericht AG BO im Kreis Doberan, Bezirk Rostock, 1961; ebd., Einsatz AG BO in Halle, 10.-13. 8. 1960. 
Genossenschaftsbauern der DBD in Cottbus gab sich nicht mit der ihnen zugedachten, völlig untergeordneten Rolle in den LPG-Aktivs zufrieden, sondern forderte eine Betriebsparteiorganisation der DBD in den LPG ${ }^{303}$. Ihr Verhältnis zur DBD war ungebrochen, im Unterschied zu einem großen Teil der „spätberufenen" Genossenschaftsbauern.

Ein weiteres Bündel an Verhaltensmustern bezog sich speziell auf die Einstellung zur DBD. Die Stimmung der Mitglieder war im Sommer 1960 desaströs. Die wichtigste Aufgabe der Partei bestand darin, überhaupt wieder Kontakt zur Basis herzustellen. Sie schickte Brigaden durchs Land, die die inaktiven Parteimitglieder wiedergewinnen, dazu auch in Einzelgesprächen um jedes Mitglied ringen sollten. Für ein gezieltes Vorgehen legte man in jedem Bezirk „Schwerpunktgemeinden“ fest, in denen offenbar besonderer Handlungsbedarf bestand ${ }^{304}$. In Anbetracht der Tragweite der Kollektivierung hielt sich der absolute Mitgliederverlust der DBD in Grenzen ${ }^{305}$. Zu berücksichtigen ist allerdings, daß in den vier Jahren seit 1956 ein durchschnittlicher jährlicher Mitgliederaustausch von gut $6 \%$ vonstatten ging ${ }^{306}$. Diejenigen, die die Partei verließen oder ausgeschlossen wurden, nahmen stets auch Protestpotential mit ${ }^{307}$. Eigentümer von wirtschaftlich soliden Betrieben zögerten die Flucht in den Westen hinaus, solange es ihnen erträglich schien und sie nicht unmittelbar verfolgt wurden. Viele erfolgreiche Mittelbauern überschätzten ihre Widerstandsfähigkeit gegen die Kollektivierung. Unmittelbar nach dem offiziellen Abschluß der Vollkollektivierung stieg 1960 der Anteil von Genossenschaftsbauern der DBD unter den Flüchtigen erheblich an, weil viele in der

303 Ebd., Instrukteureinsatz in Cottbus, 20.-23. 7. 1960.

304 Als solche „Schwerpunkte“ zur „Festigung" der Partei nannte die Organisationsabteilung im III. Quartal 1960 jeweils die Kreise: Grimmen, Grevesmühle und Wolgast im BV Rostock, Güstrow, Ludwigslust und Schwerin im BV Schwerin, Neustrelitz, Straßburg und Waren im BV Neubrandenburg, Belzig und Nauen im BV Potsdam, Angermünde und Freienwalde im BV Frankfurt/Oder, Calau und Spremberg im BV Cottbus, Burg und Halberstadt im BV Magdeburg, Eisleben und Sangershausen im BV Halle, Heiligenstadt und Worbis im BV Erfurt, Rudolstadt und Pössneck im BV Gera, Görlitz, Niesky und Bautzen im BV Dresden, Torgau im BV Leipzig und Annaberg im Bezirk KarlMarx-Stadt, ACDP VI-052-186/2, Organisationsbericht III. Quartal 1961; ebd., Analyse über die org. Entwicklung der Partei im II. Quartal 1961, 16. 8. 1961, zu 9 Brigadeeinsätzen im Bezirk Rostock, bei denen man 665 Kollegen wieder für die Partei gewinnen konnte.

305 Insgesamt hatte sich die Mitgliederzahl von Anfang 1959-1960 aufgrund der Koppelung von Mitgliederanwerbung und LPG-Eintritt sogar erhöht und betrug Ende 196085300.

306 Die durchschnittlichen jährlichen Abgänge seit 1956 betrugen rund $6 \%$, die Aufnahmen rund $6,7 \%$. Berechnet nach Tabelle 5, auch Fußnote 8 . Rund 8900 Personen verließen die Partei 1959/60, rund 8700 wurden in diesem Zeitraum neu aufgenommen.

307 Als Ursachenprofil für die Austritte ermittelte die Abt. Organisation: 10\% der Austritte würden offen ausgesprochen mit der sozialistischen Umgestaltung der Landwirtschaft zusammenhängen, 27,3\% würden angeben, daß sie die Mitarbeit wie auch die Beitragszahlung ablehnen; $41,5 \%$ gingen auf "politisch-ideologische Unklarheiten “ zurück. Vorwiegend Arbeiter und Hausfrauen argumentierten, keine Verbindung mehr zur Landwirtschaft zu haben. Bei den Ausschlüssen des Jahres 1960 handelte es sich zu rund $94 \%$ um Westflüchtige. ACDP VI-052-186/1, Abt. Organisation, Einschätzung der organisatorischen Entwicklung im III. Quartal, 1. 11. 1960. 
Sicherheit, die die LPG-Mitgliedschaft jetzt bot, ihre Flucht vorbereiteten, vor allem als die Brigaden der Nationalen Front abgezogen waren ${ }^{308}$.

Bei der Haltung der Mitglieder Anfang der sechziger Jahre war von Bedeutung, daß die Mehrheit die SED und den Staatsapparat für die Kollektivierung verantwortlich zieh und der eigenen Partei eine mindere, nur abgeleitete Schuld vorhielt. Dort, wo die Brigaden mit Unterstützung der DBD sehr rigoros für die Kollektivierung agitiert hatten, brach die Basis danach großteils weg, in überwiegend einzelbäuerlichen Gegenden häufig geschlossen. Viele Parteiversammlungen konnten mangels Beteiligung keine Beschlüsse fällen. Bis November 1960 gelang es, dieses Phänomen in den Bezirken Schwerin, Neubrandenburg, Frankfurt, Cottbus, Halle, Dresden und Karl-Marx-Stadt zu vermindern, „keine wesentlichen Veränderungen " gab es dagegen in Magdeburg und Gera, während sich in Potsdam und Suhl die Zahl der beschlußunfähigen Zusammenkünfte noch erhöhte ${ }^{309}$. Auf lange Sicht erwiesen sich vor allem über das Land verstreute Inseln von Kreisverbänden und Ortsgruppen, die jegliche Mitarbeit verweigerten, als problematisch ${ }^{310}$. Der regionale und dörfliche Zusammenhalt war schon für den Durchbruch zur LPG maßgeblich gewesen: In den Ortsgruppen der DBD, in denen in den fünfziger Jahren kaum ein bäuerliches Mitglied einer LPG angehörte, entschied sich angesichts des steigenden Drucks Ende der fünfziger Jahre oft dann entweder die überwiegende Mehrheit der Ortsgruppe oder so gut wie niemand davon für einen LPG-Eintritt. Weitaus seltener kam es vor, daß nur ein Drittel bis die Hälfte der Parteimitglieder vor den Frühjahrsmonaten 1960 beitrat.

Abgesehen von Parteiaktivisten der Kollektivierung vor Ort, warf ein erheblicher Teil der eigenen Partei vor, "die DBD hätte sie in die Genossenschaft ge$z$ wungen und nicht davor geschützt “ 311 . Sie habe als Interessenvertreterin, für die man sie durchaus hielt, versagt; nun da man in der LPG sei, brauche man die DBD nicht mehr, hieß es allerorten. Ironisch fügte man hinzu, der LPG-Vorsitzende kümmere sich jetzt um alles, daher erübrige sich die DBD-Ortsgruppe. Auch bei den „positiv Denkenden sei die Meinung verbreitet, daß die SED alles alleine macht und die DBD nicht gebraucht werde“; ähnlich sehe es auch in der CDU aus, notierte die SED als Ergebnis zahlreicher Brigadeeinsätze in der Provinz ${ }^{312}$. Verbittert über uneingelöste Versprechen griff man Argumentationsfiguren der Agitatoren auf: Man verdiene in der LPG nicht so gut, wie vorher versichert worden war, daher könne man sich weder den Parteibeitrag noch das Abonnement des „Bauern-Echo“ leisten. Als Genossenschaftsbauer habe man weniger freie Zeit als vorher, die man nicht mit Lesen des „Bauern-Echo“ zubringen wolle, wo ohnehin

308 Siehe dazu Tabelle 26.

309 Entsprechend bemüht war die Parteizentrale, die Organisation in den Kreisen und Ortsgruppen zu verbessern, siehe z. B. Sekretariatsvorlage der Abt. Organisation „Statistische Einschätzung über die Verbesserung der Leitungstätigkeit auf der Grundlage der Beschlüsse der 3. Parteivorstandssitzung“, 19. 11. 1960, ACDP VI-052-0543.

310 SAPMO DY 30 IV A2/15/92, Die Situation in der DBD vor den Volkskammerwahlen 1963, 30. 10. 1963.

311 ACDP VI-052-186/1, Einschätzung organisatorische Entwicklung im III. Quartal, 1. 11. 1960.

312 SAPMO DY 30 IV 2/15/5, Bericht über Einsatz in Cottbus, 7.-9. 2. 1961. 
nur das gleiche wie in den Mitteilungsblättern der SED stünde ${ }^{313}$. Versuchten die Brigaden die Genossenschaftsbauern zur Mehrarbeit, zum Brigadeprinzip und zur Entlohnung nach dem Leistungsprinzip anzuhalten, entgegnete man umgekehrt, durch die Kollektivierung so viel Geld verdient zu haben, daß man jetzt auf zusätzliche Arbeit verzichten könne ${ }^{314}$.

Obgleich man die Bedingungen, um die Mitglieder zurückzugewinnen, 1961 schon für erheblich günstiger hielt als 1960, blieb auch nach dem Mauerbau und trotz zunehmender wirtschaftlicher Konsolidierung der LPG rund ein Drittel der DBD-Mitglieder weiterhin mit politischen „Unklarheiten“ behaftet ${ }^{315}$. Mißmut und jahrelange Passivität brachten ein tiefes politisches Unbehagen zum Ausdruck, nicht nur vorrangig wirtschaftlich motiviertes Protestverhalten. Dennoch: Das Gros der DBD-Mitglieder akzeptierte über die Parteianbindung auch das Herrschaftssystem, die DBD erfüllte ihre Transmissionsfunktion. Dies ist auch daran abzulesen, wie sehr die Mitglieder sich in ihrer Kritik die Argumentationsstrategien des Herrschaftsapparates zu eigen machten, denn bei unverhüllter Kritik liefen sie Gefahr, als Diversanten verfolgt zu werden. Diese Befunde bestätigen die These, daß „für die DDR [...] nicht der Erfolg der Herrschaftsstrategien auffällig“ ist, „sondern das Ausmaß, in dem auf sie Bezug genommen wurde“316.

\section{Politische Stellung und Anleitung der Partei 1961-1963}

Das Projekt des Sozialismus hatte die DBD als Partei im Kern getroffen. Denn unter diesem Signum reklamierte die SED als dessen Vorreiterin eine Legitimation neuer Qualität für sich, um auf Funktion und Stellung der Bauernpartei einzuwirken und diese neu zu definieren. Der Zustand der Parteiführung in Sekretariat und Parteivorstand belegt, wie paralysiert und konzeptionslos die obere Ebene auf diese Situation reagierte. Der rasante Funktionsverlust der DBD, der 1963 hinsichtlich ihrer Beteiligung an der staatlichen Agrarpolitik wie des politischen Charakters der Partei auf einen Tiefpunkt zusteuerte, war jedoch nicht nur eine Folge

313 ACDP VI-052-0542, Protokoll Präsidium, 29. 8. 1960, „Bauern-Echo“-Werbeaktion. Von Februar bis Juni schrumpfte die Zahl der Abonnements von 86839 auf 68755 , also um rund $20 \%$. Vgl. BStU ASt Chm. Vorl. AIM 2421/62, Schönweiß, Vorlauf Personalakte, Bl. 60, Aussprachebericht, 13.12. 1960.

314 So begründete die Versammlung der DBD in Bernsdorf, Kreis Grevesmühlen, den Umstand, daß 50\% der Mitglieder nicht für die LPG arbeiten würden. BStU ASt Rst. AIM 186/63, Bd. 1/II, Binder, Bl. 45f., Bericht vom 24. 1.1961.

315 So Grüneberg noch 1963 zur DBD: SAPMO NY 4233/44, Bl. 284-288, Aussprache mit PV der DBD, 26. 4. 1963; ACDP VI-052-0326, Protokoll Präsidium, 30. 5. 1961. In Suhl, Magdeburg, Erfurt, Dresden, Neubrandenburg und Gera wurden 6-10tägige operative Einsätze durchgeführt. In Bautzen, Strausberg, Sömmerda hatten rund 100 Mitglieder schon mehrere Jahre lang keinen Parteikontakt mehr, 23 hatten 38 Monate lang keinen Beitrag bezahlt.

316 Lüdtke, DDR, S. 12. 
der von der SED aufoktroyierten Politik ${ }^{317}$, sondern hatte durchaus Ursachen im Führungsapparat der Partei.

Bis 1963/64 brauchte die SED die DBD zur dauerhaften Gewährleistung des erreichten Zustandes in den Genossenschaften. Die DBD sollte helfen, die vormaligen Einzelbauern zu Genossenschaftsbauern umzuformen, die für den Sozialismus empfänglich sein würden. Wenngleich einerseits Abstriche im Politisierungsgrad hinzunehmen waren, so sollten Mitglieder der DBD andererseits diesen politischen Anspruch durch ihre Integration in den Produktionsprozeß bestätigen, abzulesen etwa an ihrer Planerfüllung. Der Beitrag der DBD zur Ausformung der Kollektivierung vollzog sich in enger Abstimmung mit der SED; man stellte sich diesen Vorgang so vor, daß sich eine formale LPG-Zugehörigkeit zu einer von Überzeugung getragenen Mitgliedschaft wandelte und traditionelle Lebens- und Wirtschaftsweisen von sozialistisch geprägten Vorstellungen überformt wurden.

Die durch die Kollektivierung erst hervorgerufenen wirtschaftlichen und politischen Friktionen garantierten eine dauerhafte Existenz der DBD, vor allem so lange die SED nur unzureichend in den LPG vertreten war ${ }^{318}$. Während die Arbeitsgruppe $\mathrm{BO}$ den zuständigen Mitarbeitern in den Bezirkssekretariaten noch im Oktober 1959 mitgeteilt hatte, daß sich die Tätigkeit der DBD in vollgenossenschaftlichen Dörfern auf die „weitere ideologisch-politische Überzeugungsarbeit" beschränke ${ }^{319}$, mußte sie im Frühjahr 1961 die Blockpolitik als Instrument wiederbeleben. Dazu entsandte sie eine Reihe von Instrukteuren in Bezirke und Kreise ${ }^{320}$. Wie man bei dieser Gelegenheit feststellte, waren die Bezirksleitungen der SED durchgängig nur sehr schlecht über den Zustand ihrer Blockpartner informiert. Zunächst demonstriert dies das konzeptionslose, verfrühte Vorpreschen der Arbeitsgruppe Ende 1959, die die Dimension der aufgeworfenen Probleme auf dem Land völlig verkannte; darin unterschied sich die Arbeitsgruppe BO im übrigen von jenen SED-Genossen, die mit der Agrarpolitik vertrauter waren, wie in der ZK-Landwirtschaftsabteilung oder im MLF. Außerdem deuten die Befunde der Instrukteureinsätze auf de facto unkontrollierte Handlungsmöglichkeiten der Blockparteien hin. Die zahlreichen Instruktionen der Arbeitsgruppe BO richteten sich in erster Linie auf den eigenen Apparat, schärften eine bessere Selbstkontrolle und laufende Überwachung der Blockparteien ein. Vor allem jedoch kritisierte man ihn für das verbreitete und kontraproduktive "Sektierertum" speziell gegenüber der DBD, aber auch hinsichtlich anderer Parteien: In eigener Selbstüberschätzung würde man die anderen Parteien prinzipiell übergehen.

Die Arbeitsgruppe BO versuchte 1961, ihre nachgeordneten Einheiten in der Peripherie von jenen, jetzt als "sektiererisch“ eingeschätzten, ideologischen Positionen zurückzurufen, die sie selbst dort während der Radikalisierung ab Ende

317 So die Interpretation Reichelts, Blockflöte, S. 207-209, der die DBD zu sehr als Opfer der SED-Politik sieht.

318 Bis 1962 stagnierte die Werbung von Kandidaten und die Bildung von SED-Grundorganisationen in den LPG Typ I. Fortschritte waren erst $1963 \mathrm{zu}$ verzeichnen. Vgl. Matschke, Entwicklung, S. $191 \mathrm{f}$.

319 SAPMO DY 30 IV 2/15/4, Tagung der AG BO, 29./30. 10. 1959.

320 SAPMO DY 30 IV 2/15/5, Instrukteurberichte der AG BO zum Bezirk Frankfurt/Oder 9.-12. 11. 1960, Potsdam, Kreis Nauen, 2.-3.2.1961. 
1959 verursacht hatte, als die SED ihre Vorreiterrolle im Sozialismus auf Kosten anderer Parteien ausübte. Langfristig wirkte das "Sektierertum“ der SED auf die DBD-Basis anregend, teils provokativ, denn viele Mitglieder fühlten sich als Widerpart der SED im Ringen um Positionen und zum Beweis ihrer politischen wie wirtschaftlichen Befähigung herausgefordert. Nach der Überwindung des Schocks der Vollkollektivierung und der Desillusionierung nach dem Mauerbau trug diese Konstellation ab der zweiten Jahreshälfte 1961 dazu bei, die Mitgliedschaft wieder zu aktivieren. Die eigene Basis wieder zu erreichen, war andererseits eine unerläßliche Voraussetzung für das Gelingen der Transmissionsaufgabe der DBD. Da die Bauernpartei längst gleichgeschaltet war, von ihrer Spitze keinerlei Gefahr abweichender Interessenartikulation ausging, profitierte schließlich allein das SED-Regime von der neu in Gang gesetzten Aktivität der DBD-Mitgliedschaft ${ }^{321}$.

Nach der Durchsetzung der Kollektivierung war die DBD mit deren Absicherung nach innen und außen befaßt. Die mit der Bodenreform einsetzende tiefgreifende Umwälzung der Agrarstruktur in der SBZ/DDR verlangte immer auch eine deutschlandpolitische Rechtfertigung und Perspektive, bestanden seither doch erhebliche Unterschiede zur Agrarordnung der Bundesrepublik und lagen damit schwerwiegende Probleme im Falle einer Vereinigung auf der Hand. Im Frühjahr 1961 oblag es der DBD, die in der Bundesrepublik weitaus heftiger noch als die Bodenreform attackierte Kollektivierung 322 zu verteidigen. Noch im März 1952, vor der Auflösung der Westabteilungen von CDU und LDPD, war es der CDU zugefallen, einen gesamtdeutschen Agrarplan auszuarbeiten ${ }^{323}$.

Die neue deutschlandpolitische Offensive der DBD zielte zum einen auf die Beeinflussung der westdeutschen Berufskollegen und versuchte insbesondere, an die heftigen Proteste der Bauernverbände im Gefolge der Gründung der EWG anzuknüpfen ${ }^{324}$. Sie wollte „den Protest der Bauern so stark werden [...] lassen, damit eine Änderung der Agrarpolitik erreicht wird“325, gemeint war die Rücknahme des Gemeinsamen Marktes und der Westintegration der Bundesrepublik. Dazu sollte der landwirtschaftliche Strukturwandel in der Bundesrepublik als „Bauernlegen“ dargestellt werden, welches auf die Westintegration des Agrarmarktes, die Importpolitik der EWG, die Dominanz der NATO und die „Atompolitik“ Adenauers zurückzuführen sei ${ }^{326}$. Zum anderen - und dies war die wich-

321 Zumal wenn einzelne im Auftrag des MfS wichtige Landwirtschaftsbetriebe durch Spionieren „absicherten“ oder wie Bögelsack zur landwirtschaftlichen Lage des Bezirks berichteten; BStU ASt Lpz. AIM 1843/88, Bd. I/1, Bäjen, Bl. 19, Anwerbungsbericht, 4. 12. 1968. BStU MfS AIM 1305/69, Personalakte Bögelsack, Bl. 25, Verpflichtungserklärung, 5. 11.1966.

322 Vgl. Bauerkämper, Legitimation, S. 64-69.

323 Richter, Ost-CDU, S. 353.

324 ACDP VI-052-0543, Protokoll Sekretariat, 30. 1. 1961.

325 So die „Hinweise für gesamtdeutsche Arbeit", 8. 2. 1961, ACDP VI-052-0543. Die EWG machte sich 1961/62 erstmals stärker im Hinblick auf die Landwirtschaft bemerkbar. Vgl. dazu und zu Protesten des Bauernverbandes und der bäuerlichen Bevölkerung, Kluge, Agrarpolitik, Bd. 1, S. 283-340; Eichmüller, Landwirtschaft, S. 80 f.

326 „Brief an westdeutsche Berufskollegen“, ACDP VI-052-0543, bei Sekretariatsprotokoll vom 6. 2. 1961. 
tigere Ausrichtung - ging man damit auf die eigene Klientel in der DDR ein: Denn als Gegenprogramm zur internationalen Verflechtung der Landwirtschaft „unter der Herrschaft der Imperialisten und Militaristen" propagierte man für die DDR als einzig wahren Weg eine "nationale" Agrarpolitik und konstruierte einen $\mathrm{Zu}$ sammenhang zwischen Sozialismus und Bewahrung des Friedens ${ }^{327}$. Wichtiger scheint allerdings zu sein, daß eine solch "national" verstandene Agrarpolitik als erheblicher Beitrag zu einer auf die Selbstversorgung mit Nahrungsmitteln gerichteten Ernährungspolitik auch Teil einer Abgrenzungsstrategie vom Westen war ${ }^{328}$.

In diesem Sinne arbeitete die DBD daran, ihre Mitglieder von der Notwendigkeit des Mauerbaus als "friedenssichernde" Maßnahme zu überzeugen ${ }^{329}$ und führte fortan einen propagandistischen „Kampf um den Abschluß eines Friedensvertrages “ ${ }^{330}$. Befriedigt stellte man im Zusammenhang mit dieser Thematik eine Politisierung des Parteilebens fest. Die „Maßnahmen vom 13.8.“ hätten bewirkt, „daß die Versammlungen jetzt ausgesprochenen politischen Charakter tragen “331. Im Unterschied zu SED und FDJ betrieb die DBD im Schutz der Mauer keine forcierte Verfolgung politischer Gegner, denen der Fluchtweg nunmehr verschlossen war, oder eine rigorosere Personalpolitik in den eigenen Reihen. Aber angesichts des "Fehlverhaltens" einiger Funktionäre des Parteivorstandes im Umfeld des Mauerbaus sah man sich veranlaßt, die innerparteiliche "Wachsamkeit" zu erhöhen; dieses ideologische Erklärungsmuster taugte gut dazu, die eigene Unzulänglichkeit zu vertuschen ${ }^{332}$.

Dafür gab es zwei unmittelbare Anlässe: Zum ersten war der Bezirkssekretär Berlins, Günter Gedicke, aus einer Kampfgruppeneinheit entwichen ${ }^{333}$, die offenbar beim Bau der Mauer beschäftigt war; zum zweiten blieb das Gebäude des Parteivorstands am Tag nach dem Mauerbau völlig verwaist zurück. Hans Rietz war als einziger Spitzenfunktionär der DBD noch in der Nacht vom 12. auf den 13. August 1961 zusammen mit Vertretern anderer Blockparteien von Ulbricht über das Vorhaben der Grenzabriegelung informiert worden; er hielt es am nächsten Tag jedoch für nicht nötig, im Parteisitz zu erscheinen, sondern verließ in

327 Zur Konzeption einer nationalen Agrarpolitik siehe Grüneberg, DDR, Bannerträger, S. 20.

328 So für die Ära nach Ulbricht Kusch u. a., Schlußbilanz, S. 78.

329 Die Argumente unterscheiden sich in nichts von denen der SED und sind heute noch bei Reichelt nachzulesen; Reichelt, Blockflöte, S. 182 f. SAPMO DY 30 IV 2/15/53, Abt. Org. der DBD, Niederschrift der Aussprache der Sekretäre für Org. auf der Tagung am 24. 8. 1961.

330 ACDP VI-052-0546, Protokolle Sekretariat, 23. 10. und 27.11. 1961, auch zu entsprechenden Schulungen in den Kreisen.

331 SAPMO DY 30 IV 2/15/53, Abt. Org. der DBD, Niederschrift der Aussprache der Sekretäre für Org. auf der Tagung am 24. 8. 1961.

332 ACDP VI-052-0545, Protokolle Sekretariat, 21. und 28. 8. 1961. Ein Papier der Parteibetriebsgruppe, 18. 9. 1961, hob neben der Erhöhung der „Wachsamkeit“ und der Gewährleistung der "Einsatzbereitschaft" auf eine gezielte politische Arbeit, intensivere Schulung der Betriebsgruppe und stärkere Kontrolle der Mitarbeiter der Nationalen Front in ihren Wohngebieten ab.

333 Positive Beurteilungen Gedickes noch 1960, SAPMO DY 30/vorl. SED 4071. 
einer privaten Angelegenheit Berlin, ohne seine Kollegen weiter zu informieren $^{334}$. Ein Opfer dieser verstärkt nach innen gerichteten "Wachsamkeit" wurde, wie bereits dargelegt, der einst mit der gesamtdeutschen Thematik betraute politische Mitarbeiter Otto Keuthe, der dem Parteivorstand angehörte ${ }^{335}$. Um von eigenen Unzulänglichkeiten abzulenken, bestrafte die Führungsspitze ihn vor den Augen der SED als Sündenbock.

Im Zeichen der außenpolitisch gespannten Lage in Berlin suchte das MfS von vornherein zu verhindern, daß politische Mitarbeiter im Apparat des zentralen Berliner Parteivorstandes sich in den Westen absetzten oder möglicherweise Anlaufstellen für westliche Kontaktaufnahmen würden. Mit Hilfe seiner IM sorgte es erfolgreich dafür, daß bis dahin völlig unverdächtige Funktionäre mit Angehörigen in Westdeutschland oder solchen, die geflüchtet waren, aus dem Nadelöhr Berlin auf Positionen in den Bezirksverbänden wegversetzt wurden ${ }^{336}$. Eine weitere Transformationsaufgabe der DBD bestand 1961 darin, die ersten öffentlichen Enthüllungen des XXII. Parteitages der KPdSU zu den Machenschaften Stalins an die Mitglieder und niederen Funktionäre zu vermitteln und politisch abzudämpfen 337 .

Ein zweiter umfassender Aufgabenbereich, der der DBD entgegen der Vorhersage der Arbeitsgruppe $\mathrm{BO}$ wieder zufiel, bestand in der Bewältigung der wirtschaftlichen Folgelasten der Kollektivierung. Diese hatte die SED mit der überstürzten Aktion 1960 bewußt in Kauf genommen. Für die Agitatoren und Staatsfunktionäre rangierte im Frühjahr 1960 die ordnungsgemäße Frühjahrsbestellung nachrangig hinter der Durchsetzung der Vollkollektivierung ${ }^{338}$. Die Analysen des MLF unterstrichen, daß die maschinellen und technischen Kapazitäten der MTS mit einer Vollkollektivierung überfordert und die labilen LPG auf Jahre hinaus finanziell nicht in der Lage sein würden, Technik und Maschinen, wie vorgesehen, aufzukaufen. Auch bei den wirtschaftlich solideren LPG stellte das Ministerium 1960 die Neigung fest, die Technik lieber weiterhin auf Leihbasis zu niedrigen MTS-Tarifen zu nutzen, statt sie zu erstehen ${ }^{339}$. Damit wurde das grundlegende

334 Helmschrott hatte zwar Panzer fahren sehen, vermutete jedoch keinen ernsten Anlaß, wofür ihn Burkhardt im Sekretariat kritisierte; BStU MfS AP 75835/92, Helmschrott, Bd. 2, Bl. 4. BStU MfS AP 14985/92, Rietz, Bl. $115 \mathrm{f}$.

335 Vgl. S. 287.

336 Daher wurde z. B. Gaude nach Leipzig versetzt; BStU ASt. Lpz. AIM 3445/92, Personalakte Gaude, Auskunftsbericht, 23. 05. 1974. Im MfS-Auftrag sollte Zagrodnik darauf hinwirken, BStU MfS AIM 3189/63, Arbeitsvorgang Zagrodnik, Bl. 110-115, Treffbericht, 26. 11. 1960.

337 Vgl. dazu ACDP VI-052-0546, Einschätzung der 9. PV-Sitzung, Auswertung des XXII. PT der KPdSU und der 14. Tagung des ZK der SED, 20. 12. 1961; Vgl. Weber, Geschichte, S. 331-334; Staritz, Geschichte, S. $203 \mathrm{f}$.

338 SAPMO DY 30 IV 2/15/5, Bericht Instrukteur für BO in Leipzig an Büro der BL, 10. 2. 1960. Vgl. SAPMO DY 30 J IV 2/2/692, Protokoll PB, 15. 3. 1960, Anlage 13, Bl. 137-139.

339 Vgl. etwa BA DK-1/449, Bl. 27-32, Information über die Probleme, die sich aus der 4. Richtlinie über die leihweise Übergabe der Technik ergeben [undatiert 1960]. Der Ausarbeitung zufolge enthalte die Richtlinie Bestimmungen, "die die weitere Übergabe der Technik an die LPG nicht“ fördern würden. Vgl. hierzu auch BA DC-20/377, Tätigkeitsbericht des Arbeitsgebietes LW für 1959, der festhält: „Der Bericht und Beschluß über die Übergabe der Technik wurden auf Grund des bevorstehenden 7. Plenums ebenfalls noch 
Problem berührt, daß der Fortgang der Kollektivierung bis zum Frühjahr 1960 in erheblichem Maße von den Kapazitäten der Landmaschinenindustrie, der chemischen Industrie und nicht zuletzt vom Staatshaushalt abhing. Mit dem kurzfristigen Entschluß von Mitte Januar 1960 waren all diese Bedenken zugunsten einer radikal politischen Lösung zurückgedrängt worden ${ }^{340}$.

Erst in einem zweiten Schritt forderte die SED danach zunächst die wirtschaftliche Konsolidierung der LPG des Typs I und II und bekundete, daß ein sofortiger Übergang zur höher vergesellschafteten Form III und die Bildung von GroßLPG primär nicht erwünscht se ${ }^{341}$. Die DBD sollte mithelfen, die enormen Produktionseinbußen der Jahre 1960/61 aufzuholen, die vor allem durch unbestellte Flächen und eher nachrangig, wenngleich in der Propaganda hervorgekehrt, durch eine witterungsbedingte Mißernte $1961^{342}$ verursacht worden war. Die Aufgaben, die der DBD zugeteilt wurden, unterschieden sich nicht von denen der SED: Auch sie proklamierte, wie es zuvor der SED gesteuerte VI. Deutsche Bauernkongreß im Dezember 1960 vorgegeben hatte, 1961 als das "Jahr der guten genossenschaftlichen Arbeit“343.

Aufgrund ihres Einflusses im Südteil der Republik sollte die DBD darauf hinarbeiten, daß sich die in einem Dorf mehrfach vorhandenen LPG des Typs I zusammenschlossen, besonders die sich hartnäckig verweigernden Zwerg-LPG. Bei den Mitgliedern aller LPG-Formen waren die genossenschaftlichen Komponenten auf Kosten der individuellen Eigentumsmerkmale zu unterstreichen: Die Formen von Typ I und II hatten dazu den gemeinsamen genossenschaftlichen Fonds finanziell aufzustocken ${ }^{344}$; Mitglieder des Typs II sollten eine genossenschaftliche Viehwirtschaft aufbauen; Genossenschaftsbauern in LPG des Typs III versuchte man dazu zu bringen, weniger Arbeitskraft und Kapital für die individuellen Hauswirtschaften zu verwenden, sondern sich stärker der genossenschaftlichen Viehhaltung zu widmen.

Für jedes dieser Einzelziele inszenierte die SED besonders zugeschnittene „Beispiele" und versuchte dort, wo es aufgrund des ordnungspolitischen Rahmens keine Wettbewerbsstrukturen gab, künstliche „Wettbewerbe“ von LPG zu LPG, zwischen Brigaden und von Bauer zu Bauer in Gang zu setzen: Im sogenannten "Wendlandbrief“, veröffentlicht am 28. Januar 1962, stritten zwei Bauern über das Problem der individuellen Hauswirtschaften in den LPG des Typs III und verbreiteten die „Lehre“, daß die Individualwirtschaften der Gemeinschaft schaden

zurückgestellt bzw. noch nicht eingereicht.“ Im Juli hingegen hatte das PB noch eine schnellere Übergabe der Technik vorgesehen, SAPMO DY 30 J IV 2/2/657, Protokoll PB, 7. 7. 1959.

340 Schulz, "Kapitalistische Länder überflügeln“, S. 12 f. Vgl. hingegen die Interpretation von Schulz, ebd., S. 34-37.

341 Ulbricht untersagte Ende Mai 1960 überraschend die Diskussionen über Groß-LPG. Krebs, Weg, S. 390.

342 Blohm, Entwicklung, S. 729.

343 Im Schulungsplan stand: „gute genossenschaftliche Arbeit - unser Beitrag für den Sieg des Friedens und des Sozialismus - für ein Leben in Glück und Wohlstand“; ACDP VI052-0543, Protokoll und Anlagen Sekretariatssitzung, 16. 1. 1961.

344 Vgl. SAPMO DY 30 IV 2/15/5, Einsatz in Halle, 10.-13. 8. 1960. 
würden ${ }^{345}$. So sollte der Konflikt in die Genossenschaften hineingetragen und eine offene Auseinandersetzung über die Einhaltung der Statuten herbeigeführt werden; diese Einschränkung der individuellen Hauswirtschaften wagte die SED erst nach dem Mauerbau offen zu fordern. Der Brief zielte darauf, die bisher für den privaten Verbrauch und Verkauf genutzten Produkte bzw. die dafür eingesetzten Produktionsmittel für das genossenschaftliche Betriebsergebnis zu verwenden. Denn diese Produkte waren bekanntlich ablieferungsfrei und standen für den Verkauf zur Verfügung ${ }^{346}$.

Der Wettbewerb nach dem Beispiel „Albinshof" um die verlustlose Einbringung der Ernte 1961 und die Verbesserung der genossenschaftlichen Zusammenarbeit zur Übererfüllung des Planes zeichnete sich in der DBD-Variante durch zwei Stoßrichtungen aus: Neben den damit verbundenen wirtschaftlichen Zielen, denen im Mißerntejahr 1961 besondere Bedeutung zukam, diente er dazu, sich ein genaueres Bild vom ideologischen Zustand des Apparates und der Haltung der Mitglieder zu verschaffen. So wurde erhoben, ob es noch mehrere LPG des Typs I am Ort gebe, die von den DBD-Mitgliedern demnach noch nicht verschmolzen worden waren, welche Grundeinheiten noch Einzelbauern aufwiesen oder wo es noch Bäuerinnen gab, die ihren Männern nicht in die LPG gefolgt waren ${ }^{347}$. Tatsächlich mußte man feststellen, daß in "vielen Dörfern [das Beispiel] Satow nicht lebt, Wettbewerb nicht nach den Prinzipien von Albinshof geführt werde“, die Wettbewerbsbewegung also im Sande verlaufen war. Nicht näher spezifizierte "Stimmen“ aus dem Kreis der Mitglieder monierten dagegen, man erfülle nicht einmal den Plan und folglich hielte man das "Produktionsaufgebot" zu seiner Übererfüllung schlichtweg für unsinnig ${ }^{348}$.

Eine vermehrte Werbung der Bäuerinnen für die LPG setzte im Grunde erst 1962 ein, also parallel zum Bemühen, die individuellen Vieh- und Hauswirtschaften zu reduzieren. Im Zeitraum von 1961 bis zum 31. Mai 1963 wurden immerhin 42405 Bäuerinnen als Genossenschaftsmitglieder geworben, 1960 waren fünfzigbis sechzigtausend Bäuerinnen den LPG ferngeblieben ${ }^{349}$. Zwar hatte die DBD seit Ende 1958 intensiver versucht, Jugendliche und Frauen in die Parteileitungen einzubeziehen, bis Herbst 1961 existierte jedoch keine auf diese Gruppen zugeschnittene Anwerbungsstrategie. Vielmehr konzentrierte man sich offiziell auf die

345 Matschke, Entwicklung, S. 128.

346 Für die DDR liegt keine Statistik über die Bedeutung der privaten Hauswirtschaften für die Versorgung vor. Zum erheblichen Anteil dieser offiziell nur "geduldeten “ Wirtschaftsform in der Sowjetunion: Wädekin, Privatproduktion. 347 ACDP VI-052-0545, Vorlage Abt. Agrarpolitik an Sekretariat, Disposition für den Be-
richt an das Präsidium, 28. 9. 1961.

348 ACDP VI-052-0546, Sekretariatsvorlage, Gliederung für Bericht an Präsidium, 26. 10. 1961.

349 So die - zu niedrig erscheinenden - Zahlen bei Matschke, Entwicklung, S. 130-133; zum 31. 5. 1960 ging die Zahl weiblicher ständig beschäftigter Arbeitskräfte in der LW - darunter die mithelfenden weiblichen Familienangehörigen - sogar um 163000 zurück, BA DE-1/1254, Bl. 2-13, Information über Probleme in der LW, 30. 9. 1960, hier Bl. 6 f. Prokop, Übergang, S. 221; Grüneberg, DDR, Bannerträger, S. 20. Matschke zufolge gab es 1960 allein im Bezirk Potsdam noch rund 9800 Bäuerinnen außerhalb der LPG, im Bezirk Rostock gehörten nur etwa 35\% der ehemaligen Einzelbäuerinnen den LPG an. 
parteilosen männlichen Einzelbauern, die in aller Regel die entscheidende Instanz für einen Eintritt in die LPG waren. Im September 1961 gab es erstmals einen eigenen Bäuerinnenlehrgang an der Zentralen Parteischule der DBD in Borkheide ${ }^{350}$. Die Partei zählte Ende 1963 immer noch 1026 Bäuerinnen, die keiner LPG beigetreten waren, vor allem in den Bezirken Schwerin und Dresden ${ }^{351}$. Dies ist nicht nur auf eine besondere politische Distanz der Frauen zur LPG und auf fehlende wirtschaftliche Anreize zurückzuführen. So hielt die Abteilung Organisation fest, daß die Bäuerinnen als Saisonarbeitskräfte vielfach mehr verdienen würden denn als Mitglied ${ }^{352}$; durch die „aufgeblähten“ individuellen Hauswirtschaften seien sie ohnehin vollauf beschäftigt und außerdem fehlten in den LPG oftmals entlastende Einrichtungen wie Wasch- und Gemeinschaftsküchen oder Kindergärten.

Vorrangig bestünden jedoch noch ,überlebte Auffassungen über die gesellschaftliche Rolle der Bäuerinnen, wobei die Auffassung besteht, die Frau hat nichts zu sagen, es genügt, wenn der Mann Mitglied ist ". Sicherlich beleuchtet dieses Verhalten die weit verbreitete Tendenz, an der hergebrachten Lebenspraxis auf den Höfen und der dafür konstitutiven Arbeitsteilung zwischen den Geschlechtern festzuhalten. Im Falle jener mittelbäuerlichen Betriebe, die es sich vordem leisten konnten, daß die Frau ausschließlich den Haushalt führte, ist die Abwehr des Eintritts aber nicht vorschnell als geschlechtsspezifische Schieflage zu interpretieren, sondern als Bemühen, den bisherigen sozialen Status zu wahren ${ }^{353}$. Wie auch für die SED beobachtet, waren weibliche Landwirtschaftslehrerinnen leichter für die LPG zu gewinnen als ehemalige Einzelbäuerinnen.

Die Personalpolitik von SED wie DBD bis 1963 zeichnete sich durch eine Verdrängung weiblicher Führungskräfte in den LPG aus. Im Zuge der Zusammenlegung kleinerer LPG rückten häufig Männer in die vormals von Frauen besetzten Positionen ein ${ }^{354}$. Die eingeforderte Professionalisierung der LPG-Leitungspositionen führte ebenfalls zur Benachteiligung der Frauen. Obgleich die DBD sich offiziell bemühte, den Frauenanteil in den Vorständen zu erhöhen, wurden weibliche Führungskräfte im Zuge der Kollektivierung aus Leitungspositionen in den Bezirken abberufen. So mußte die langjährige Bezirksvorsitzende Berlins, Frieda Müller, Volkskammerabgeordnete und Vorsitzende der LPG Typ III „Freie

350 ACDP VI-052-0545, Themen- und Ablaufplan zu Bäuerinnenlehrgang an der ZPS, bei Tagesordnung Sekretariat, 26. 9.1961.

351 ACDP VI-052-0553, Analyse über organisatorische Festigung der Partei im 1. Halbjahr 1963, 28. 8. 1963.

352 Dies rührte her von der Arbeitskräftepolitik der SED, die Industriearbeitern, die sich verpflichteten, 2 Jahre in einer LPG zu arbeiten, eine Prämie zahlte. Diese wurde bei einem Wechsel der LPG immer wieder fällig. Kritik der bäuerlichen Bevölkerung an dieser "Wanderarbeit“ in: BStU ASt Rst. AIM 186/63, Arbeitsvorgang Binder, Bd. II/1, Bl. 47, Bericht vom 24. 1. 1961.

353 Vgl. ACDP VI-052-0553, Analyse über organisatorische Festigung der Partei im 1. Halbjahr 1963, 28. 8. 1963 (Zitat).

354 Matschke, Entwicklung, S. 132 f. Bis Ende 1962 ging die Zahl der weiblichen Vorsitzenden in LPG Typ I und II von 148 auf 74 zurück; der Anteil weiblicher Vorstandsmitglieder betrug 1961 in LPG Typ III 27,2\%, in LPG des Typs I sogar nur rund $18 \%$. 
Erde“, ihren Posten an einen Mann abgeben ${ }^{355}$. Die DBD förderte nun eine „Spezialistenausbildung " für ihre weiblichen Mitglieder und versuchte damit Tradition und sozialistische Leistungsanforderungen zu verknüpfen. Besonders in den kleineren und mittleren Betrieben mit einem hohen Anteil an Tierhaltung waren es häufig die Frauen, die für Pflege und Zucht zuständig und insofern längst „Spezialistinnen" waren ${ }^{356}$.

Entgegen durchaus vorhandenem agrarökonomischen Sachverstand schreckte die DBD in dieser Zeit nicht davor zurück, offensichtliche Fehlentscheidungen mitzutragen. Dazu zählte das schließlich völlig gescheiterte „Offenstallbauprogramm" oder der überoptimistische Anbau von Mais in klimatisch ungeeigneten Lagen. Im Trend der Zeit riet das „Bauern-Echo“ zur Verfütterung von Antibiotika zu Mastzwecken und propagierte eine für die Tiere schädliche, viel zu frühe Färsendeckung, weil diese darauf hoffen ließ, den Einbruch der Viehwirtschaft infolge der Kollektivierung schnell auszugleichen ${ }^{357}$.

Bei der Vorbereitung des VII. Deutschen Bauernkongresses im März 1962 unternahm die SED den ersten Anlauf, die Musterstatuten der LPG zu verändern ${ }^{358}$. Dabei zielte man darauf, die mindervergesellschafteten Formen des Typs I und II so auszugestalten, daß ihr Zweck als bloße Durchlaufstufen zu Typ III erkennbar wurde 359 . Man zog verschiedene Modelle als Ansatzpunkte in Erwägung ${ }^{360}$. Kalkuliert modifizierte man schließlich lediglich das Musterstatut des Typs II, alsojenes Typs, der quantitativ kaum ins Gewicht fiel. Eine heftige Gegenwehr von seiten der Mitglieder war daher nicht zu befürchten; man hatte aber dennoch einen rechtlichen Hebel geschaffen, der auf andere Typen übertragbar war. Die Neuregelung betonte die Aufgabe, eine genossenschaftliche Viehhaltung aufzubauen, vor allem aber begrenzte sie die Möglichkeiten des Austritts praktisch auf den Fall eines Wechsels in eine andere LPG 361 .

Implizit veränderte diese Modifikation den Eigentumscharakter, da die Mitglieder keine freie Verfügungsgewalt mehr besaßen. Im Vergleich zu den anderen diskutierten Varianten ist die schließlich beschlossene deutlich entschärft. Eine Mitarbeit der DBD an dieser entscheidenden rechtlichen Veränderung ist nicht nachzuweisen; offenbar billigte die SED dem DBD-Sekretariat keine Mitsprache

355 SAPMO DY 30/vorl. SED 4072, Beurteilung SED BL Groß-Berlin, 18. 10. 1959.

356 Vgl. Broschüre „Zentraler Erfahrungsaustausch des Präsidiums des Parteivorstandes der DBD mit Kolleginnen unserer Partei, 6. 3. 1964 in Berlin“. Siehe allgemein Griepentrog, Struktur, S. $68 \mathrm{ff.}$

357 „Bauern-Echo“, 19. 5. 1960; ebd., 21. 5. 1960.

358 Matschke, Entwicklung, S. $136 \mathrm{f}$.

359 Diese Zielsetzung eindeutig in: ACDP VI-052-0546, Abt. Agrarpolitik, Vorschläge zur Erweiterung und Änderung der Musterstatuten der LPG, 4. 1. 1962, mit handschriftlichem Vermerk „wird wieder eingezogen“. Zu den Kooperativen siehe Gabler, Entwicklungsabschnitte, passim.

360 ACDP VI-052-0546, Abt. Agrarpolitik, Vorschläge zur Erweiterung und Änderung der Musterstatuten der LPG, 4. 1. 1962.

361 Umschrieben mit Ausscheiden „aus gesellschaftlichen Gründen“, die anderen Möglichkeiten waren Tod oder Ausschluß. Tümmler, Agrarpolitik, S. 62-66, GBl. DDR II 1962, S. 521, Beschluß über das Musterstatut für landwirtschaftliche Produktionsgenossenschaften vom Typ II vom 2. 8. 1962; Arlt, Rechte, S. 375. 
in diesen rechtlichen Belangen zu. Gesichert ist jedoch, daß die Träger hoher staatlicher Funktionen, Reichelt, Scholz und Rietz diese Entscheidung mittrugen.

Der Handlungsrahmen der DBD wurde auf die wirtschaftliche Stabilisierung der Genossenschaften reduziert, die weitere rechtliche und ideologische Ausformung reklamierte die SED allein für sich. Die Konzentration auf wirtschaftliche Belange kam dem Zustand der DBD entgegen. Denn eher als mit politischen Parolen konnte man die enttäuschte Mitgliedschaft bei ihrer Berufsehre als Bauern wieder packen. Manche DBD-Bauern zeigten sich durchaus weiterhin dem wirtschaftlichen Erfolg zuliebe risikofreudig. So besorgten sich die DBD-Mitglieder und LPG-Bauern in Ragow, Kreis Jüterbog, noch 1962 (!) Saatkartoffeln aus Westberlin, worüber die SED nicht erfreut war: „Es kursiert dort das Argument: ,Ja, das sind Kartoffeln von Adenauer.' Die Genossen der Sicherheit [MfS] und der Abt. Landwirtschaft erhielten den Auftrag, in Ragow diese Frage zu untersuchen und offentlich auszuwerten." ${ }^{362}$

Um ihre Existenz als Partei überhaupt zu legitimieren, brauchte die Bauernpartei die Agrarpolitik als Wirkungsfeld, das ihr zugeschrieben wurde. Es ist daher bezeichnend für den geringen Stellenwert, den die SED ihrer Blockpartnerin noch zubilligte, als sie mit Hilfe von IM Stefan Zagrodnik Anfang 1962 die Auflösung der Hauptabteilung Agrarpolitik betrieb. Durch die Einrichtung einer Abteilung „Produktionspropaganda“, die die Ziele des Siebenjahrplanes vorgeblich organisatorisch besser aufgreifen konnte, schraubte man letztlich die Kompetenz der DBD in Agrarfragen zurück. Die SED versuchte, eine ohnehin nur potentiell vorhandene Konkurrenz der DBD auszuschalten ${ }^{363}$. Bislang hatte die Abteilung von ihrem Einblick in höchste Regierungspolitik profitiert; daher konnte sich die DBD, trotz aller Einschränkungen, wenigstens auf diesem Terrain vor ihren Mitgliedern profilieren 364 .

Die sich bis 1963 anbahnende Entwicklung wurde durch personelle Veränderungen in der Führungsspitze begünstigt. Eine federführende Rolle spielte $\mathrm{Za}$ -

362 BLHA Rep. 530, Nr. 1436, Bericht Sektor Information, 25. 5. 1962, BL Potsdam, Abschrift Bericht der KL Jüterbog, 24. 5. 1962.

363 Gegen die Interpretation Reichelts, der allein die SED für diese Entscheidung verantwortlich macht, ist anzuführen, daß im Dezember 1961 außer Goldenbaum alle Sekretäre der DBD dieser Umwandlung zustimmten (BStU MfS AIM 3189/63, Arbeitsvorgang Zagrodnik, Bl. 169-172, Treffbericht, 6. 12. 1961). Zutreffend ist vielmehr, daß während einer Unterredung aller Sekretäre im ZK mit Heinz Ackermann im August 1960 schon damals die Überführung einzelner Arbeitsgebiete der Abt. in andere Abt., etwa an die Abt. Schulung, sowie eine Strukturveränderung im PV angeregt worden war. Ebd., BI. 103 f., Treffbericht, 24. 8. 1960. Reichelt, Blockflöte, S. $206 \mathrm{f}$. Nach der Auflösung der Abt. betrieb Zagrodnik zwischenzeitlich die Auflösung der Instrukteurbrigade beim PV. Die Instrukteure sollten, entsprechend der damaligen Konzeption der SED, in wirtschaftsschwache LPG delegiert werden (Ebd., Bl. 177-180, Treffbericht, 15. 3. 1962). Im Zuge der Neugliederung des Sekretariates Mitte 1962 setzte sich Zagrodnik auch für die Auflösung der Abt. Wirtschaft ein (Ebd., Bl. 184-186, Treffbericht, 6. 9. 1962).

364 Siehe dazu z.B. die statistischen Materialien ministerieller Provenienz in den Akten der Abt. Agrarpolitik der DBD, ACDP VI-052-247/1, Abt. Agrarpolitik MLF 1953-1965, Projekt des Perspektivplanes der Landwirtschaft bis 1965, vertrauliche Verschlußsache [undatiert]. 
grodnik, der im September 1961 die Leitung der Abteilung Agrarpolitik übernahm $^{365}$, um so gezielter auf ihre Auflösung hinwirken zu können. Der bisherige Abteilungsleiter, Herbert Hoffmann, wurde zu einem Kurs in die Schweriner Kaderschmiede der SED für Agrarfunktionäre wegdelegiert und 1962 nach Potsdam versetzt ${ }^{366}$. Seine Absenz schwächte Goldenbaums Rückhalt, zählte Hoffmann doch in der Regel zu seinem Troß ${ }^{367}$. Ebenso verminderte die Ablösung Körbers 1961 als Leiter der Abteilung Organisation und 1962 als Kaderleiter Goldenbaums Einfluß im Sekretariat. Zwar hatte Körber anfangs seine Stimme im Sekretariat durchaus gegen ihn erhoben, sich später aber immer mehr dessen Positionen angenähert, wie Titel und Zagrodnik einhellig dem MfS und ZK zutrugen ${ }^{368}$.

Mit diesem Austausch der altgedienten Funktionäre durch jüngere Kader entfernte man zugleich eine Führungsgeneration, deren agrarpolitischer Erfahrungshorizont noch in die Zeit zurückreichte, als die DBD einzel- und genossenschaftsbäuerliche Politik vertreten hatte. Zwar führte man dem Apparat des Parteivorstandes so in der Tat jüngere, fachlich auf dem neuesten Stand stehende Kader zu. Ihre Loyalität wurde jedoch weniger an ihrem Verhältnis zur Bauernpartei gemessen, als vielmehr am Grad ihrer Kooperationsbereitschaft gegenüber MfS und SED; viele hatten sich durch langjährige Spitzeldienste empfohlen.

Hierbei ist zu betonen, daß sich eine Mitarbeit als IM - auch die altgedienten Funktionäre hatten der Staatssicherheit zugearbeitet - nach 1957 qualitativ von früheren Tätigkeiten unterschied, weil erst seither neben den informatorischen Aspekten die aktive operative Handlungsanleitung für Ziele der SED getreten war. Die SED ließ laufend die Sessel für einen Elitenaustausch in der DBD-Führungsspitze räumen. Sogar im Falle hochrangiger DBD-Funktionäre setzte sie durch, daß diese sich sowohl fachlich weiterqualifizierten als auch - sofern sie für hohe Staatsämter in Frage kommen wollten - ein Studium an SED-Parteischulen absolvierten. Positionen im Apparat des Parteivorstandes, die wegen der Schulbesuche zeitweise frei wurden, nahmen dann häufig im Sinne der SED bewährte Personen ein ${ }^{369}$. Dieser vorübergehende Einsatz in einem wichtigen Amt schlug

365 ACDP VI-052-0541, Protokoll Sekretariat, 15. 5. 1961.

366 Dies geschah unter dem Vorwand, seine KPD-Mitgliedschaft vor 1933 erst 1954/55 angegeben zu haben, BStU MfS AIM 3189/63, Arbeitsvorgang Zagrodnik, Bl. 184-186, Treffen am 6. 9. 1962.

367 ACDP VI-052-0544, Protokoll Sekretariat, 19.6. 1961.

368 BStU MfS AIM 3189/63, Arbeitsvorgang Zagrodnik, Bl. 181-183, Treffbericht, 19. 7. 1962; BStU MfS AIM 9130/63, Titel (= "Lehmann"), Arbeitsvorgang, Bd. 2, Bl. 142, Bericht, 15. 10. 1962.

369 So besuchten Paul Scholz 1961, Herbert Eichhorn, Wilhelm Weissgärber und der langjährige Mitarbeiter im Ministerium Fritz Weißhaupt 1962 das Institut zur Ausbildung landwirtschaftlicher Funktionäre der SED in Schwerin. Anstelle von Weißhaupt übernahm Bruno Müller eine Funktion im Apparat des Landwirtschaftsrates. BStU MfS AIM 3189/ 63, Arbeitsvorgang Zagrodnik, Bl. 187f., Treffbericht, 8. 10. 1962. Lt. ebd., Bl. 148-151, Treffbericht, 3. 8. 1961, absolvierte Körber gerade eine Prüfung als staatlich geprüfter Landwirt (Bl. 146f.). Hans Rietz sollte ab September 1960 die Karl-Marx-Schule besuchen, BStU ASt Lpz. AIM 3445/92, Arbeitsvorgang Gaude, Bd. 1, S. 118, Treffbericht, 29. 6. 1960. Scholz sollte 1962 auf eine Schule geschickt werden, Körber ein Fernstudium aufnehmen, ACDP VI-052-0546, Protokoll Sekretariat, 13.11.1961. 
sich wiederum positiv in ihrer Kaderbiographie nieder und beförderte so den weiteren Aufstieg in der Partei.

Die anhaltenden Rivalitäten unter den Spitzenfunktionären stießen Einfallstore für die SED auf. Auf Betreiben der Arbeitsgruppe BO brach Anfang 1961 der alte Dissens zwischen Goldenbaum und Scholz auf der einen Seite und Rietz und Rose auf der anderen auf ${ }^{370}$. Die SED trug offensichtlich gezielt dazu bei, Hans Rietz im Jahr 1962 in der DBD zu demontieren, den sie erst im Jahr zuvor als stellvertretenden Staatsratsvorsitzenden und Gegenpart zu Goldenbaum aufgewertet hatte. Rietz' Glaubwürdigkeit war angeschlagen. Goldenbaum litt unter der fortwährenden Brüskierung, weil er, obgleich Parteivorsitzender, bei hohen staatlichen Anlässen sich mit einem Platz in der zweiten Reihe hinter Rietz begnügen mußte und im übrigen weniger als dieser verdiente ${ }^{371}$. Persönliche Eitelkeit und Machtgier wie das Schüren von Konflikten durch die SED schadeten der Partei. Die Installierung von IM sicherte Information und unmittelbaren Einfluß der SED. Sie sollten einerseits als vermeintliche Partner Goldenbaums im innerparteilichen Schlagabtausch fungieren - so etwa in Gestalt des Sekretärs und persönlichen Vertrauten Goldenbaums Rudi Rothe ${ }^{372}$ - oder wurden als sachkompetente Funktionäre eingesetzt, die im Apparat des Parteivorstandes immer mehr Ansehen genossen, während die kleinlichen Konflikte der alten Garde dort zusehends auf Unverständnis stießen; zu dieser Gruppe zählte etwa Werner Titel als Vorsitzender der Betriebsgruppe.

1962 erreichten die Interventionen der Arbeitsgruppe BO in die Personalpolitik ebenso wie die inhaltliche Anleitung der DBD neue Dimensionen. Offensichtlich unterschätzte Goldenbaum in dieser Situation den Einfluß der Arbeitsgruppe BO auf Matern, als er meinte, weiterhin alles allein und persönlich nur mit diesem regeln zu können ${ }^{373}$. Die Besetzung des Postens des Kadersekretärs mit Zagrodnik bestimmte der ZK-Apparat im Alleingang. Das Zusammenspiel der Überlegungen von Zagrodnik mit denen des MfS im Hinblick auf eine künftig neue Organisationsstruktur des DBD-Parteivorstandsapparates hatte fatale Folgen.

370 Auf Anregung des ZK hatte Goldenbaum im ZK die Personalakten der leitenden Funktionäre studiert. Dabei war in seiner und Scholz' Akte ein „Vermerk aufgetaucht“, in dem er und Scholz „so negativ eingeschätzt werden, daß sie für Partei untragbar sein müßten“. Der Vermerk war als Ergebnis einer Sekretariatssitzung, die in Vorbereitung des IV. PT 1955 stattgefunden hatte, auf Anweisung von Rose und vermutlich mit Wissen von Rietz - letzteres konnte nie nachgewiesen werden - von Siegfried Küster niedergeschrieben und an das ZK weitergeleitet worden. Rose wich aus, Rietz bestritt jegliche Verantwortung. Scholz sah in diesem Vermerk den Grund, „weshalb er in dieser Zeit kaum noch Aussprachen im ZK gehabt hätte [...] Es wäre offensichtlich gewesen, daß das Vertrauensverhältnis zum ZK zu ihm getrübt gewesen sei." BStU MfS AIM 3189/63, Arbeitsvorgang Zagrodnik, Bl. 127-129, Treffbericht, 14. 2. 1961 (Zitate); BStU MfS AIM 3890/89, Rothe, Bd. 1, Bl. 9-12, Treffbericht HA V/3, 10. 2. 1961, Bl. 15-17, Treffbericht, 25. 3. 1961; ACDP VI-052-0326, Protokoll Präsidium, 21. 3. 1961.

371 BStU MfS AIM 3189/63, Arbeitsvorgang Zagrodnik, Bl.181-183, Treffbericht, 19.7. 1962.

372 BStU MfS AIM 3890/89, Personalakte Rothe, 6. 6. 1961 Vorschlag zur Werbung, 3. 11. 1961 Verpflichtungserklärung.

373 BStU MfS AIM 3189/63, Arbeitsvorgang Zagrodnik, Bl. 181-183, Treffbericht, 19. 7. 1962. 
Aus Zagrodniks Idee, den hohen Funktionären zur Entlastung persönliche Referenten zuzuweisen, entwickelte die Arbeitsgruppe BO Mitte der sechziger Jahre die Praxis, Goldenbaum, den die SED nun als Vorsitzenden halten wollte, unmittelbar einen SED-Mitarbeiter der Arbeitsgruppe, Heinz Ackermann, zur Seite zu stellen ${ }^{374}$.

Im August 1962 ordnete das ZK Stellenstreichungen bei den politischen Mitarbeitern der DBD in den Bezirks- und Kreisverbänden an, deren Zahl 1959, als für die Kollektivierung dringend Personal nötig war, noch erhöht worden war. 1962 erfolgte die Reduzierung unter dem Vorwand der Angleichung der ApparatgröBen der Blockparteien, tatsächlich jedoch reagierte man damit auf ihren Bedeutungsschwund als Transmissionsriemen ${ }^{375}$. Die Bezirksleitung der SED Rostock exerzierte derweil erfolgreich die Abkoppelung des DBD-Bezirksverbandes von der zentralen Parteileitung vor. So brachte sie Ernst Mecklenburg, den ehrgeizigen und opportunistischen 1. Sekretär des Bezirksverbandes problemlos dazu, den bislang von der DBD beanspruchten Posten des stellvertretenden Vorsitzenden des Rates des Bezirkes für Landwirtschaft an die SED abzutreten, ohne den Parteivorstand vorher zu konsultieren ${ }^{376}$.

Das Jahr 1963 markierte für die Bauernpartei einen Tiefpunkt ihrer Geschichte. Sie mußte hinnehmen, auf allen Ebenen, vom Minister bis zu den Kreisen, aus der staatlichen Leitung der Landwirtschaft weitgehend verdrängt zu werden. Auf ihrem VII. Parteitag 1963 in Schwerin führte sie schließlich den Dolch gegen sich selbst.

Ein schleichender Verfall staatlicher Verantwortlichkeit der DBD war seit der Übernahme der Agrarkommission (später Landwirtschaftskommission) des Politbüros durch Gerhard Grüneberg während der 7. ZK-Tagung im Dezember 1959 zu beobachten. Diese SED-Parteikommission, in der DBD-Politiker wie Hans Reichelt und Paul Scholz nur konsultativ geduldet waren ${ }^{377}$, arbeitete an

${ }^{374}$ Nach der Auflösung der Abt. Agrarpolitik fragte man Zagrodnik im ZK, ob er nicht Kadersekretär der DBD werden wolle. Ebd., Bl. 173-176, Treffbericht, 16. 1. 1962, Bl. 184-186, Treffen am 6. 9. 1962. BStU MfS AIM 9130/63, Personalakte Titel, Bl. 51, 16. 9. 1961, Notiz der HA V/3, telefonische Mitteilung des GI „Lehmann“ (=Titel).

375 Auf diese Weise wurden 65 Stellen von politischen Mitarbeitern bei der DBD gestrichen. BStU MfS AIM 3189/63, Arbeitsvorgang Zagrodnik, Bl. 173-176, Treffbericht, 16. 1. 1962, Bl. 177-180, Treffbericht, 15. 3. 1962; SAPMO DY 30 IV 2/15/2, Schreiben und Anlage, 8. 8. 1962. Noch einschneidender traf es die NDPD, auf deren Funktion in der Deutschlandpolitik man nun offenbar noch mehr verzichten zu können glaubte. Sie verlor 227 von 659 politischen Mitarbeitern.

376 Goldenbaum hingegen habe dem damaligen 1. Sekretär der BL der SED, Harry Tisch, entgegnet, "[g]erade weil ich Kommunist bin, kann ich mit dieser Verfahrensweise nicht einverstanden sein" und ihm die Bedeutung des Mehrparteiensystems erläutert. BStU MfS AIM 3189/63, Arbeitsvorgang Zagrodnik, Bl. 173-176, Treffbericht, 16. 1. 1962, Zitat Bl. 175. BStU ASt Rst. AIM 186/63, Arbeitsvorgang Binder, Bd. II/1, Bl. 180-185, Bericht über die Aussprache des Bezirkssekretariats der DBD Rostock beim PV [undatiert]. Vgl. Reichelt, Blockflöte, S. 244-255; Jäger/Walter, Demokratische Bauernpartei Deutschlands, S. 141.

377 Offenbar plante vor allem der neue ZK-Abteilungsleiter LW Kiesler, niemanden aus der DBD zu berücksichtigen. SAPMO DY 30 IV 2/7/22, Bl. 131-133, $142 \mathrm{f}$., Aufstellungen der Mitglieder der Landwirtschaftskommission, 6. 1. 1960 und 19. 7. 1960, handschrift- 
einer Neustrukturierung des staatlichen Anleitungswesens der Agrarwirtschaft, das seit der Hochphase der Vollkollektivierung als reformbedürftig galt. Seit der 7. ZK-Tagung laborierte man immer wieder mit verschiedenen Maßnahmen, um eine „einheitliche und straffere Leitung“ zu gewährleisten ${ }^{378}$. Mitte Mai 1962 legte die SED die staatliche Leitung der Landwirtschaft in den Bezirken und Kreisen in die Obhut der Ständigen Kommissionen für Landwirtschaft der Bezirks- und Kreistage ${ }^{379}$. Für den Vorsitz dieser Kommissionen kamen nur SED-Mitglieder in Frage.

Zwar forderte Ulbricht auf dem VII. Deutschen Bauernkongreß im Frühjahr 1962 die DBD-Kollegen zur Mitarbeit auf. Diese waren jedoch kaum mehr mit Befugnissen ausgestattet, denn viele von ihnen schieden aus den nun abgeschafften LPG-Beiräten aus und in den Ständigen Kommission kamen DBD-Politiker allenfalls für stellvertretende Funktionen in Frage ${ }^{380}$. Die Arbeit der Kommissionen flankierten sogenannte Aktive, die sich aus den ehemaligen LPG-Beiräten rekrutierten, und an denen auch DBD-Funktionäre teilnehmen durften. Grüneberg verdrängte im Juli 1962 Paul Scholz aus dem Amt des stellvertretenden Ministerpräsidenten für Landwirtschaft und Nahrungsmittelversorgung. Im Herbst 1962 wurden die Fachabteilungen für Landwirtschaft bei den Räten der Bezirke und Kreise und damit zugleich die dort präsenten DBD-Kollegen den Ständigen Kommissionen unterstellt ${ }^{381}$.

Die 17. Tagung des ZK der SED im Oktober 1962 entwarf in Anlehnung an die Struktur des industriellen Sektors das Konzept der Staatlichen Leitung der Landwirtschaft nach dem Produktionsprinzip. Dieses mündete nach dem VI. Parteitag der SED im Januar 1963 und einem Staatsratsbeschluß vom Februar 1963 in die Einrichtung des zentralen Landwirtschaftsrates beim Ministerrat der DDR, der das bisherige Ministerium ersetzte ${ }^{382}$. Zur Anleitung der landwirtschaftlichen Kader bis in die Grundorganisationen hinein wurden neu und parallel zur Industrie die „Büros für Landwirtschaft“ eingerichtet ${ }^{383}$. Grüneberg leitete das zentrale

liche Ergänzung am 6. 1., wonach Reichelt und Scholz bei Beratungen hinzugezogen werden.

378 SAPMO DY 30 J IV 2/2/692, Protokoll PB, 15. 3. 1960, Anlage 6, Bl. 100-102.

379 Vgl. Roesler, Plan, S. 133 f.

380 Reichelt, Blockflöte, S. 200; zu Veränderungen von Parteiaufbau und Arbeitsweise der ländlichen Parteiorganisationen der SED seit 1960 siehe Prokop, Übergang, S. $194 \mathrm{f}$.

381 Roesler, Plan, S. 134.

382 Nachdem man 1960 die Organisation der Erfassung der Produkte im Ministerium zusammengeführt hatte, verfügte man Anfang 1963 erneut eine Trennung im „Staatlichen Komitee für Erfassung und Aufkauf landwirtschaftlicher Erzeugnisse und materielltechnische Versorgung der Landwirtschaft“. Lt. Reichelt griff Ulbricht dabei rumänische Vorbilder auf; Prokop, Übergang, S. 224; Roesler, Plan, S. 134; Reichelt, Blockflöte, S. 201. Weitere Ausführungen bei Tümmler, Agrarpolitik, S. 97-100; Lapp, Ministerrat, S. 184, 188, 193. Herbst u. a., DDR, Bd. 2, S. 676 f., Bd. 1, S. 587. Vgl. weiter SAPMO DY 30 J IV 2/2/869, Protokoll PB, 26. 2. 1963, Bl. 2 f.; BA DC-20 I/4-694, Beschluß über die Richtlinie zur Leitung der sozialistischen Landwirtschaft nach dem Produktionsprinzip, 15. 3. 1963.

383 Prokop, Übergang, S. 224; siehe Matschke, Entwicklung, S. 193-195. Das Nebeneinander der Büros für Landwirtschaft und Industrie führte zu Friktionen, wie Matschke einräumt. 
Büro und hatte damit eine weitere Schlüsselposition für die Durchsetzung politischer Entscheidungen inne, die das Verhältnis zwischen SED- und DBD-Personal vor Ort berührte ${ }^{384}$. Der Druck, rein fachliche Belange der Landwirtschaft zu allererst unter politisch-ideologischen Gesichtspunkten zu behandeln, wurde dadurch erheblich erhöht ${ }^{385}$.

Die Konzeption der staatlichen Leitung der Landwirtschaft unterschied sich grundlegend von der bislang geltenden ministeriellen Struktur. Für die DBD resultierte daraus, daß sie ihre bisherige Präsenz in staatlichen Spitzenfunktionen weitgehend einbüßte, angefangen bei der Leitung des Ministeriums, die sie auch nach Wiedererrichtung desselben im Jahr 1972 nicht mehr wiedererlangen konnte. Die Formulierung des Staatsratserlasses vom 11. Februar 1963 stellte klar, daß der Landwirtschaftsrat beim Ministerrat offiziell der SED als herrschender Partei unterstellt war ${ }^{386}$. Die Verdrängung der DBD wurde durch das zweigliedrige Modell des Landwirtschaftsrates begünstigt, das dem „Territorialprinzip“ folgend auf die Ebenen der Bezirke und Kreise übertragen wurde; die organisatorische Aufteilung in einen Rat, der künftig mit geringerer Kompetenz betraut war, und eine Produktionsleitung, die neue, vor allem mit der Planung betraute wichtige Schlüsselpositionen übernahm, gab die Beschränkung auf Ratspositionen für die DBDMitglieder vor.

Die DBD verlor aufgrund dieser Umstrukturierung nicht nur sämtliche Posten als stellvertretende, für Landwirtschaft zuständige Vorsitzende der Räte der Bezirke bzw. Kreise, sondern ihr blieben auch die neuen wichtigen Positionen in den Produktionsleitungen von oberster Ebene an bis in die Kreise hinein fortan verschlossen. Dies geschah, obwohl Grüneberg auf dem VII. Parteitag der DBD 1963 vorgab, eine bestimmte Parteizugehörigkeit sei für die Besetzung unerheblich. Infolge dieser Dezentralisierung und Straffung des staatlichen Apparates mußten über 300 landwirtschaftliche Führungskräfte der DBD ihre bisherigen Positionen aufgeben. Sie hatten sich häufig mit niederrangigen Stellen in den Produktionsleitungen zu begnügen oder wurden zum Wechsel in ganz andere Aufgabenfelder veranlaßt ${ }^{387}$.

Das Argument unzureichender Qualifikation der DBD-Kollegen, mit dem die SED und Grüneberg diese Deklassierung immer wieder zu begründen suchten, war letztlich vorgeschoben. Selbst hochqualifizierten Funktionären der DBD eröffnete sich in den folgenden Jahrzehnten, trotz verschiedentlicher Vorstöße der

384 Schon vorher gab es Zusammenstöße zwischen Grüneberg und DBD-Amtsträgern, die als stellvertretende Vorsitzende der RdB fungierten. MLHA BPA Schwerin IV/2/3/196, Protokoll Bürositzung der SED-BL, 10. 8. 1961, TOP 2.

385 Dieser Gesichtspunkt wird in den wenigen, überwiegend aus DDR-Feder stammenden Darstellungen zu dieser Übergangsphase und der sich anschließenden Ausprägung des NÖSPL im Hinblick auf die Landwirtschaft bislang völlig ausgeblendet. So auch bei Roesler, Plan. Vgl. Egler, System.

386 GBl. DDR I 1963, S. 2 f. Er legte fest, daß der „Landwirtschaftsrat beim Ministerrat mit seiner Produktionsleitung für die Durchführung der Beschlüsse des Zentralkomitees der SED und der Regierung auf dem Gebiet der Landwirtschaft verantwortlich" war.

387 Diese Zahl nennt Reichelt, Blockflöte, S. 201. 
$\mathrm{DBD}^{388}$, keinerlei Chancen auf staatliche Spitzenpositionen in der Landwirtschaft. Das vorgebliche Qualifizierungsdefizit der DBD-Politiker trieb die Anpassung des bisherigen parteieigenen Schulungssystems an die Schulungsprinzipien der SED in den sechziger Jahren voran. Die Öffnung von SED-Parteigremien für Facheliten in dieser Zeit geschah unter der Prämisse, daß umfassende Kontrollen im Vorfeld diesen ein Höchstmaß an Loyalität und unbedingte Akzeptanz der führenden Rolle der SED attestiert hatten. Ihrer Fachkompetenz und praktischen Erfahrung nach hätten mehr DBD-Funktionäre und Mitglieder einbezogen werden müssen. Allein ihre Mitgliedschaft in einer Blockpartei ließ potentielle Bewerber für ein hohes staatliches Amt jedoch als zweifelhaft erscheinen. Daher setzte deren Berufung häufig die zusätzliche „Feuerprobe“ einer Mitarbeit für die Staatssicherheit voraus.

Nach dem VI. Parteitag der SED kürte das Politbüro den Kandidaten des Politbüros Georg Ewald zum Vorsitzenden des Landwirtschaftsrates beim Ministerrat und zum Leiter der entscheidenden Produktionsleitung ${ }^{389}$. Der ehemalige Minister Reichelt wurde stellvertretender Vorsitzender des Landwirtschaftsrates und einer von mehreren stellvertretenden Produktionsleitern. Er gehörte der Koordinierungsgruppe für Landwirtschaft an, in der Grüneberg federführend agierte, durfte sich jedoch weiterhin Minister nennen ${ }^{390}$. Im Bruch mit hergebrachten ministeriellen Strukturen schreckte man offenbar davor zurück, auf prestigeträchtige Titel zu verzichten. Statt DBD-Mitgliedern verantwortungsvolle staatliche Ämter zuzubilligen - dies hätte der DBD als Partei weiterhin zumindest vor ihrer Mitgliedschaft Legitimation verliehen -, erhöhte die SED vordergründig die Mitwirkung der Basis: Anstelle von 30 Volkskammermandaten wie seit 1950 teilte man der DBD 196352 Mandate und 11 Nachfolgekandidaten zu⒐ Bedeutsame Ämter in der Volkskammer übernahmen Gewährsleute des MfS: Helmschrott hatte den Vorsitz der Volkskammerfraktion inne, Zagrodnik saß dem Ausschuß für Land- und Forstwirtschaft vor.

\section{Die totale Anpassung: der VII. Parteitag der DBD 1963}

Der VII. Parteitag, der vom 3. bis 5. Mai 1963 in Schwerin stattfand, leitete das programmatische Ende der DBD als eigenständige Partei ein. Die Versammlung beschloß, das zuvor auf dem VI. SED-Parteitag entworfene "Programm des Sozialismus“392 unverändert zu übernehmen und verzichtete auf ein eigenes Pro-

388 So zutreffend Reichelt, Blockflöte, S. 201, 204.

389 SAPMO DY 30 J IV 2/2/866, Protokoll PB, 5. 2. 1963, Bl. 5.

390 SAPMO DY 30 J IV 2/2/820, Protokoll PB, 19.3. 1963, Bl. 3, 7. Das Protokoll unterstrich ausdrücklich Ulbrichts Kompetenz; weiter richtete man eine Koordinierungsgruppe für LW unter Grüneberg ein, der Wittkowski, Reichelt, Helmuth Koch, Heinrich Heid, K.H. Dietrich und Kiesler angehörten. Barth u. a. (Hg.), DDR, S. 1603, 1963/64 absolvierte Reichelt ein Hochschulstudium.

391 SED, S. 169 f., Reichelt, Blockflöte, S. 351. Die VdgB verlor 1963 ihre Fraktionen in der Volkskammer und in den Bezirkstagen; Herbst u.a. (Hg.), DDR, Bd. 2, S. 1120.

392 Programm der SED, zweiter Teil: Der umfassende Aufbau des Sozialismus, in: Protokoll 
gramm. Den Grund formulierte Goldenbaum im Einleitungsreferat: „Das Programm des Sozialismus [...] ist der Kompaß für die Arbeit aller Werktätigen. Es ist das Programm des ganzen Volkes, weil es den Lebensinteressen des Volkes entspricht. Es ist darum auch unser Programm. "393 Eine zum Parteitag herausgegebene Dokumentensammlung unter dem Leitmotto „Die Aufgaben unserer Partei beim umfassenden Aufbau des Sozialismus in der DDR" wiederholte gebetsmühlenartig die von der Staatspartei vorgegebene Einordnung des VI. SED-Parteitages; dieser leite eine „neue Epoche des Sozialismus“ ein, wofür der Übergang zur Vollkollektivierung eine maßgebliche Voraussetzung gewesen sei ${ }^{394}$. Auch die neu beschlossenen Statuten der DBD waren ganz und gar im Sinne dieses neuen "Entwicklungsstadiums" formuliert. Sie erhöhten die ideologischen Anforderungen an die Mitglieder, indem sie die erzieherische Rolle der Partei besonders hervorkehrten. Außerdem wurde „die Lösung der ökonomischen Probleme“ für jedes Mitglied „zum Hauptinhalt der Parteiarbeit“ erklärt. Dies alles war der Vormacht der SED unterworfen und geschah vermeintlich zur „Stärkung des Bündnis der Genossenschaftsbauern mit der SED“395.

Geplant war der Parteitag von der DBD zunächst anders: In historischer Rückbesinnung auf eine 15jährige Parteigeschichte arbeiteten einige Mitarbeiter und Sekretäre an einem umfänglichen Text und wollten dazu einen Bildband publizieren ${ }^{396}$. Angesichts des Wegbrechens jeglichen eigenständigen programmatischen Profils diente dieser Rückbezug auch kompensatorischen $Z$ wecken. Eigentlich war für den Parteitag nicht vorgesehen, ein neues Programm zu verabschieden, und in den Vorbereitungen tauchte ein solcher Punkt auch nicht auf. Die DBD hatte schon anläßlich des VI. Parteitages im Mai 1960 in einem entsprechenden Parteidokument dem neuen „Entwicklungsstadium“ in der Landwirtschaft - der Vollkollektivierung - genüge getan. Allerdings beschäftigte man sich mit einem neuen Parteistatut ${ }^{397}$. An den verschiedenen Entwürfen des Statuts ist die programmatische Handschrift der Arbeitsgruppe BO ersichtlich: Obgleich sich schon diese Ursprungsfassungen am "Programm des Sozialismus" der SED ausrichteten, mußten die einschlägigen Passagen zusätzlich nach vorne geschoben

der Verhandlungen des VI. PT der SED, Bd. IV, S. 337-392. Zum VI. SED-PT, Ludz, Parteielite, S. 64-67; vgl. Stephan, Geschichte, S. 59f. Im Unterschied zur Interpretation der KPdSU - Chruschtschow sprach bereits vom "Sieg des Sozialismus" - formulierte die SED-Führung eine Etappe des "umfassenden Aufbaus des Sozialismus“, die die Übergangsphase des Kapitalismus zum Sozialismus abschließen sollte. Kaiser, Machtwechsel, S. 59-61.

393 Protokoll des VII. PT der DBD, S. 20.

394 Siehe Broschüre: Dokumente des VII. PT, z. B. S. 32.

395 So Scholz zur Abänderung der Statuten, Protokoll des VII. PT, S. 162-166, Zitat S. 163.

396 Zur Vorbereitung des Dokumentes "15 Jahre DBD“ siehe ACDP VI-052-0550, Protokolle Sekretariat, 28. 1., 5. 2. 1963. Vgl. ACDP VI-052-0551, Protokolle Sekretariat, 19. 3., 17. 4. 1963.

397 Dazu die Entwürfe vom 29.3. 1963 (unterzeichnet von Körber) und vom 11.4. 1963 in ACDP VI-052-0551. Lt. einer Aufstellung vom 28. 2. 1963 über die Zusammensetzung der Kommission übernahm Scholz statt Goldenbaum den Vorsitz der Statutenkommission, ebd. 
werden ${ }^{398}$. Im Unterschied zu den Ausführungen von Paul Scholz auf dem Parteitag zwang die Arbeitsgruppe BO die DBD dazu, das Parteieintrittsalter von 16 auf 18 Jahre zu erhöhen, und verbannte die DBD damit aus dem attraktiven Segment der Jugendlichen diesen Alters.

Zwei Wochen vor dem Parteitag intervenierte die Leiterin der Arbeitsgruppe BO Irene Köhler erfolgreich bei Grüneberg und drängte auf einschneidende Änderungen im geplanten Referat des Parteivorstandes, das Goldenbaum halten sollte, sowie im Dokument „15 Jahre DBD “399. Ihr Ad-hoc-Eingriff bewirkte zweifellos die Adaption der Vorgaben des VI. SED-Parteitages und seines Programmes. Allerdings stieß Köhler offenbar auf keine Gegenwehr, eine solche ist zumindest nicht nachzuweisen. Goldenbaum war in der fraglichen Zeit persönlich ganz absorbiert von den Divergenzen mit dem ZK, die die künftige Zusammensetzung des Präsidiums und nicht zuletzt seinen Rückhalt in der Parteiführung betrafen ${ }^{400}$. Einem IM-Bericht von Goldenbaums persönlichem Referenten, Rudi Rothe, zufolge arbeitete dieser wenige Tage vor dem Parteitag völlig zerfahren an seinem Referat. Goldenbaum war maßlos verärgert, daß das ZK Georg Böhm, den Goldenbaum außerordentlich schätzte, aufgrund seiner lange verschwiegenen NSDAP-Anwärterschaft als Präsidiumsmitglied ausschlug. Im Fall von Ernst Mecklenburg hingegen, der sich in Goldenbaums Sicht als Bückling vor Karl Mewis und der SED auszeichnete, war Grüneberg bereit, über eine NSDAP-Mitgliedschaft hinwegzusehen, an die Mecklenburg sich nicht erinnern konnte. Schließlich einigte man sich mit dem ZK darauf, anstelle von Mecklenburg den Bezirksvorsitzenden eines anderen großen Agrarbezirkes - Werner Titel aus Frankfurt/Oder - in das Präsidium zu wählen. Auch Titel war IM.

Während Ingrid Köhler an jenen Teilen von Goldenbaums Referat, die landwirtschaftliche Fragen berührten, lediglich die fehlende Selbstkritik der DBD monierte, hielt sie die Ausführungen zur nationalen Frage für völlig unzureichend. Mit keiner Silbe werde die Bedeutung des 13. August 1961 aufgegriffen, zu wenig die "friedliche Koexistenz" als einzig mögliche Politik unterstrichen; vielmehr trügen die Ausführungen dazu eher verteidigende Züge, statt die „militaristischen Kreise" Westdeutschlands aggressiv anzugreifen. Die Verfasser des Referates litten offenbar selbst unter „Unklarheiten im Hinblick auf die Lösung der nationalen Frage“, so Köhler. Sie empfahl die Hervorkehrung des „Programms des Sozialismus" der SED als Allheilmittel zur Klärung der "neuen Etappe unserer Entwicklung" gerade aus dem Grund, „weil es in diesen Grundfragen unter ca. $30 \%$ der Mitgliederschaft der DBD nicht wenige Unklarheiten gibt ${ }^{\star 401}$. Im Kern

398 Ebd., Entwurf des Statuts vom 11. 4. 1963.

399 SAPMO NY 4233/44, Bl. 278-283, Köhler an Grüneberg, 25. 4. 1963. Danach das folgende.

400 Auffälligerweise enthalten die IM-Berichte der Zeit nichts über ein Konfliktverhältnis zwischen dem Sekretariat und dem ZK oder im DBD-Sekretariat, BStU MfS AP 661/92, Goldenbaum, Bl. 140f., Bericht, 22. 5. 1963. SAPMO NY 4233/44, Zusammensetzung des Präsidiums der DBD [so sollte auf 1. PV-Sitzung gewählt werden], gez. Köhler. Auch zum folgenden.

401 Ebd., Bl. 278-283, Köhler an Grüneberg, 25.4. 1963, Stellungnahme zum Referat der DBD, Zitat Bl. 278. 
rückte die Arbeitsgruppe BO damit vom jahrelang propagierten Vorgehen einer gruppenspezifischen Beeinflussung sich politisch-ideologisch distanziert verhaltender Bevölkerungsteile ab. In utopiegläubiger Verkennung setzte Köhler voraus, daß die DBD tatsächlich Chancen habe, mit dem SED-Programm die von ihr anvisierten Bevölkerungsgruppen zu erreichen.

Darüber hinaus überschätzte die Arbeitsgruppe das Ausmaß an zumutbarer Selbstzerfleischung in der $\mathrm{DBD}^{402}$. Köhler verlangte, daß die $\mathrm{DBD}$ eine viel schärfere Kritik an ihren zurückgezogenen, also von der SED verdrängten Staatsfunktionären üben solle, die angeblich den "neuen Anforderungen“ nicht mehr gewachsen gewesen seien. Sogar Grüneberg folgte ihr in diesem Punkt nur verhalten, jedenfalls modifizierte er diese Vorgabe geschickt in seiner Parteitagsrede. Er argumentierte, nicht die unzureichende Qualifikation der DBD-Kollegen sei ausschlaggebend für die Verdrängung gewesen, sondern die vorgeblich bessere der SED-Kader, und präsentierte diese als Vorbilder 403 . Nach dem Parteitag war die Arbeitsgruppe BO zwar mit dessen Gesamtverlauf zufrieden, nun jedoch nahm sie Anstoß am Referat des Parteivorsitzenden Goldenbaum ${ }^{404}$.

Die Steuerung des Parteitages, die Personalfestlegungen der Gremien sowie die strukturelle Anpassung und Zerschlagung der handlungsrelevanten politischen Abteilungen im Parteivorstand führten vor Augen, wie gering die Manövrierfähigkeit der DBD 1963 noch war. Auch kleine Erfolge bei Personalentscheidungen in den Parteigremien - siehe die Aufnahme von Titel statt Mecklenburg ins Präsidium - brachten die Partei bestenfalls vom Regen in die Traufe. Aufgrund der permanenten Selbstbespiegelung des eigenen organisatorischen oder ideologischen Zustands, kleinlichen innerparteilichen Zwists und der Verbrüderung der auf Macht lauernden Diadochen im Sekretariat mit der Staatssicherheit provozierte die DBD die eigene Selbstentmachtung. Außer Goldenbaum, der sich wiederum in Rivalitäten erging und darüber erlahmte, hatte die Führung im Sekretariat die Bauernpartei als eigenständiges Projekt mit besonderem Profil weitgehend aufgegeben.

Die Arbeitsgruppe BO hatte mit ihrer totalen Ausrichtung der DBD auf das SED-Programm den Bogen jedoch überspannt, da die SED weiterhin am blockpolitischen Konzept einer spezifischen Transmissionsaufgabe für die DBD zugunsten der SED festhalten wollte. Denn damit die DBD Mitglieder gewinnen und halten konnte, die für die SED weniger empfänglich waren, mußte zwischen DBD und SED irgendeine Differenz erkennbar sein ${ }^{405}$. Daher verordneten Ulbricht und Grüneberg der DBD nach dem Parteitag in einem persönlichen Gespräch wieder einen auf deren Belange und Klientel zugeschnittenen Auftrag: Anläßlich einer "Aussprache" teilten sie dem Präsidium unzweideutig mit, daß sich die DBD auf Dörfer mit LPG Typ I konzentrieren solle. Freilich bestand besonders

402 Deutlich abzulesen ist dies in der Reaktion der Mitglieder über den PT, ebd., Bl. 293-295, Informationen, 3. 5. 1963, Bl. 296-299, Informationen, 4. 5. 1963.

403 So Reichelt, Blockflöte, S. 202.

404 SAPMO NY 4233/44, Bl. 302-307, Betr. PT der DBD, 7. 5. 1963 mit Diktatzeichen Köhlers.

405 Vgl. ebd., Bl. 293-295, Informationen, 3. 5. 1963. 
Ulbricht gleichzeitig darauf, daß die DBD und ihre Mitglieder in allen Genossenschaften zur Steigerung des „Betriebsergebnisses“ beitragen müßten ${ }^{406}$.

Diese Festlegung umfaßte eine Zurückdrängung aus Gefilden, die ideologisch und in der herrschaftlichen Durchdringung der SED vorbehalten sein sollten den LPG des Typs III - mithin eine Beschränkung auf andere Gebiete; zum zweiten war die Konzentration der DBD auf LPG des Typs I im Jahr 1963 angesichts von deren wirtschaftlicher Bedeutung jedoch eine überaus anspruchsvolle Anforderung 407 . Dennoch: Mit einer Entdifferenzierung der Klassenzugehörigkeit als Bauer bzw. Genossenschaftsbauer in Ulbrichts Ideal einer sozialistischen Menschengemeinschaft - sinnfällig gefaßt in der Neudefinition der SED als Partei des "ganzen werktätigen Volkes“408 - schwand zugleich eine bisher aus diesen ideologischen Klassenabgrenzungen hergeleitete Existenzberechtigung und Legitimation der DBD: Sie war bislang die Partei für die Bauern gewesen. Als Angehörige "des ganzen werktätigen Volks" sollten Genossenschaftsbauern aus der Sicht des Jahres 1963 jedoch ihren Platz dauerhaft in der SED einnehmen. Auch der Aufgabenzuschnitt, den die Arbeitsgruppe BO 1966 für die DBD festlegte, folgte dieser ideologischen Selbstdefinition der SED, die diese in einer bestimmten Phase des Sozialismus für angemessen hielt. Für die DBD bedeutete die neue Zuschreibung eine weitere Einengung. Die DBD sollte 1966 unter den LPG-Angehörigen nur noch jene anwerben dürfen, die „aus Gründen ihrer Herkunft und Weltanschauung oder faschistischer Vergangenheit für eine Mitgliedschaft in unserer Partei [SED] in absehbarer Zeit nicht infrage kommen" 409 .

Die hier genannte Zielgruppe der DBD galt identisch auch für die CDU. Insgesamt zeichnete sich eine schleichende Entdifferenzierung in der bündnispolitischen Konzeption für die Blockparteien ab; diese dürfte ebenfalls auf die neue Funktionszuschreibung für die Sozialistische Einheitspartei zurückzuführen sein. Erst unter Erich Honecker und seiner ideologischen Konzentration auf die "Arbeiterklasse“ in der marxistisch-leninistischen Partei ${ }^{410}$ gelang es der DBD, in der Rangfolge der verbündeten Parteien aufzusteigen. Denn sie war die einzige Blockpartei, deren Profil sich wie jenes der SED in erster Linie über die Organisierung einer „Klasse“ legitimierte, in ihrem Fall der Klasse der Genossenschaftsbauern. Auch ihre Mitglieder zeichneten sich durch die Zugehörigkeit zu einer bestimmten Klasse aus. Fortan nahm die DBD in der litaneihaften Wiederholung der Verbündeten nach der SED die zweite Position ein und verwies CDU, LDPD

406 SAPMO DY 30 IV A2/15/92, Kommuniqué über die Aussprache zwischen dem Ersten Sekretär des ZK der SED und dem Präsidium des PV der DBD. Siehe auch ACDP VI052-0552, Entwurf für Gespräch mit Ulbricht, Kommuniqué, 12. 7. 1963.

$407 \mathrm{Vgl}$. Analyse der PB, wonach die LPG dieses Typs rund 28\% der LNF bewirtschafteten, aber über $40 \%$ des Aufkommens an Milch und über 30\% an Fleisch deckten. SAPMO DY 30 J IV 2/2/874, Protokoll PB, 9. 4. 1963, Anlage 5, BI. 91-101.

408 Mit dem neuen, auf dem VI. PT beschlossenen Statut verabschiedete sich die SED von der „Partei der Arbeiterklasse“, Protokoll des VI. PT der SED, Bd. IV, S. 406; Weber, Geschichte, S. 345 f.; Kaiser, Machtwechsel, S. 39.

409 SAPMO DY 30 IV A2/15/3, Bericht der Abt. BO über DBD 1966, zitiert nach Reichelt, Blockflöte, S. 207f. Vgl. zur Bündnispolitik der SED gegenüber den Bauern 1966, Wachowitz, SED, S. 27 ff., jedes 7. Mitglied einer LPG Typ III sei Mitglied der SED.

410 Vgl. dazu Weber, Geschichte, S. 408. 
und NDPD auf die hinteren Ränge $e^{411}$. Freilich ging damit nicht ohne weiteres ein politischer Bedeutungsgewinn einher, allerdings bleibt dies noch im einzelnen zu untersuchen. Denn ideologische Faktoren allein eignen sich nur bedingt für die Bestimmung der tatsächlichen Herrschaftsverhältnisse in der DDR.

411 Siehe dazu die bündnispolitische Standardliteratur der SED aus dem Jahr 1972, Im Bündnis auf bewährtem Wege. Erst ab diesem Zeitpunkt galt Goldenbaum der SED auch als "lieber Kollege“, während sich die anderen Vorsitzenden der Blockparteien mit der Anrede „werter Kollege“ begnügen mußten. Vgl. hingegen Suckut, DDR-Blockparteien im Lichte, S. 113, der daraus eine laufende Privilegierung der DBD als „verläßlichste“ Verbündete der SED ableitet. Zum drohenden Bedeutungsverlust 1963 und -gewinn ab 1971 auch Jesse, Parteien, S. 100. Vgl. Haschker, Politik, S. 328, 332 f. 